\title{
A Survey of Experimental Research on Contests, All-Pay Auctions and Tournaments
}

\author{
Emmanuel Dechenaux ${ }^{\mathrm{a}}$, Dan Kovenock ${ }^{\mathrm{b}}$, and Roman M. Sheremeta ${ }^{\mathrm{c}}$ \\ ${ }^{a}$ Department of Economics, Kent State University \\ Kent, OH 44242, USA \\ ${ }^{\mathrm{b}}$ Economic Science Institute, Chapman University \\ One University Drive, Orange, CA 92866, USA \\ ${ }^{\mathrm{c}}$ Argyros School of Business and Economics, Chapman University \\ One University Drive, Orange, CA 92866, USA
}

September 28, 2012

\begin{abstract}
Many economic, political and social environments can be described as contests in which agents exert costly efforts while competing over the distribution of a scarce resource. These environments have been studied using Tullock contests, all-pay auctions and rank-order tournaments. This survey provides a review of experimental research on these three canonical contests. First, we review studies investigating the basic structure of contests, including the contest success function, number of players and prizes, spillovers and externalities, heterogeneity, and incomplete information. Second, we discuss dynamic contests and multibattle contests. Then we review research on sabotage, feedback, bias, collusion, alliances, and contests between groups, as well as real-effort and field experiments. Finally, we discuss applications of contests to the study of legal systems, political competition, war, conflict avoidance, sales, and charities, and suggest directions for future research.
\end{abstract}

JEL Classifications: C7, C9, D7, H4, J4, J7, K4, L2, M5

Keywords: contests, all-pay auctions, tournaments, experiments.

Corresponding author: Roman Sheremeta, sheremet@chapman.edu

* We have benefitted from the helpful comments of Loukas Balafoutas, Mike Caldara, Tim Cason, Gary Charness, Subhasish M. Chowdhury, Cary Deck, John Duffy, Jörg Franke, David Gill, Turkmen Goksel, Arye Hillman, Tanjim Hossain, Yaakov Kareev, Changxia Ke, Erik Kimbrough, Kai Konrad, Wolfgang Leininger, Noah Lim, Mike McBride, Aidas Masiliunas, Kristin Michelitch, Florian Morath, David Ong, Amnon Rapoport, Brian Roberson, Ariel Rubinstein, Dmitry Ryvkin, Tal Shavit, Jason Shogren, Matthias Sutter, Katya Vasilaky, Casper de Vries, Bart Wilson and participants in seminars at Chapman University, the University California at San Diego, and the University of Texas at Dallas, and the 2012 International Foundation for Research in Experimental Economics Conference at Chapman University. We thank Andy Schotter and Charles Noussair for providing data and Jianing You and David Zhang for valuable research assistance. Part of this work was completed while Kovenock and Sheremeta were visiting the Max Planck Institute for Tax Law and Public Finance. We remain solely responsible for any errors or omissions. 


\section{Table of Contents}

1. Introduction

2. Three Canonical Contest Models

2.1. Tullock or Lottery Contests

2.2. All-Pay Auctions

2.3. Rank-Order Tournaments

2.4. The Contest Success Function

3. Contest Structure

3.1. Number of Players

3.2. Heterogeneous Players

3.3. Spillovers and Externalities

3.4. Multiple Prizes

3.5. Endogenous Prizes

3.6. Incomplete Information

4. Dynamic Contests

4.1. Sequential Contests

4.2. Wars of Attrition

4.3. Races

4.4. Multi-Stage Contests with Carryover

4.5. Multi-Stage Elimination Contests

4.6. Endogenous Entry

5. Static Multi-Battle Contests

5.1. Constant-Sum Colonel Blotto Games

5.2. Non-Constant-Sum Blotto-like Games

5.3. Asymmetric Objectives

6. Extensions

6.1. Sabotage in Contests

6.2. Feedback in Contests

6.3. Bias in Contests and Affirmative Action

6.4. Collusion and Communication

6.5. Alliances in Contests

6.6. Contests Between Groups

7. Real-Effort and Field Experiments

7.1. Real-Effort Experiments

7.2. Field Experiments

8. Applications

8.1. Legal Systems

8.2. Political Competition and Lobbying

8.3. War

8.4. Conflict Avoidance

8.5. Sales Contests

8.6. Charity

8.7. Behavior and Gender

9. Conclusions and Future Directions 


\section{Introduction}

Many economic, political and social environments can be described as contests in which competing agents have the opportunity to expend scarce resources - such as effort, money, time, or troops - in order to affect the probabilities of winning prizes. Examples range from the competition for mates, college admission, patents, research grants, or promotions within firms, to the process of litigation or lobbying politicians, to elections, sports competitions, and violent global conflicts (Tullock, 1967; Krueger, 1974). As is obvious from this list, these environments have attracted considerable attention in applications in a wide range of fields, both in- and outside of economics. They have also been studied extensively by economic theorists in what has become known as the field of contest theory. Although this field continues to attract many young theorists, it has its roots in three models developed in the mid-seventies to early eighties: the Tullock (1980) model of rent-seeking, the Lazear and Rosen (1981) rank-order tournament model, and the all-pay auction (Hirshleifer and Riley, 1978; Nalebuff and Stiglitz, 1983; Dasgupta, 1986; Hillman and Riley, 1989). At least one of these three theoretical models has appeared in the vast majority of applications. Konrad (2009) provides an extensive review of the theoretical literature.

Despite the abundance and maturity of the theoretical literature, much less effort has been devoted to empirically investigate individual behavior in different contests and compare such behavior with theoretical predictions. The main reason is that it is not trivial to measure individual effort in the field since the researcher can only observe the performance of contestants, which is a function of effort, ability and luck (Ericsson and Charness, 1994). The majority of empirical studies use either firm level data (Prendergast, 1999) or sports data (Szymanski, 2003). ${ }^{1}$ Because it is typically difficult to measure the actual effort expended by players in the field, almost all of these studies focus solely on investigating whether the pattern of outcomes is consistent with the theoretical predictions. With naturally occurring data, it is difficult to evaluate even the very basic incentive effects of contests because of endogeneity (Ehrenberg and Bognanno, 1990). For example, theoretically, higher prizes in contests should increase individual efforts and thus performance. However, in practice, higher prizes also attract contestants of higher ability, confounding the basic incentive effects of contests (Lynch and Zax, 2000).

Controlled experiments allow researchers to test contest theory without confounding effects and endogeneity issues. Some experiments allow direct measurement of individual effort, while controlling for the relative abilities of contestants and the amount of noise (luck) in the

\footnotetext{
${ }^{1}$ Most studies examining firm level data find support for incentive effects of tournaments, i.e. larger prizes promote more effort (O'Reilly et al., 1988; Main, et al. 1993; Knoeber and Thurman, 1994; Eriksson, 1999; Lazear, 2000; Bognanno, 2001; Audas et al., 2004; DeVaro, 2006). Similarly, support for incentive effects of tournaments is found in studies examining sports data. Some of the sports that have been used to study contest theory are baseball, basketball, and hockey (Mosteller, 1952; Ferrall and Smith, 1999; Berger and Pope, 2011), sumo wrestling (Balafoutas et al., 2012), horse and dog racing (Coffey and Maloney, 2010), tennis (Jackson, 1993; Sunde, 2009; Malueg and Yates, 2010), golf (Ehrenberg and Bognanno, 1990; McFall et al., 2009), bowling (Abrevaya, 2002), foot racing (Maloney and McCormick, 2000; Lynch and Zax, 2000) and auto racing (Becker and Huselid, 1992).
} 
tournament. The first studies to test contest theory using laboratory methods were done by Bull et al. (1987) and Millner and Pratt (1989). These studies have inspired a substantial and rapidly developing experimental literature on contests. The purpose of this paper is to survey this work.

The assumptions underlying the three canonical models of contests lead to vastly different equilibrium behaviors. Tullock (or lottery) contests and rank-order tournaments usually have pure strategy equilibria for the specifications applied, whereas all-pay auctions have only non-degenerate mixed strategy equilibria. Moreover, the models have traditionally been applied to different areas of economic analysis. The term Tullock or lottery contest has been commonly used in the study of $\mathrm{R} \& \mathrm{D}$ races and political or rent-seeking competitions. Rank-order tournaments (or sometimes tournaments) have been used in the principal-agent, contract design and labor literatures. Therefore, resources exerted in the process of competing in these contests are usually called efforts or expenditures. All-pay auctions have been used in the auction literature and in lobbying and military applications. Resources exerted competing in all-pay auctions are usually called bids or expenditures.

In any given application, contest expenditures may be viewed as a good or bad from the standpoint of the modeler or contest designer. For instance, when modeling political or rentseeking competition, contest expenditure is often viewed as social waste, in the sense that a welfare maximizing social-planner would seek to minimize it (Tullock, 1980). In contrast, in management applications where rank-order tournaments have often been applied, effort is viewed as valuable because it contributes to the firm's output. Similarly, for patent races a social planner may desire the positive externalities generated from increases in R\&D spending. Finally, in many all-pay auction applications expenditure is viewed as desirable, such as the case of charitable fundraising or a seller of an object engaging in an all-pay auction to maximize revenue. Consequently, in some applications of contests the designer may be interested in maximizing expenditure and in some cases minimizing expenditure. Although applications of the three canonical models are usually different, all three models assume that (i) players exert costly irreversible efforts while competing for a prize and (ii) an individual player's probability of winning the prize depends on the players' relative expenditures. Obviously, the exact probability of winning the prize is defined differently for the three contests and is determined by a contest success function that maps the vector of player expenditures to the probability of winning. In the all-pay auction, the player exerting the highest effort wins the prize with certainty. In the rankorder tournament, the player with the highest performance, which is the sum of effort and a random component, wins the prize with certainty. Finally, in the Tullock contest, the probability of winning equals the ratio of a player's effort to a fixed power $r \geq 0$ to the sum of each of the other players' efforts, each raised to the same power $r$. The special case where $r=1$ is the case of the lottery contest.

We survey 228 experimental papers on contests. The majority of these papers are already published or in press (152 papers), while other papers are still cited as working papers (76 papers). More than $90 \%$ of working papers have been written within the last five years. Figure 1 displays the time trend of papers published in academic journals. The figure indicates a dramatic 
increase in the number of published papers over the last decade, with more than $50 \%$ of the papers published in the last five years. The vast majority of experimental studies are conducted in the lab (87\%) employing chosen-effort experiments (76\%). Some experimental studies are conducted in the field (13\%), with $70 \%$ of the field studies published within the last five years. Out of 152 published papers, $36 \%$ of the papers are based on lottery contests, $24 \%$ are based on all-pay auctions, $24 \%$ on rank-order tournaments and about $16 \%$ of the studies examine other contest structures (usually using binary decisions or real-effort tasks).

Figure 1: Time Trend of Papers Published in Academic Journals.

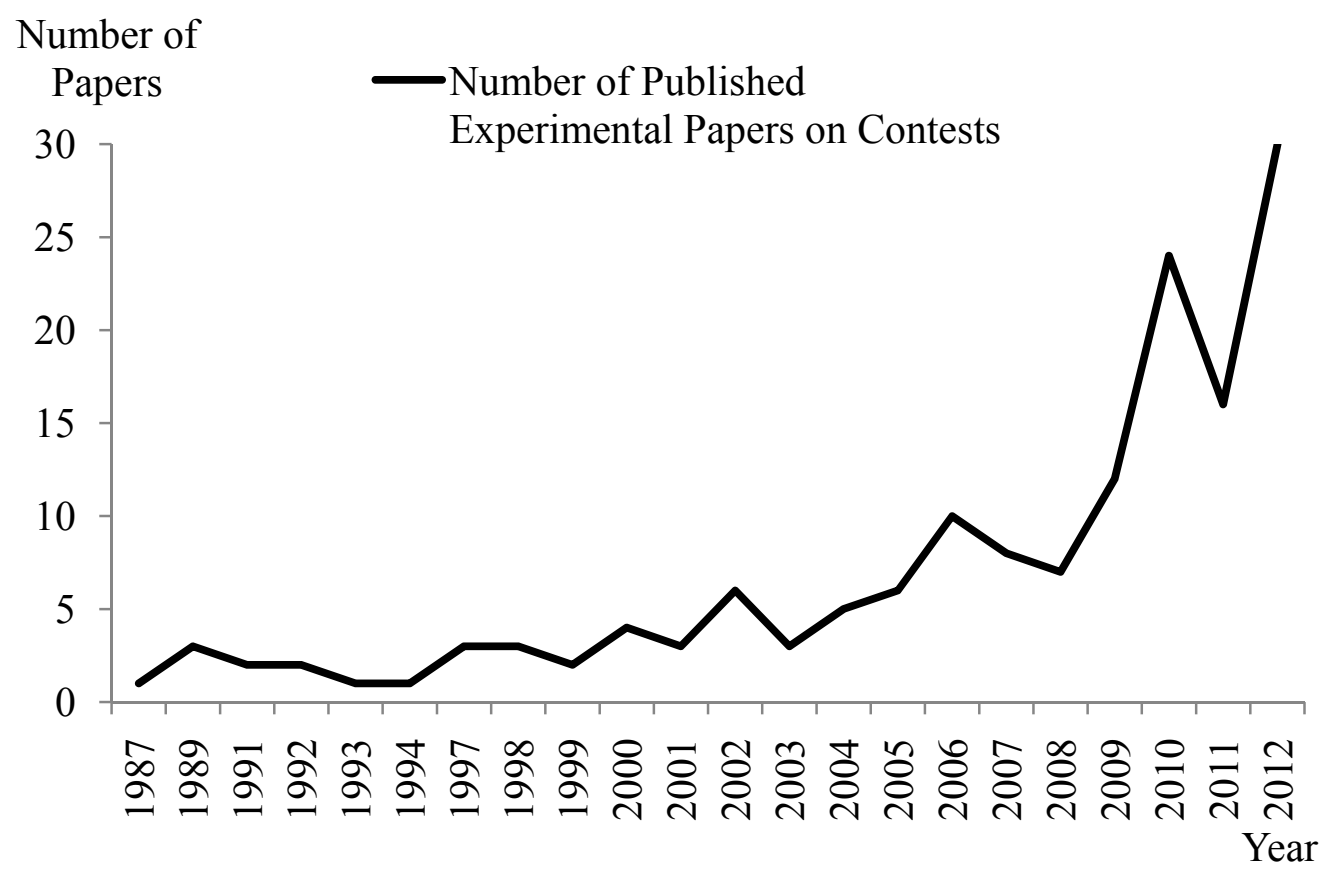

The experimental papers on contests presented in this survey span the fields of economics, management, marketing, law and political science. 16 of the published papers are published in the top five economics journals: American Economic Review (7), Journal of Political Economy (2), Quarterly Journal of Economics (5), Econometrica (1), and Review of Economic Studies (1). The majority of the papers are published in different economics field journals, including Experimental Economics (4), Economic Theory (3), Games and Economic Behavior (8), Journal of Labor Economics (3), Journal of Public Economics (2), Journal of Economic Behavior and Organization (15), Journal of Economic Psychology (3), Journal of Economics and Management Strategy (3), Public Choice (10), and International Journal of Industrial Organization (5), as well as general interest journals including Economic Journal (3), European Economic Review (3), International Economic Review (3), Journal of the European Economic Association (4), and Economic Inquiry (6). Finally, many experimental papers on contests are also published in fields other than economics: Management Science (8), Marketing Science (1), Managerial and Decision Economics (2), Organizational Behavior and Human 
Decision Processes (2), Journal of Marketing Research (2), and Journal of Conflict Resolution (3).

We begin by reviewing studies investigating the basic structure of contests, including the contest success function, the number of players and prizes, spillovers and externalities, heterogeneity, and incomplete information. Then we discuss dynamic contests and multi-battle contests. We also review experimental research on sabotage, feedback, bias, collusion, alliances, and contests between groups, as well as real-effort and field experiments. Finally, we discuss different applications of contests to the study of legal systems, political competition, war, conflict avoidance, sales, charity, and suggest directions for future research.

\section{Three Canonical Contest Models}

A contest is a game in which players have the opportunity to expend scarce resources (such as money, time or effort) in order to affect the probabilities of winning prizes, the values of which are ranked identically by the players (but may not be identical in absolute terms). The distinguishing characteristic of a contest is the fact that a higher expenditure of the scarce resource(s) has a nonnegative (and sometimes strictly positive) effect on the probability of winning the more valuable prizes.

There is a wide variety of possible contests that meet the above conditions, but our focus throughout this survey will be, respectively, on (i) the Tullock contest, (ii) the all-pay auction and (iii) the rank-order tournament. To provide a simple theoretical overview, consider the following nested formulation due to Sheremeta et al. (2012).

Assume there are $n$ risk-neutral players competing for a single prize of value given by $v$. Each player $i$ expends an effort $e_{i}$ and bears a cost of effort $c\left(e_{i}\right)$. The performance or output of player $i, y_{i}$, depends on player $i$ 's effort $e_{i}$ and a random variable $\varepsilon_{i}$, drawn from some common distribution with cumulative distribution function $F$ :

$$
y_{i}\left(e_{i}, \varepsilon_{i}\right)=e_{i}+\varepsilon_{i}
$$

The additive random component $\varepsilon_{i}$, can be thought of as unobservable luck or performance error. It can also be interpreted as an unknown ability $\varepsilon_{i}$ (Rosen, 1986).

Player $i$ 's probability of winning the contest as a function of the observable $n$-tuple of outputs $y=\left(y_{1}, y_{2}, \ldots, y_{n}\right) \geq 0$ is given by

$$
\hat{p}_{i}\left(y_{i}, y_{-i}\right)=\frac{y_{i}^{r}}{\sum_{j=1}^{n} y_{j}^{r}},
$$

if $\sum_{j=1}^{n} y_{j}>0$ and $\hat{p}_{i}\left(y_{i}, y_{-i}\right)=\frac{1}{n}$ otherwise, where $r \geq 0$ is a parameter that measures the sensitivity of the probability of winning to the ratio of individual player outputs. In practice, for the appropriate measure of the outputs, $\hat{p}_{i}\left(y_{i}, y_{-i}\right)$ may be estimated because it is based purely 
on the observable player outputs, rather than the potentially unobservable allocations of the scarce resource. The random mapping that compounds (1) and (2) to take a vector of player efforts $e=\left(e_{1}, e_{2}, \ldots, e_{n}\right)$ and obtain the probability that each player $i$ wins the contest is called the contest success function (CSF): $p_{i}\left(e_{i}, e_{-i}\right)$.

The outcome-contingent payoff of player $i$ in the contest is

$$
\pi_{i}= \begin{cases}v-c\left(e_{i}\right) & \text { if } i \text { wins } \\ -c\left(e_{i}\right) & \text { if } i \text { loses }\end{cases}
$$

Given the performance function (1), the CSF induced by (1) and (2), and the outcomecontingent payoff function (3), the expected payoff for player $i$ can be written as:

$$
E\left(\pi_{i}\right)=p_{i}\left(e_{i}, e_{-i}\right) v-c\left(e_{i}\right)
$$

A simple version of a Tullock contest can be obtained by setting $y_{i}=e_{i}$ in (1), $r \geq 0$ in (2), and $c\left(e_{i}\right)=e_{i}$ in (3). One may interpret such a contest as a case in which there is no noise in the performance function (1), so $\varepsilon_{i}=0$, but where the CSF coincides with (2), so that the probability of winning the prize equals the ratio of individual effort to aggregate effort and individual output to aggregate output. When $r$ is relatively small (a sufficiently noisy CSF) and there are no externalities of effort, the Nash equilibrium in a simple Tullock contest is in pure strategies and it is unique. The case where $r=1$ is referred to as the lottery contest. The equilibrium is not in pure strategies when $r$ is relatively large (Baye et al., 1994), and it not unique when there are externalities of effort (Chowdhury and Sheremeta, 2011b). In the remainder of the paper we refer to contests where $0 \leq r<\infty$ and $y_{i}=e_{i}$ as Tullock or lottery contests.

To obtain a simple version of the all-pay auction, we set $y_{i}=e_{i}$ in (1), $r=\infty$ in (2), and $c\left(e_{i}\right)=e_{i}$ in (3). The crucial difference when compared to the Tullock contest is that, except in the event of ties, the outcome is deterministic; the player with higher effort wins the contest with certainty. There is no pure strategy equilibrium in the all-pay auction and only non-degenerate mixed strategy Nash equilibria exist in which players choose efforts randomly over the interval $[0, v]$ (Hillman and Riley, 1989; Baye et al., 1996).

Finally, to obtain a simple rank-order tournament we set $y_{i}=e_{i}+\varepsilon_{i}$ in (1), $r=\infty$ in (2), and $c\left(e_{i}\right)=c(e)$ in (3), where $c_{e}>0$ and $c_{e e}>0$. The crucial difference between the rankorder tournament and the Tullock contest and the all-pay auction is that in the former there is a noise component $\varepsilon_{i}$ in the performance function (3), i.e., $y_{i}=e_{i}+\varepsilon_{i}$. As in Tullock (1980), the rank-order tournament is often formulated in a way that generates a unique pure strategy Nash equilibrium. This occurs if there is a sufficient combination of noise and convexity of cost (Lazear and Rosen, 1981). In the rest of the paper we will refer to contests where $r=\infty$ and $y_{i}=e_{i}+\varepsilon_{i}$ as Lazear-Rosen or rank-order tournaments. 


\subsection{Tullock or Lottery Contests}

The first attempt to examine a lottery contest using laboratory methods dates back to Millner and Pratt (1989). Their experiment is based on the original Tullock (1980) model with $r$ $=1$ and $r=3$. Subjects were placed in groups of two and the composition of the groups changed from period to period. However, instead of using a design in which the subjects make simultaneous single decisions, the subjects were allowed to adjust their decisions during a continuous time interval. Although the null hypothesis for Nash equilibrium behavior for the case $r=3$ was misspecified, for the benchmark lottery case of $r=1$ the two main findings of Millner and Pratt (1989) are that (i) the average dissipation rate (measured as the total effort divided by the prize value) in the lottery contest is significantly higher than the risk-neutral equilibrium prediction and (ii) there is a high variance in individual efforts.

Figure 2: Distribution of Efforts in a Lottery Contest.

Fraction

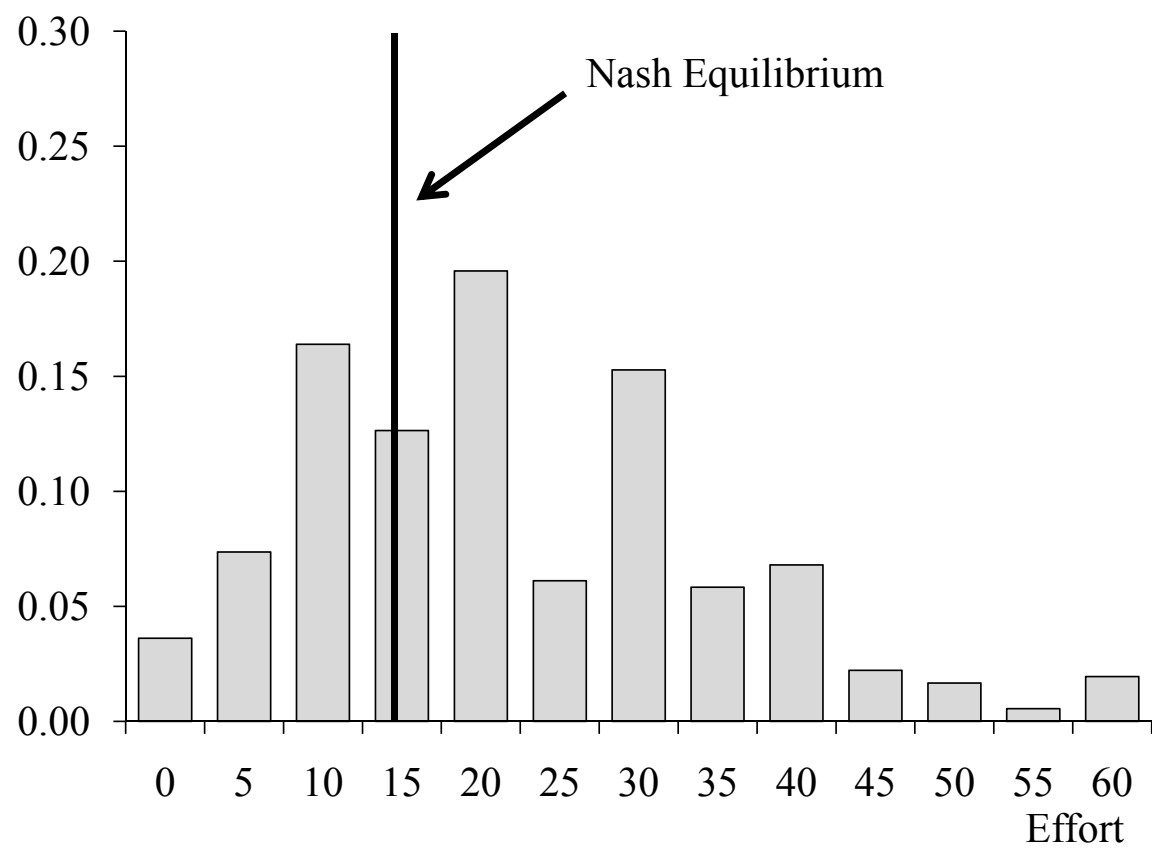

Note: The data are taken from Sheremeta (2011a).

A follow up study by Shogren and Baik (1991) pointed out the misspecified theoretical benchmark for $r=3$, and reexamined the Tullock lottery contest with $r=1$ by introducing a simpler single-choice design. Their results show that subjects learn to play Nash equilibrium in the final periods of the experiment. Unfortunately, a key feature of Shogren and Baik's experimental design prevents a direct comparison to Millner and Pratt's (1989) findings. Specifically, in their experiment, Shogren and Baik implicitly imposed risk neutrality. In response, Millner and Pratt (1991) conducted a new experiment to study the effect of riskaversion on subjects' behavior in lottery contests. As in their earlier experiment, subjects were 
allowed to adjust their decisions during a continuous time interval, so they were not formally testing the simultaneous move game. Nevertheless, Millner and Pratt (1991) found that more risk-averse subjects choose lower efforts than less risk-averse subjects, with efforts still higher than predicted. Since Millner and Pratt $(1989,1991)$, many other experiments on lottery contests have replicated the anomalous results of overbidding (which we also refer to as over-dissipation or over-expenditure of effort) and high variance of effort (Davis and Reilly, 1998; Potters et al., 1998; Anderson and Stafford, 2003; Sheremeta, 2010a, 2010b, 2011a; Sheremeta and Zhang, 2010; Mago et al., 2011, 2012; Price and Sheremeta, 2011, 2012; Morgan et al., 2012a, 2012b).

Figure 2 displays a distribution of effort levels commonly observed in lottery contests. The data are taken from Sheremeta (2011a), where $n=2$ players compete for a prize of $v=60$ in a lottery contest (i.e., $r=1, y_{i}=e_{i}$, and $c\left(e_{i}\right)=e_{i}$ ). According to the theoretical prediction, the Nash equilibrium effort is $e^{*}=v(n-1) / n^{2}=15$. Nevertheless, average efforts are significantly higher than predicted and the variance is substantial.

Figure 3: Non-Monetary Utility from Winning.

Effort for

a Prize of 0

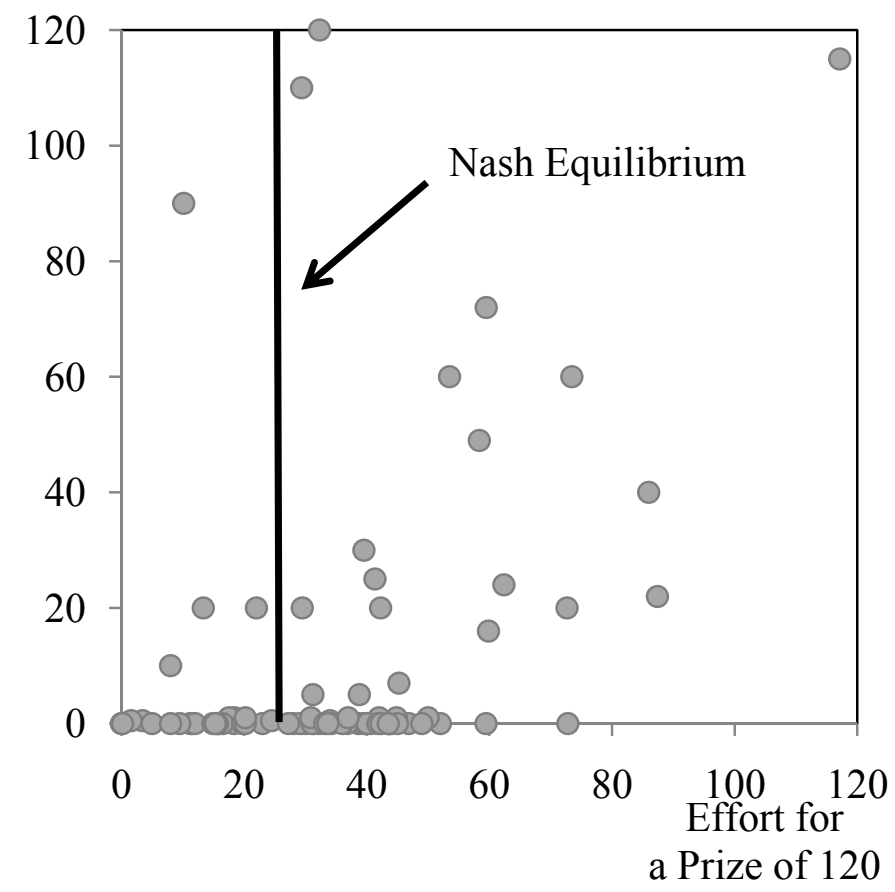

Note: The data are taken from Sheremeta (2010b).

The magnitude of overbidding in some studies is so high that average subjects' earnings are negative. A common explanation is that, in addition to monetary incentives, subjects derive a non-monetary utility from winning which contributes to overbidding (Schmitt et al., 2004; Parco et al., 2005; Sheremeta, 2010a, 2010b; Chen et al., 2011; Price and Sheremeta, 2011, 2012; Brookins and Ryvkin, 2011; Mago et al., 2012). For instance, Sheremeta (2010b) directly elicits 
the subjects' non-monetary utility of winning by letting them participate in a simple lottery contest with a prize value of zero. Interestingly, about $40 \%$ of the subjects exert positive costly effort to win this contest with zero prize and these effort levels are correlated with efforts in contests for a strictly positive prize. Figure 3 displays the correlation between effort for a prize of $v=0$ and effort for a prize of $v=120$. The data are taken from Sheremeta (2010b), where $n=4$ players compete in a lottery contest. According to the theoretical prediction, the Nash equilibrium effort is $e^{*}=v(n-1) / n^{2}=22.5$ when the prize is $v=120$. Figure 3 shows that subjects who exert higher efforts for the prize of zero also exert higher efforts for the positive monetary prize of 120 (correlation coefficient of 0.38 ). ${ }^{2}$

Related to the utility of winning argument, several studies show that overbidding may be driven by spiteful preferences and inequality aversion (Herrmann and Orzen, 2008; Bartling et al., 2009; Eisenkopf and Teyssier, 2010, 2012; Abbink et al., 2012; Balafoutas et al., 2012; Mago et al., 2012; Sheremeta et al., 2012). Balafoutas et al. (2012), for example, find that spiteful and inequality-averse subjects exert significantly higher efforts in contests. Another commonly cited explanation for overbidding is that subjects are prone to mistakes (Potters et al., 1998). These mistakes add noise to the Nash equilibrium solution, and thus may cause overbidding in contests. Several studies have provided support for this argument by analyzing the quantal response equilibrium model (McKelvey and Palfrey, 1995), which accounts for errors made by subjects, and testing the predictions of this model in lottery contests (Schmidt et al., 2011; Sheremeta, 2011a; Lim et al., 2012). Related to mistakes, overbidding in contests can also be explained by the fact that subjects exhibit certain judgmental biases, such as non-linear probability weighting and the hot hand fallacy, which prevent them from exerting rational effort levels in contests (Parco et al., 2005; Amaldoss and Rapoport, 2009; Sheremeta and Zhang, 2010).

Recent studies by Price and Sheremeta $(2011,2012)$ and Sheremeta (2011a) show that another factor contributing to overbidding is that subjects receive free endowments of money (house money) and such endowments are usually much higher than the predicted Nash equilibrium effort level. However, when subjects earn their endowments before participating in a lottery contest, their subsequent efforts in contests are lower than when endowments are freely given (Price and Sheremeta, 2012). Also, efforts are lower when subjects' strategy spaces are restricted or the endowment of money is spread over the entire experiment (Price and Sheremeta, 2011; Sheremeta, 2011a). ${ }^{3}$

The high variance in individual behavior is usually attributed to subjects' demographic differences (Price and Sheremeta, 2012), heterogeneous preferences towards winning (Sheremeta, 2010a, 2010b), risk (Miller and Pratt, 1991; Sheremeta, 2011a; Schmidt et al., 2011), losses (Kong, 2008; Eisenkopf and Teyssier, 2010) or spitefulness and inequality aversion

\footnotetext{
${ }^{2}$ Whether this correlation comes from non-pecuniary benefits from winning or other sources demands further research. For instance, it may be the case that subjects who make errors in assessing their bidding strategies for a prize of value zero also are likely to make errors in bidding for higher value prizes. At the same time, it may well be the case that the non-pecuniary benefits from winning are not invariant to the monetary value of the prize.

${ }^{3}$ Interestingly, Faravelli and Stanca (2012b) show both theoretically and experimentally that restricting the number of tickets that contestants can purchase in a lottery contest may actually increase individual efforts.
} 
(Herrmann and Orzen, 2008; Balafoutas et al., 2012). Price and Sheremeta (2012), for example, find that men and more religious subjects tend to exert up to $25 \%$ lower effort than women and less religious subjects. Sheremeta (2010a, 2010b) finds that subjects who demonstrate having higher non-monetary utility of winning exert higher effort in lottery contests (see Figure 3 ). ${ }^{4}$ Several experimental studies (Millner and Pratt, 1991; Anderson and Freeborn, 2010; Sheremeta and Zhang, 2010; Schmidt et al., 2011; Sheremeta, 2011a) find that risk-averse subjects exert lower efforts in lottery contests than risk-neutral or risk-seeking subjects. Kong (2008) investigates the impact of loss-aversion on individual behavior in contests and finds that more loss-averse subjects exert higher efforts than less loss-averse subjects. Balafoutas et al. (2012) find that subjects who exhibit spiteful behavior exert higher efforts in contests than less spiteful subjects.

Finally, Chowdhury et al. (2012b) show that features of the experimental design can explain a significant portion of the subjects' non-equilibrium behavior. For instance, the Tullock lottery CSF may be implemented either as a probability or as a deterministic share, without affecting the risk neutral Nash equilibrium prediction. In a two-by-two design, Chowdhury et al. investigate the effects of sharing the prize proportionally and of specifying a strictly convex cost function, while holding the risk neutral Nash equilibrium effort level constant. Compared to the probabilistic CSF, the share rule results in effort levels that are closer to the risk neutral prediction. The variance in individual efforts is also lower under the share rule and the distribution of individual efforts converges towards Nash equilibrium over time. Combining the share rule with a strictly convex cost function further strengthens these results. ${ }^{5}$

\subsection{All-Pay Auctions}

In this section we discuss the contest known as an all-pay auction with complete information (Hillman and Riley, 1989; Baye et al., 1996). ${ }^{6}$ In such a contest the highest bidder wins the prize with certainty and all bidders have to pay their bids. Baye et al. (1996) characterize the entire set of equilibria for the all-pay auction with complete information, a continuous strategy space and possibly asymmetric prize valuations. All equilibria are in mixed strategies and in games with three or more players, for certain configurations of the players' valuations of the prize, multiple equilibria exist. One feature of Nash equilibrium is that it may be asymmetric even in symmetric games. Before summarizing the state of our knowledge on behavior in all-pay auctions, it is important to note that procedural differences can have

\footnotetext{
${ }^{4}$ Part of the individual variance can be also explained by the quantal response equilibrium, since in such an equilibrium subjects draw their bids from a certain distribution function (Schmidt et al., 2011; Sheremeta, 2011a; Lim et al., 2012). Nevertheless, the quantal response equilibrium cannot explain why some subjects consistently make higher bids, while others consistently make lower bids (Sheremeta, 2011a).

${ }^{5}$ Fallucchi et al. (2012) also find that using the share rule instead of the probabilistic CSF reduces overbidding. Masiliunas et al. (2012) document that letting subjects play against computer opponents with pre-determined actions, further enhances this result.

${ }^{6}$ Early treatments of special cases of all-pay auctions include Hirshleifer and Riley (1978), Nalebuff and Stiglitz (1983) and Dasgupta (1986).
} 
confounding effects on bids. When designing all-pay auction experiments, the researcher should pay close attention to factors such as the mesh of feasible strategies (what is the number of possible bids?), whether caps are introduced by design (is there a maximum bid?) and the size of the starting balance (is it possible for subjects to run out of cash?).

Similar to Tullock contests, overbidding relative to the Nash equilibrium prediction in aggregate data emerges as an empirical regularity. Davis and Reilly (1998) were arguably the first to report substantial overbidding in all-pay auctions using a design that focused on asymmetric auctions. Their important finding carries over to symmetric all-pay auctions. Indeed, except for Potters et al. (1998), the majority of studies using symmetric all-pay auctions with complete information also find that session averages reflect overbidding (Gneezy and Smorodinsky, 2006; Ernst and Thöni, 2009; Lugovskyy et al., 2010; Fehr and Schmidt, 2011; Klose and Sheremeta, 2012; Ong and Chen, 2012). While Potters et al. find evidence of equilibrium play in their two-player all-pay auction experiment, their design imposed an exogenous cap on bids (15\% above the prize value), which may have biased behavior toward lower, equilibrium bids. In contrast, a later study by Gneezy and Smorodinsky (2006) finds that the sum of effort levels (or "revenue", in the language of auction theory) is much higher than predicted and often twice to five times higher than the common prize value. Winning bids are frequently within 10 percentage points of the value of the prize and sometimes exceed it. Gneezy and Smorodinsky (2006) employ a between-subject design with the number of bidders as the treatment variable $(n=4,6,8,12)$, symmetric players and fixed matching. ${ }^{7}$ Varying the number of bidders exogenously mainly affects participation, which is defined as a strictly positive bid. As the number of bidders goes up, so does the number of subjects submitting zero bids. A specification of the quantal response equilibrium yields predictions that are consistent with some, but not all features of the data (see Anderson et al., 1998). Gneezy and Smorodinsky's own adhoc model, which assumes two-stage reasoning on the part of the subjects, is better supported by the data. It helps bring to the forefront the following notion: In games where losses are possible but a player's minmax payoff is zero (from bidding zero), bidders might employ two stages of reasoning: "should I bid or should I play my minmax action of zero?" and "conditional on bidding, how much should I bid?".

More generally, Gneezy and Smorodinsky (2006) find that subjects appear to randomize over a set of bids as theory predicts, but they tend to place too much weight on relatively low and relatively high bids. Figure 4 displays a distribution of bids in one of the treatments from Gneezy and Smorodinsky (2006). In this treatment, there are $n=4$ players competing for a prize of $v=$ 100 in an all-pay auction (i.e., $r=\infty, y_{i}=e_{i}$, and $c\left(e_{i}\right)=e_{i}$ ). The picture shows clear evidence of bimodal behavior, with some subjects submitting very low and others submitting very high

\footnotetext{
${ }^{7}$ A between-subject design is one in which each subject is exposed to a single treatment. In this case, each subject in Gneezy and Smorodinsky's experiment participated in a session where the number of subjects was fixed throughout the treatment. Fixed matching refers to an experimental protocol in which, in an $n$-player game, each subject interacts with the same $n$ - 1 other subjects in every period of the experiment. By contrast, when there is random matching, the subjects are randomly rematched into new groups of $n$ players after every period.
} 
bids. ${ }^{8}$ Many other all-pay auction studies generate distributions with a similar shape. Ernst and Thöni (2010), Liu (2011) and Klose and Sheremeta (2012) rely on loss aversion from Kahneman and Tversky's (1979) prospect theory to explain bimodal behavior. The basic assumption is that players evaluate outcomes relative to a reference point. If they earn more than their reference point, they are in the domain of gains, otherwise in the domain of losses. The utility function is concave in the domain of gains and convex in the domain of losses. In addition, people suffer more from the loss of a certain amount of money than they enjoy from the win of the same amount. A utility function based on these assumptions gives rise to a bimodal bidding behavior in the equilibrium of an all-pay auction (Ernst and Thöni, 2010; Liu, 2011).

\section{Figure 4: Distribution of Efforts in an All-Pay Auction.}

Fraction

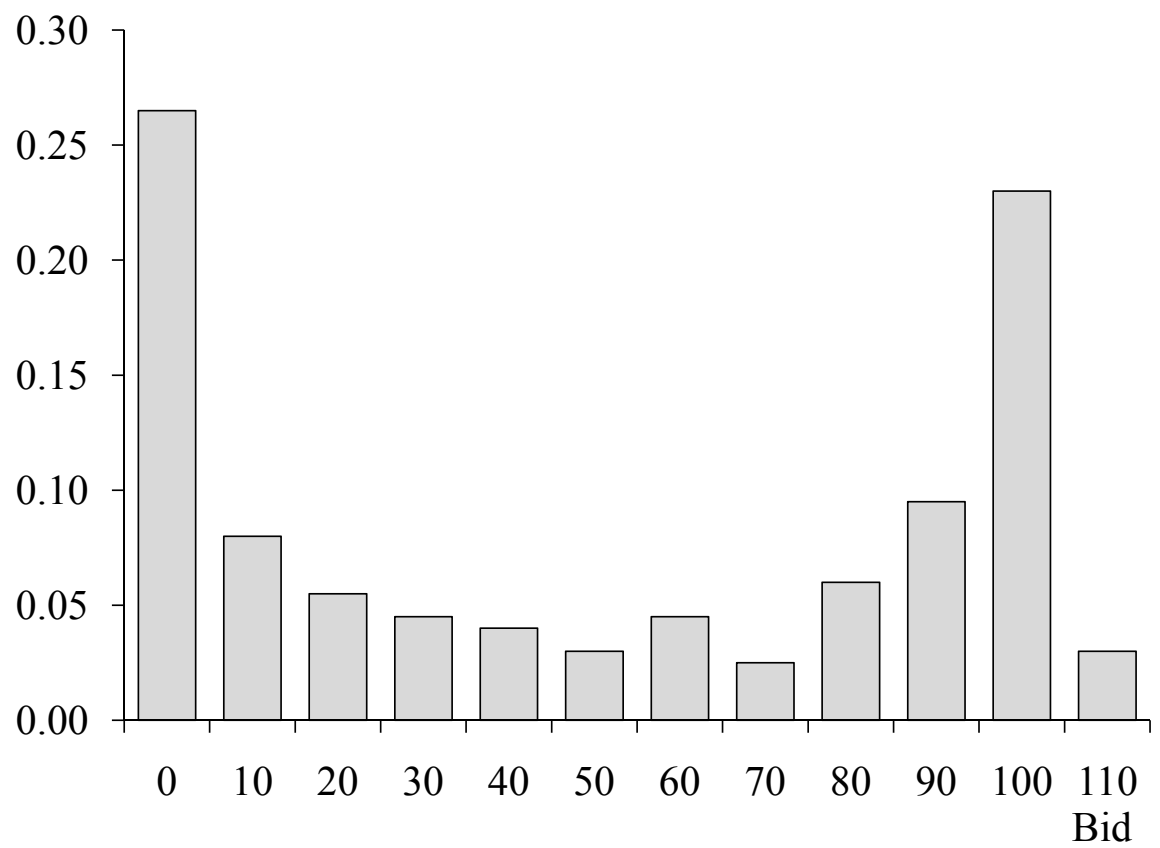

Note: The data are taken from Gneezy and Smorodinsky (2006).

Bimodal behavior in all-pay auctions with complete information is reminiscent of Müller and Schotter's (2010) concept of bifurcation for all-pay auctions with incomplete information (see also Barut et al, 2002; Noussair and Silver, 2006; Hörisch and Kirchkamp, 2010). Müller and Schotter (2010) also invoke loss aversion to explain bifurcation. By contrast, Minor (2012) uses the concept of "coarse thinking," a psychological phenomenon by which subjects collapse possible competitors into a single stereotype (i.e., strong and weak). Overall, it is quite interesting to note that bimodal bidding (equivalently bifurcation) is observed both in games of complete information as well as in games of incomplete information. The key difference,

\footnotetext{
${ }^{8}$ In the symmetric complete information all-pay auction with a continuous strategy space and $n=4$, there is a continuum of asymmetric Nash equilibria in which all but two players place probability mass at 0 . Hence, a significant incidence of zero bids may be consistent with behavior in asymmetric equilibria.
} 
however, is that in complete information all-pay auctions, bimodal bidding arises because individual subjects seem to randomize over a set of bids and they frequently play either very low or very high bids. In games of incomplete information, which we discuss in Section 3.6, individual subjects overbid when they draw a favorable type (low cost or high valuation) and they underbid when they draw an unfavorable type (high cost or low valuation).

Lugovskyy et al. (2010) further explore observed deviations from Nash equilibrium in all-pay auctions. In long sessions, lasting 60 periods, with fixed matching of four-player groups, they show that learning seems to bring bids closer to the Nash equilibrium prediction in the aggregate. Aggregate over-dissipation decreases as well in long sessions under random matching, but remains above the levels observed with fixed matching. In their early experimental treatment of an asymmetric all-pay auction, Davis and Reilly (1998) also report that experience reduces overbidding. ${ }^{9}$ Finally, in Lugovskyy et al. (2010), the difference in behavior between fixed and random matching protocols is attributed to possible collusion when the fixed matching protocol is used. ${ }^{10}$

While caution is warranted when drawing parallels between the two contest forms, it is natural to ask whether the pattern of overbidding in all-pay auctions arises from the same factors as in lottery contest experiments. For example, as in lottery contests, overbidding in all-pay auctions may be caused by mistakes (Gneezy and Smorodinsky, 2006), a non-monetary utility of winning and judgmental biases (Ernst and Thöni, 2010; Liu, 2011; Klose and Sheremeta, 2012). However, further research is required to conclusively determine whether patterns of data in allpay auctions and lottery contests are caused by the same phenomenon.

\subsection{Rank-Order Tournaments}

Since the seminal paper by Lazear and Rosen (1981), rank-order tournaments have been extensively investigated in the lab. To the best of our knowledge the first laboratory experiment on rank-order tournaments is Bull et al. (1987). Bull et al. implement rank-order tournaments

\footnotetext{
${ }^{9}$ Rapoport and Amaldoss (2000, 2004) and Amaldoss and Jain (2002) implement all-pay auctions with caps on bidding and possibly heterogeneous valuations. All three papers assume that no player wins the prize in case of a tie at the highest bid (see also Cohen et al. (2012) on the discussion of ties in lottery contests). Amaldoss and Jain (2002) also consider the more commonly employed equal sharing rule. Reminiscent of overbidding, high-valuation subjects bid the cap more frequently than the symmetric equilibrium predicts. In all three studies, whether or not the subjects learn to play the mixed strategy equilibrium is an important aspect of the analysis. An original contribution common to all three articles is the estimation of the experience weighted attraction learning model, which fits the data rather well (Camerer and Ho, 1999). We note that Rapoport and Amaldoss's (2000) findings must be interpreted with care as the authors focus on a non-unique symmetric equilibrium even when players are asymmetric. For a formal discussion, the reader is referred to Dechenaux et al. (2006) and Rapoport and Amaldoss (2008). Similarly, some of the findings in Amaldoss and Jain (2002) should be interpreted cautiously in light of Dechenaux et al. (2003). Otsubo (2012) also examines behavior in a discrete all-pay auction with caps on bidding. The two players have identical values for winning the prize and in the case of a tie one player (call him a stronger player) receives the prize. Theory predicts that stricter caps decrease the bids of both players and increase the probability that the strong player wins. The experimental results mainly confirm these predictions.

${ }^{10}$ Lugovskyy et al. (2010) also consider a negative all-pay auction in which the lower bound of the strategy space is not zero, but -1000 . The support of the equilibrium strategy is $[-1000,0]$. The authors observe bids above zero, which is evidence of behavior that is not easily rationalized without resorting to a utility of winning.
} 
between pairs of subjects whose output is the sum of effort and a uniformly distributed productivity shock, i.e., $y_{i}=e_{i}+\varepsilon_{i}$ where $\varepsilon_{i} \sim U[-a, a]$. In their design, a sufficiently disperse support of the distribution of the noise parameter $\varepsilon_{i}$ guarantees that a unique pure strategy Nash equilibrium exists. The main purpose of the experiment was to test the theory and to compare the performance of a rank-order tournament to a simple piece-rate incentive scheme. The main finding of Bull et al. (1987) is that the average effort levels in tournaments are well predicted by theory and are similar to efforts under the piece-rate scheme. However, the variance of effort is much greater under the tournament.

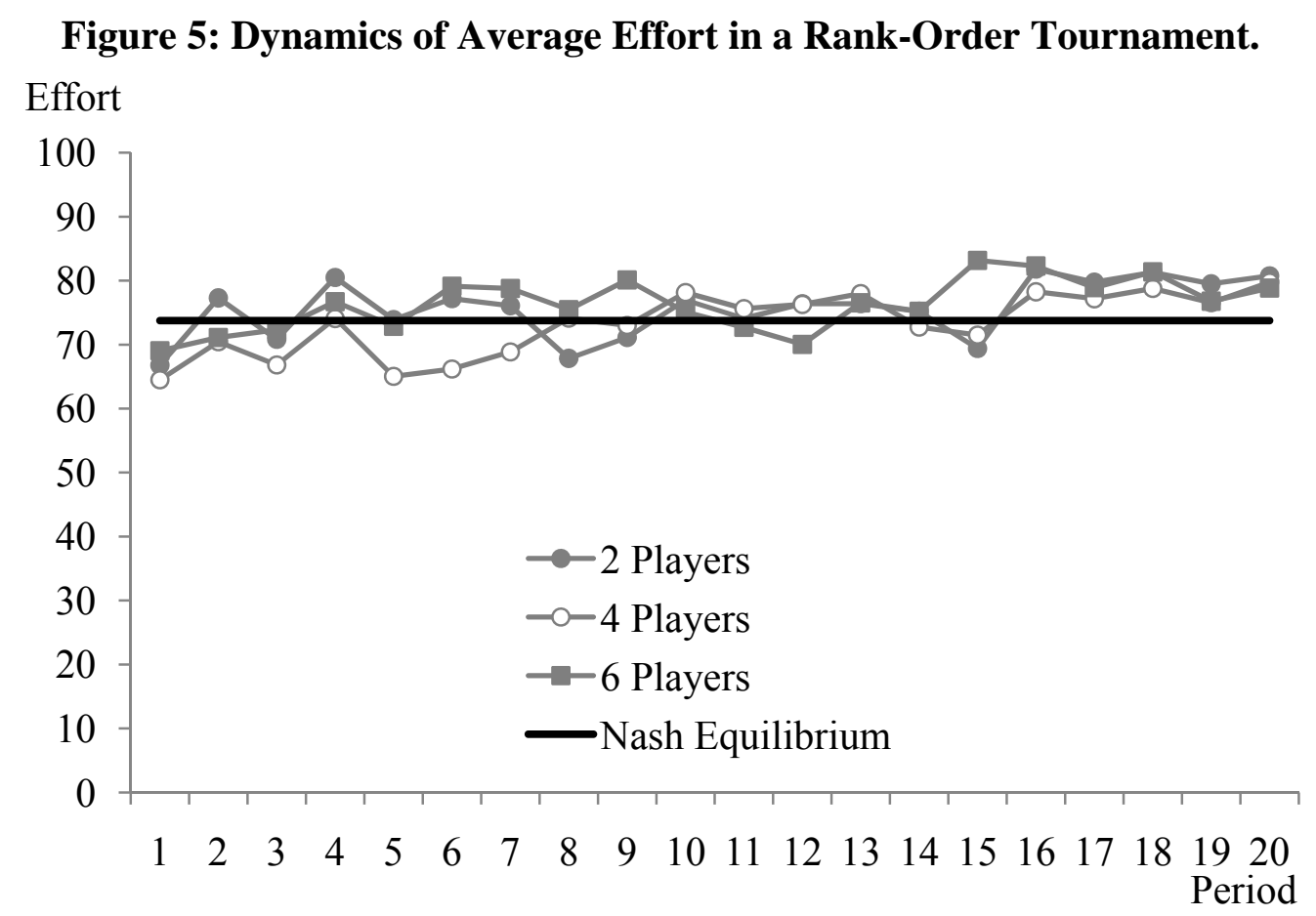

Note: The data are taken from Orrison et al. (2004).

The findings of Bull et al. (1987) have been replicated by a large number of experiments on rank-order tournaments (Schotter and Weigelt, 1992; Nalbantian and Schotter, 1997; Harbring and Irlenbusch, 2003, 2005, 2008; Orrison et al., 2004; Wu and Roe, 2005; Wu et al. 2006; Harbring et al., 2007; Harbring and Lünser, 2008; Eriksson et al., 2009b; Eisenkopf and Teyssier, 2010, 2012; Sheremeta and Wu, 2011; Agranov and Tergiman, 2012). Several exceptions are Chen et al. (2011), who observe over-expenditure in contests with asymmetric contestants, and Kräkel and Nieken (2012), who observe twice as high effort levels than predicted in a tournament with minimum productivity requirements. Figure 5 displays the dynamics of average effort over the length of the experiment commonly observed in rank-order tournaments. The data are taken from Orrison et al. (2004) where $n=2,4$ or 6 symmetric players compete for large prizes of $v_{1}=\$ 2.04$ (1, 2 or 3 prizes, respectively) and small prizes of $v_{2}=$ $\$ 0.86$ (1, 2 or 3 prizes, respectively) in a rank-order tournament (i.e., $r=\infty, y_{i}=e_{i}+\varepsilon_{i}$, 
$\varepsilon_{i} \sim U[-a, a]$ and $c\left(e_{i}\right)=e_{i}^{2} / b$, where $a=60$ and $\left.b=15,000\right)$. According to the theoretical prediction, the Nash equilibrium effort is $e^{*}=\left(v_{1}-v_{2}\right) b / 4 a=73.5$. As Figure 5 indicates, for every $n$, the average effort is quite close to the predicted level and there is no overbidding.

The absence of over-expenditure (overbidding) in rank-order tournaments is in sharp contrast to the findings from lottery contests and all-pay auctions. One possible explanation for this finding is that in experiments involving rank-order tournaments, the cost of effort is generally taken to be strictly convex, contrary to the linear cost function employed in experiments on lottery contests and all-pay auctions. In fact, in their experiments on the all-pay auction, Müller and Schotter (2010) find that overbidding is substantial when the cost of effort is linear, but vanishes when the cost function is strictly convex. Another explanation for the lack of over-expenditure in rank-order tournaments is the high dispersion, specified by most researchers, of the performance noise $\varepsilon_{i}$. With a uniform distribution and quadratic effort costs, a large support of the distribution of the random noise component is needed to guarantee that a pure strategy Nash equilibrium exists. But then, the substantial amount of noise in the CSF may lead subjects to restrain effort and decreases the incidence of overbidding. ${ }^{11}$ In fact, Nieken (2010) finds that when given the choice between two distributions of performance noise, subjects are reluctant to choose the distribution with the higher variance even when a risk neutral player would find it beneficial to do so. This finding confirms our conjecture that aversion to random shocks in the CSF could help explain the absence of overbidding in rank-order tournaments. Whether it is the convexity of costs or the presence of noise in the CSF that mitigates overbidding in rank-order tournaments remains an interesting question for future research.

Although on average there is little overbidding in rank-order tournaments, heterogeneity of individual behavior is widespread (Bull et al., 1987). The high variance of effort is especially problematic because in a labor-management context, where rank-order tournaments are often employed in the field (for a review see Charness and Kuhn, 2011), a high variance in individual performance can impose a substantial cost on employers and reduce the overall efficiency of the work place (Lazear, 1999, 2000). What might account for the high variance in individual effort? In their follow-up to Bull et al. (1987), Drago and Heywood (1989) argue that part of the variance in the Bull et al. data may simply be due to relatively flat payoff functions. They conduct several additional treatments and show that the variance in effort is comparable between a tournament and piece-rate scheme when payoff functions (as functions of vectors of efforts) are kept as similar as possible across the two reward schemes. Eriksson et al. (2009b) experimentally examine an alternative explanation for the high variance in effort in simple rank-order tournaments. They find that allowing subjects to choose their payment scheme between the

\footnotetext{
${ }^{11}$ However, Kareev and Avrahami (2007) examine the role of uncertainty in the evaluation of relative performance in two player real-effort tournaments, and find that more uncertainty may actually lead to higher effort. In their experiments subjects perform a real-effort task (adding two digit numbers) for six periods. In one treatment, the experimenter uses only one out of the six periods (minimal scrutiny, more uncertainty) to compare the relative performance of the two subjects. In the other treatment, the experimenter uses all six periods (full scrutiny, less uncertainty) to compare the relative performance. The results show that minimal scrutiny can lead to better performance than full scrutiny. In an additional experiment, Kareev and Avrahami show that for minimal scrutiny to be effective, the abilities of competing subjects should be sufficiently similar.
} 
tournament and the piece-rate scheme significantly reduces the variance of effort in rank-order tournaments. They also find that risk-averse subjects are less likely to enter the tournament, which has an additional negative effect on the variance of effort.

Sheremeta and $\mathrm{Wu}$ (2011) test the comparative statics predictions of the canonical Lazear and Rosen (1981) tournament theory, i.e., the principal optimizes over tournament prizes subject to incentive compatibility and participation constraints. Sheremeta and Wu (2011) conduct an experiment in which some of the subjects play the role of the principal and the other subjects are agents. Consistent with the theory, and other experimental studies examining the incentive effects of tournaments (Harbring and Irlenbusch, 2005; Harbring and Lünser, 2008; Falk et al., 2008), subjects increase their effort in response to an increase in the winner's prize. ${ }^{12}$ However, the authors also find several empirical puzzles that appear to contradict the canonical theory: (i) reducing the prize spread by increasing the loser's prize, while holding the winner's prize constant, does not necessarily reduce the agents' efforts; (ii) increasing the loser's prize while holding the prize spread constant increases the agents' efforts; (iii) principals choose seemingly generous loser prizes that leave nearly all rents to the agents. Controlling for social preferences does not resolve the puzzles, although social preferences do influence individual behavior. Sheremeta and $\mathrm{Wu}$ (2011) show that the puzzles can be explained by the canonical model once the standard textbook assumption of separable agent utility is replaced by a non-separable utility function.

An important advantage of rank-order tournaments over alternative compensation schemes is that tournament incentives are not affected by common shocks (random noise that impacts all players equally), since common shocks do not change the relative ranking of players' efforts (Wu and Roe, 2005; Wu et al., 2006; Agranov and Tergiman, 2012). As a result of filtering common shocks, tournaments reduce agents' risk exposure, making them more attractive than other compensation schemes. Wu and Roe (2005) and Wu et al. (2006) show both theoretically and experimentally that in the presence of common shocks tournaments outperform fixed performance contracts and piece-rates by eliciting higher efforts. In a related study, Agranov and Tergiman (2012) also examine individual behavior in tournaments and alternative compensation schemes in the presence of common shocks. They find that relative piece-rates (where a contestant receives payment in proportion to own performance and is also penalized by a higher performance of the other contestant) can elicit even higher effort levels than tournaments.

\subsection{The Contest Success Function}

A number of theoretical studies establish common links between the canonical contests in the literature. For example, Che and Gale (2000) provide a link between the rank-order tournament and the all-pay auction. Specifically, they examine the case where the noise

\footnotetext{
${ }^{12}$ The significant incentive effect of prize spreads in tournaments is also documented in several experimental studies investigating monitoring in rank-order tournaments (Uske, 2008; Güth et al., 2009; Avrahami et al., 2012).
} 
parameter in the rank-order tournament $\varepsilon_{i}$ generates a contest success function (CSF) that is piecewise linear in the difference between the two players' efforts and ask what happens when the noise disappears. In this case, the rank-order tournament (i.e., $r=\infty$ and $y_{i}=e_{i}+\varepsilon_{i}$ ) approaches the all-pay auction (i.e., $r=\infty$ and $y_{i}=e_{i}$ ). Hirshleifer and Riley (1992) and Jia (2007) show that with the appropriate assumptions on the distribution of noise $\varepsilon_{i}$, a variant of the rank-order tournament involving multiplicative noise (i.e., $r=\infty$ and $y_{i}=e_{i} \varepsilon_{i}$ ) is equivalent to Tullock's lottery contest (i.e., $r=1$ and $y_{i}=e_{i}$ ). Baye and Hoppe (2003) and Fu and Lu (2012) identify conditions under which a variety of more general models, such as research tournaments and patent races, are strategically equivalent to the Tullock contest. Even within the same family of Tullock-like contests, Chowdhury and Sheremeta (2012) show that different types of contests can be strategically equivalent.

Setting aside a large theoretical literature on the equivalence between different types of contests, there are only a few experimental studies comparing different contest structures (Davis and Reilly, 1998; Potters et al., 1998; Cason et al., 2010; Sheremeta et al., 2012). ${ }^{13}$ Davis and Reilly (1998) and Potters et al. (1998) compare behavior in all-pay auctions to lottery contests. Both studies find that, as theory predicts, the perfectly discriminating all-pay auction $(r=\infty)$ generates higher efforts than the probabilistic lottery contest $(r=1)$. However in both types of contests, the subjects expend higher effort than the Nash equilibrium prediction. The reason why effort is higher in the all-pay auction than in the lottery contest is because the all-pay auction provides a participant with sharp incentives to outbid his rivals. As a result, subjects participating in all-pay auctions earn lower payoffs than in lottery contests. Cason et al. (2010) provide evidence that, consistent with theoretical predictions, the 'cut-throat' nature of all-pay auctions makes them less attractive to entry by participants. In a real-effort experiment, they find that lottery-type contests elicit more entry and greater total effort than all-pay auctions. To the extent that effort is socially desirable, the lottery contest and its variants perform better by limiting the degree to which heterogeneity among contestants discourages weaker entrants, but without altering the effort expended by stronger entrants.

Finally, Sheremeta et al. (2012) compare both theoretically and experimentally three alternative contest structures. In a rank-order tournament, the prize is allocated to the highest performing contestant. In a lottery contest, the prize is allocated randomly with probabilities given by the contestants' share of total performance. In a proportional-prize contest, that same prize is divided among the contestants according to their share of total performance. The results of the experiment indicate that, consistent with theory, the rank-order tournament generates higher efforts and lower payoffs than the other two contests. Contrary to theoretical predictions, the lottery contest generates higher efforts and lower payoffs than the proportional-prize contest.

\footnotetext{
${ }^{13}$ These studies only compare different contest models. None of these studies directly addresses the issue of equivalence between contest structures.
} 


\section{Contest Structure}

As discussed by Konrad (2009), even simple one-stage contests are often characterized by many parameters (i.e., number of players, heterogeneity of players and number of prizes) and they can have very different structures (i.e., incomplete information, spillovers and externalities). All of these factors play an important role in influencing the behavior of individual players. In this section we review the experimental literature investigating some of these factors.

\subsection{Number of Players}

Theoretically, it is not clear how the number of players impacts individual behavior in contests. For example, for the symmetric case it is generally true that when a contest is modeled as an all-pay auction or as a lottery contest, then the expected individual effort decreases with the number of players (Konrad, 2009). However, when the contest is modeled as a rank-order tournament, then, depending on the distribution of noise, the expected effort may decrease, increase, or remain unchanged when the number of players increases (Gerchak and He, 2003).

The experimental evidence on the effect of the number of players on individual behavior in contests is also somewhat mixed. Sheremeta (2011a), for example, finds that the average effort in a symmetric two-player lottery contest is $33 \%$ of the prize value, while in the corresponding four-payer contest the average effort is $25 \%$ of the prize. Therefore, as predicted by the theory, the average individual effort decreases in the number of players. Morgan et al. (2012a) also find support for this comparative static prediction with different group sizes. On the other hand, Lim et al. (2012) find that the average individual effort does not respond to the number of players. They attribute their findings to the fact that subjects make mistakes when choosing an effort level.

In all-pay auctions, Gneezy and Smorodinsky (2006) find that the average effort decreases in the number of players. On the other hand, Harbring and Irlenbusch (2003) document that the average effort weakly increases in the number of players. A potential explanation for these differences is that in Harbring and Irlenbusch (2003), subjects' efforts are restricted by a maximum effort cap set, while in Gneezy and Smorodinsky (2006), subjects can choose any effort (even higher than the prize value).

In rank-order tournaments, Orrison et al. (2004) find that the average effort does not change in the number of players when the noise component $\varepsilon_{i}$ is uniformly distributed. List et al. (2010) investigate the effect of the number of players under different distributions of noise. They design three treatments in which, depending on the noise distribution, a risk-neutral contestant's effort should decrease, increase or remain the same. They find that, contrary to theoretical predictions, the average individual effort always decreases in the number of players. Relaxing the risk-neutrality assumption and allowing for risk-aversion, explains this pattern of behavior. As in experimental studies of lottery contests (Millner and Pratt, 1991; Sheremeta, 2011a; Schmidt et al., 2011), List et al. (2010) find that risk-averse players exert less effort in rank-order tournaments than risk-neutral players. 
To summarize, although there is some disagreement between experimental findings across the three canonical contests regarding the effect of group size on individual effort, overall, the evidence seems to favor a negative relationship between group size and individual effort. However, such an interpretation should to be taken with caution because the relationship between group size and individual effort depends both on the experimental design and the underling theoretical structure.

\subsection{Heterogeneous Players}

The theoretical literature on contests has recognized that greater heterogeneity between players (appropriately normalized depending on the contest) leads to lower aggregate effort (Baye et al., 1993; Baik, 1994; Stein, 2002). Heterogeneity is usually introduced through differences in players' valuations of the prize (Hillman and Riley, 1989; Baye et al., 1993, 1996), one player's head-start over another (Weigelt et al., 1989), players' impact on the CSF (Baik, 1994), or differences in relative costs of effort (Schotter and Weigelt, 1992; Gradstein, 1995). A common theoretical finding of these studies is that, when appropriately defined, greater heterogeneity decreases individual and aggregate effort in contests. The reason for this is the so called "discouragement effect." Although the technical details underlying the discouragement effect differ from model to model, they basically arise because a weaker player, either with higher unit costs of effort or a lower value of winning, finds it relatively unprofitable trying to beat the stronger player and, consequently, cuts back on his costly expenditure. This, in turn, may allow the stronger player to bid more passively as well when compared to a contest in which he faces a player of similar strength. In some types of contests, this effect is quite strong. For instance, in a two-player all-pay auction aggregate expenditures decline in the unique Nash equilibrium if the weaker player's value of the prize is held fixed and the stronger player's value is increased above that level. Even the increase in the stronger player's value of the prize is not sufficient to avoid having effort discouraged in the aggregate (here the weak player's effort in the mixed strategy equilibrium decreases on average while the strong player's distribution of effort does not change). In contrast, in a two-player Tullock lottery contest, a unilateral increase in a player's value of winning will increase aggregate effort, but for a fixed average valuation of the prize, aggregate expenditure is decreasing in the difference in the two players' values.

The impact of player heterogeneity on individual behavior has been thoroughly investigated in lottery contests (Davis and Reilly, 1998; Anderson and Stafford, 2003; Fonseca, 2009; Anderson and Freeborn, 2010; Kimbrough et al., 2011). Davis and Reilly (1998) compare a four-player symmetric lottery contest for a given prize with a five-player lottery contest in which the added player has a higher value of the prize. They find that adding the high-value bidder increases the total expenditure, which is consistent with the comparative static prediction. However, individual expenditures across the two contests for the four low-value players are not consistent with the comparative static prediction. Anderson and Stafford (2003) use a more complex design with a variable number of players, cost heterogeneity and an entry fee to study the theoretical predictions of Gradstein (1995). They find that, consistent with the theoretical 
predictions, cost heterogeneity reduces the aggregate number of players who enter. Moreover, for larger groups, higher heterogeneity decreases individual and aggregate efforts. Fonseca (2009), Anderson and Freeborn (2010) and Kimbrough et al. (2011) experimentally study lottery contests with heterogeneous players, where heterogeneity arises from the contestants' differing impacts on the CSF. All three studies find that, as predicted by the theory, more heterogeneity between players leads to lower efforts in lottery contests.

The first study investigating a complete information all-pay auction with asymmetric players is Davis and Reilly (1998). Consistent with theoretical predictions, Davis and Reilly find that, introducing a higher valuation player into a model in which players have a given common value reduces the individual efforts of the original symmetric players relative to their efforts in the symmetric game. However, as before, there is significant overbidding, both in the benchmark symmetric game and the asymmetric game, with a substantial portion of the overbidding in the latter game being driven by the behavior of the stronger players. Fehr and Schmidt (2011) replicate these findings in an experiment designed to investigate the "exclusion principle" of Baye et al. (1993). The results of their experiment indicate that it may not be profitable for a contest organizer to exclude the strong player in favor of more homogeneity - as the exclusion principle would predict - because strong players significantly overexert effort relative to the theoretical prediction. Thus, excluding such players may actually strictly reduce the contest organizer's revenue. Finally, Deck and Sheremeta (2012) and Liu (2011) find some support for a discouragement effect in dynamic all-pay auctions with asymmetric players, where theoretical benchmarks suggest that the discouragement effect might be even stronger than in simultaneous move games (see Leininger, 1991; Konrad and Kovenock, 2009).

Asymmetries have also been investigated in rank-order tournaments (Weigelt et al., 1989; Schotter and Weigelt, 1992). Weigelt et al. (1989), for example, study biased rank-order tournaments, and find that when one player has an unfair head-start over another, both players exert lower effort than symmetric players. Schotter and Weigelt (1992) extend this analysis to the case of both "unfair" (where the rules favor one identical player over another) and "uneven" (where players have different costs of effort) tournaments. As before, they find that either asymmetry between players reduces individual efforts.

Overall, it seems that chosen-effort experiments on lottery contests, all-pay auctions and rank-order tournaments provide support for a "discouragement effect." Whether such a discouragement effect exists in real-effort and field settings is an open question. Hammond and Zheng (2011), for example, investigate the effect of heterogeneity (reflecting individual abilities) on subjects' performance in a real-effort contest. They find that subjects do not respond significantly to an increase in the degree of heterogeneity. ${ }^{14}$ On the other hand, two other studies

\footnotetext{
${ }^{14}$ To measure ability and form more or less homogeneous groups, the authors first let the subjects make decisions under a piece-rate scheme. Then groups are formed to compete in a contest, but the participants are not informed of the exact level of heterogeneity in their group of four. The theoretical predictions are based on a rank-order tournament where the noise parameter $\varepsilon_{i}$ enters the production function (a) either as an additive component, i.e., $y_{i}\left(e_{i}, \varepsilon_{i}\right)=e_{i}+\varepsilon_{i}$, or (b) as a multiplicative component, i.e. $y_{i}\left(e_{i}, \varepsilon_{i}\right)=e_{i} \varepsilon_{i}$. The results of the experiment allow the authors to reject the multiplicative production function, (b), where higher ability raises the marginal product of
} 
provide evidence for (Gill and Prowse, 2012) and evidence against (Berger and Pope, 2011) the discouragement effect in real-effort experimental settings. We discuss these studies in more detail in Section 6.2.

\subsection{Spillovers and Externalities}

In many contests an individual's payoff may directly depend on the opponents' expenditures (Baye et al., 2005, 2012; Chowdhury and Sheremeta, 2011b). For example, in the war of attrition, where the amount of time a player is willing to fight is interpreted as a bid, a winning player need only fight as long as his rival (that is, the winner only pays the rival's lower bid). In innovation contests one firm's R\&D effort may provide information spillovers that benefit its rival. In a patent race the expenditure of a rival can decrease the patent value for the winner, creating a negative spillover. Another example where spillovers and externalities are important is litigation. Depending on the litigation system, losers have to compensate winners for a portion of their legal expenditures or up to the amount actually spent by the loser.

Several experimental studies have examined contests with spillovers. For instance, Dechenaux and Mancini (2008) have examined a two-player contest with a generalized contest payoff function as in Baye et al. (2005). Specifically, the payoff for player $i$ is given by

$$
\pi_{i}\left(e_{i}, e_{j}\right)= \begin{cases}v_{i}-\beta e_{i}-(1-\alpha) e_{j} & \text { if } i \text { wins } \\ v_{i} / 2-e_{i} & \text { if } i \text { ties } \\ -\alpha e_{i}-(1-\beta) e_{j} & \text { if } i \text { loses }\end{cases}
$$

The CSF in Dechenaux and Mancini (2008) corresponds to an all-pay auction. By contrast, Coughlan and Plott (1997) employ a lottery CSF and a payoff function that differs slightly from that in equation (5). As in contests without spillovers, both studies find significant overbidding in comparison to the Nash benchmark. We discuss the results from these two studies in more detail in Section 8.1.

Cohen and Shavit (2012) study a lottery contest version of the sad loser auction (see Riley and Samuelson, 1981; Baye et al., 2012). In such a contest, the designer reimburses the winner's cost of effort (bid), so the payoff for player $i$ is given by

$$
\pi_{i}\left(e_{i}, e_{j}\right)= \begin{cases}v_{i} & \text { if } i \text { wins } \\ -e_{i} & \text { if } i \text { loses }\end{cases}
$$

Theory predicts that lottery contests with refunds should generate higher average bids than all-pay lottery contests (Matros and Armanios, 2009). The results of the experiment provide support for this prediction. Theory also predicts that the revenue of a contest designer should be

effort (complementarities) in favor of an additively separable specification, (a), where effort and ability do not interact. 
higher in the lottery contest with refunds (once the cost of the winner's effort is refunded). This prediction is not supported in the experiment, mainly because low valuation players bid too low in contests with refunds. Overall, Cohen and Shavit (2012) find evidence that subjects' behavior is more consistent with a corner solution, in which low valuation players bid zero.

\subsection{Multiple Prizes}

Over a century ago, Galton (1902) provided a simple statistical argument that in order to maximize the total effort in a contest it may be optimal to split a fixed purse into two separate prizes (his suggestion was the ratio of 3 to 1 between the first and the second prize). Recent theoretical research has shown that the form of the optimal prize structure in contests depends on many factors (for a review see Sisak, 2009). Clark and Riis (1998) and Fu and Lu (2009), for example, show that in a symmetric lottery contest modified to allow multiple prizes the highest aggregate effort is obtained by offering one grand prize. Barut and Kovenock (1998) show that in an $n$-player symmetric contest in which the $m$-th highest bidder receives the $m$-th largest prize, an invariance principal arises: any distribution of a fixed purse across $n$ (nonnegative) prizes yields the same expected total expenditure as long as the lowest value prize is zero. Moldovanu and Sela (2001) show that in the all-pay auction with incomplete information and private values of a multiplicative coefficient in the cost function (reflecting idiosyncratic ability) one grand prize elicits the highest effort from participants when the common component of the cost of effort function is either linear or concave. However, if the contestants have a convex common component of cost several prizes may be optimal. Moreover, across a wide range of specific contest models, a single-prize may not be optimal when contestants are risk-averse (Krishna and Morgan, 1998; Kalra and Shi, 2001) or heterogeneous (Szymanski and Valletti, 2005; Moldovanu and Sela, 2007).

There is a growing number of experimental studies investigating the optimality of the prize structure in contests (Harbring and Irlenbusch, 2003; Orrison et al., 2004; Lim et al., 2009; Müller and Schotter, 2010; Chen et al., 2011; Sheremeta, 2011a; Schmidt et al., 2011; Stracke et al., 2012). These studies are based on different theoretical models (i.e., lottery contests, all-pay auctions and rank-order tournaments), and thus they are not directly comparable. Nevertheless, one aspect common to all of these studies is the assumption that the contest designer allocates a fixed amount of money either to one grand prize or split between multiple prizes.

Sheremeta (2011a) compares the performance of single-prize and two-prize lottery contests with four symmetric players, where the total prize value is held constant across the treatments. Consistent with the theoretical predictions of Clark and Riis (1998), the single-prize contest generates higher effort than multiple-prize contests. Among multiple-prize contests, two equal prizes produce lower effort than two unequal (one large and one small) prizes. Schmidt et al. (2011) also find that the single-prize contest results in a higher aggregate effort than the multiple-prize contest, although their theoretical model predicts that under risk neutrality both contests are equivalent. Stracke et al. (2012) show that even in a multi-stage elimination lottery contest between symmetric players, a single-prize generates higher efforts than when multiple 
prizes are allocated at the end of the contest. Multiple prizes also perform poorly in rank-order tournaments, as confirmed by Orrison et al. (2004), who find that total effort is lower in tournaments with many small prizes than with few large prizes. ${ }^{15}$

It is important to emphasize, however, that it is not always the case that a single prize produces the highest effort in a contest setting. Recall that in the model of Moldovanu and Sela (2001), multiple-prize contests can generate higher efforts if the cost of effort is convex. Müller and Schotter (2007) experimentally investigate this setting and find that, consistent with equilibrium, in the case of a linear common cost component a one-prize contest generates higher efforts than a two-prize contest, whereas in case of a quadratic common cost component a twoprize contest generates higher efforts than a one-prize contest. ${ }^{16}$ They also find that, while theory predicts effort levels that are continuous and increasing in the coefficient representing ability, observed effort is bimodal. As per our discussion in Sections 2.2 and 3.6, low ability players drop out and exert little or no effort while high ability players try too hard and overbid.

When contestants are heterogeneous in some dimension, in theory, multiple-prize contests may be optimal (Szymanski and Valletti, 2005; Moldovanu and Sela, 2007). Intuitively, if there is one very strong player and only one prize, then the weaker players may be discouraged from exerting effort as per the "discouragement effect" introduced in Section 3.2. Chen et al. (2011) investigate the optimal number of winning prizes in rank-order tournaments with heterogeneous contestants, where strong players have an ex ante advantage in terms of their initial endowment over weak players. They find that in all treatments, there is significant overexpenditure of effort relative to the Nash equilibrium by both strong and weak players. Moreover, in the treatment with two strong players and one weak player, strong players increase their effort when the number of prizes is raised from one to two. Similarly, Lin (2009) examines behavior in a contest for status between players of heterogeneous abilities (different private marginal costs) as modeled by Moldovanu et al. (2007). Theoretically, when the cumulative distribution of abilities exhibits an increasing failure (or hazard) rate (i.e., strong heterogeneity), it is optimal to have many status categories (i.e., many prizes). In contrast, when the cumulative distribution of abilities is sufficiently concave so as to exhibit a decreasing failure rate (i.e., weak heterogeneity), it is optimal to have only two status categories (i.e., one winning prize for a top status). The results of the experiment provide some support for these predictions, although for multiple prizes to generate a greater expenditure than one prize the distribution of abilities needs to be more concave than prescribed by the theory. In summary, both Lin (2009) and Chen

\footnotetext{
${ }^{15}$ Harbring and Irlenbusch (2003) find that the average effort increases with the number of small prizes. However, their finding is mainly driven by their experimental design. Specifically, their model is based on an all-pay auction in which players have constrained endowments and convex costs. Given such restrictions, the pure strategy equilibrium that arises is the one in which some players in the single-prize and all players in the multiple-prize contest exert maximum possible effort. Therefore, as a result of restricted endowments, the multiple-prize contest outperforms the single-prize contest.

${ }^{16}$ Freeman and Gelber (2010) conduct an experimental test of Moldovanu and Sela (2001) based on a real-effort experiment. They find that subjects' performance is higher when multiple prizes are offered than when a single prize is offered.
} 
et al. (2011) find support for theoretical arguments that in the presence of heterogeneous contestants, it may be optimal to have multiple prizes.

Finally, Kalra and Shi (2001) show theoretically that a multiple-prize rank-order tournament may generate higher total expenditure than a single-prize tournament when contestants are symmetric and risk-averse. To test these predictions, Lim et al. (2009) investigate the optimality of a multiple-prize tournament in the presence of symmetric risk-averse contestants. Based on the model by Kalra and Shi, Lim et al. predict that the optimal prize structure is one with multiple positive prizes, in which each prize is of different value. Consistent with the theoretical predictions, their experimental results indicate that increasing the number of winners generates higher effort under risk aversion. However, contrary to the theory, the prizes that maximize the total expenditure need not be strictly rank-ordered.

\subsection{Endogenous Prizes}

In many contests, it is appropriate to consider endogenously determined prizes which are functions of the profile of efforts rather than the more common assumption of an exogenous prize value. Such contests are especially interesting because theoretically they can generate qualitatively different predictions than contests with exogenous prizes (Chung, 1996; Baye and Hoppe, 2003; Long and Vousden, 1987; Chowdhury and Sheremeta, 2011b; Baye et al., 2012). For instance, Baye et al. (2012) show that in some cases, all-pay auctions with endogenous prizes will have pure strategy equilibria. Recall that by contrast, all-pay auctions with exogenous prizes only have mixed strategy equilibria. Sacco and Schmutzler (2008) study an all-pay auction where endogenous prizes depend positively on own effort and negatively on the competitors' effort. Consistent with other all-pay auction studies they find significant overbidding relative to the symmetric mixed strategy equilibrium. However, they also find evidence that subjects often coordinate on asymmetric pure strategy equilibria, where one player exerts all the effort while others exert no effort at all. A similar type of contest is studied by Fullerton et al. (2002). The main difference, however, is that in Fullerton et al. the size of the reward is determined by the outcome of a first-price (procurement) auction. A player's payoff from winning the first-price auction is equal to his bid, which is thus the prize value, minus his cost of effort (see Taylor, 1995, for the underlying model of a research tournament). In two-player contests, one of the two players often drops out of the contest, allowing the remaining contestant to submit a large prizevalue bid. By contrast, in contests with more than two players, the first-price auction mechanism yields relatively low, competitive bids. In turn, this results in large net revenue to the contest designer, often in excess of net revenue obtained under the exogenous prize contest.

The endogeneity of prizes also affects entry into contests. Cason et al. (2010) suggest that to attract more entrants it may be beneficial for a contest designer to use a proportional-prize structure. In the proportional-prize contest, prizes are endogenously determined by the relative performance of contestants. Sheremeta et al. (2012) compare the performance of a proportional- 
prize contest to a single-prize contest. ${ }^{17}$ They find that, consistent with theory, single-prize contests generate higher efforts than proportional-prize contests. But at the same time, proportional-prize contests generate higher and more equitable payoffs. This specific feature of proportional-prize contests can explain why proportional prizes elicit higher entry rates than lottery contests with a single prize (Cason et al., 2010).

\subsection{Incomplete Information}

A number of experiments have examined all-pay auctions and lottery contests in a private values environment. There is incomplete information because each bidder only knows his own valuation of the prize (or, alternatively, the marginal cost of effort). In most experiments, valuations (or costs) are drawn independently from uniform distributions. A theoretical analysis of all-pay auctions with symmetric incomplete information can be found in Krishna and Morgan (1997) and Moldovanu and Sela (2001) and treatments of the lottery contest can be found in Ryvkin (2010) and Wasser (2012).

Barut et al. (2002) were the first to experimentally examine all-pay auctions in a symmetric private values environment, but the focus of their study was all-pay auctions with multiple units in which six bidders bid to win one of either two or four identical prizes, instead of a single prize. They assumed uniformly distributed private values for a single unit. Relative to the symmetric Bayesian Nash equilibrium, underbidding at low valuations and overbidding at high valuations was observed, and the outcomes were not always efficient, in the sense that higher-valued players did not necessarily win the units. In the aggregate, there was overbidding so that average revenue is higher than predicted. ${ }^{18}$

The follow up study by Noussair and Silver (2006) used six-player single-prize all-pay auctions, again with uniformly distributed private values. They also found aggregate overbidding relative to the Bayesian Nash equilibrium, with average revenues far above the theoretically predicted expected revenue. As in Barut et al. auction outcomes were not always efficient. In one session, the highest value bidder won the prize only $82 \%$ of the time. When considering subject level data, a prominent outcome in both Barut et al. and Noussair and Silver is the phenomenon Müller and Schotter (2010) refer to as bifurcation (see Section 2.2): low-valuation subjects underbid, while high-valuation subjects tend to overbid. For instance, Figure 6 is drawn from data obtained from Noussair and Silver (2006). The frequency of zero bids is much higher than predicted by equilibrium behavior. For example, in the Bayesian Nash equilibrium only subjects with a valuation of zero should bid zero, whereas in the experiment, the modal bid for subjects with valuations in the 25 th percentile appears to be zero. It was also common for subjects with valuations in the 75th percentile to place bids near their valuation. In two-player all-pay auctions, Dechenaux and Mancini (2008) find that low-valuation players behave more aggressively than in

\footnotetext{
${ }^{17}$ A version of a proportional-prize contest is also studied by Schmidt et al. (2011), Chowdhury et al. (2012b), Fallucchi et al. (2012), and Masiliunas et al. (2012).

${ }^{18}$ The experiment of Mohamudally-Boolaky (2011) replicates the findings of Barut et al. (2002) in the setting of a multi-unit all-pay auction with supply uncertainty.
} 
Noussair and Silver's (2006) six-player auctions, suggesting that this finding does not prevail in smaller auctions.

Figure 6: Bifurcation in the All-Pay Auction with Incomplete Information.

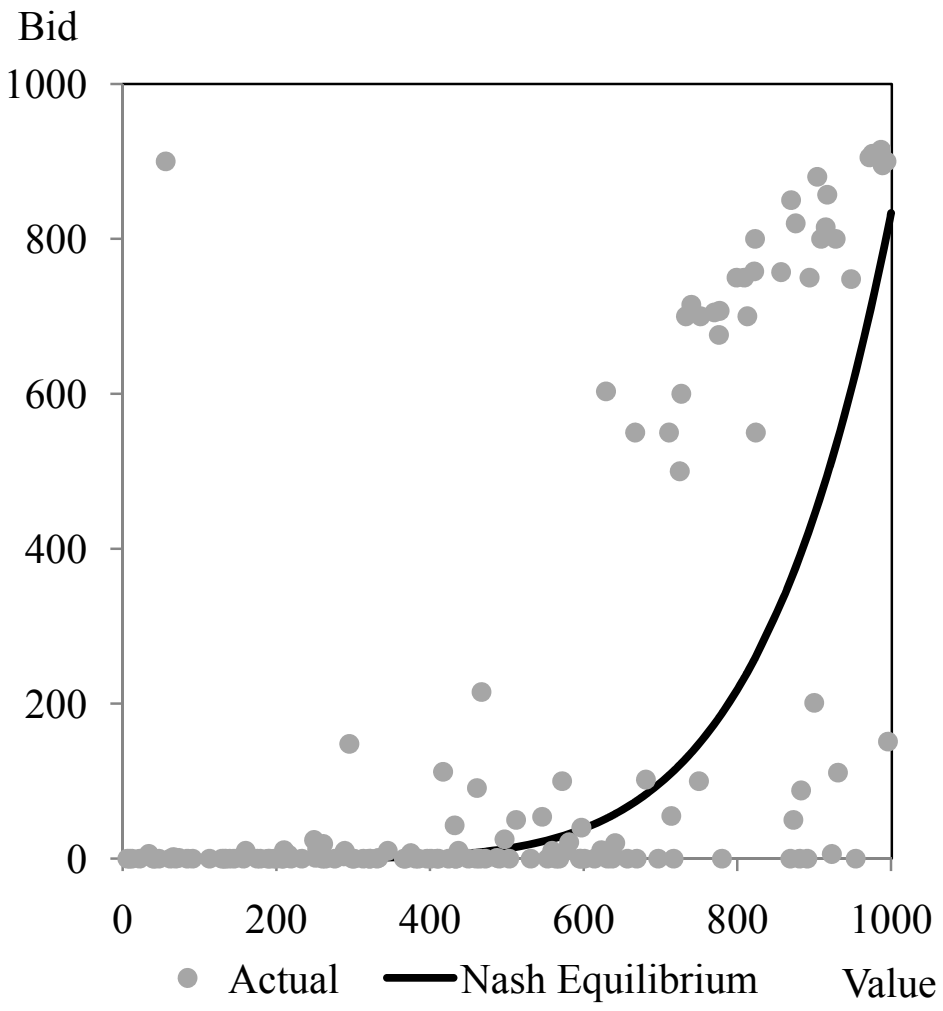

Note: The data are taken from Noussair and Silver (2006).

One of the key findings in these studies is that all-pay auctions are less likely to be efficient than winner-pay auctions, especially when the number of units for sale is small. Also, as might be anticipated, predicted revenue equivalence generally, but not always, fails in the laboratory. Noussair and Silver (2006) found that the single-prize all-pay auction generates higher revenue than the first-price winner-pay auction, but Barut et al. found that for the multiunit generalizations of these auctions, there was no significant difference in revenues. On the other hand, Barut et al. did find that the multi-unit all-pay auction generated higher revenue than an English Clock auction. Finally, in both Barut et al. (2002) and Noussair and Silver (2006), a model that forecast bids in the long run showed that average bids trend downwards towards the Bayesian Nash equilibrium over time, but they converge to a level that is bounded strictly above the equilibrium.

The bifurcation terminology was coined by Müller and Schotter (2010), who consider four-player all-pay auctions and a between-session design in which they vary the curvature of the cost function (strictly convex versus linear) and the number of prizes (one versus two). A multiplicative coefficient in the cost function, which measures ability, is the subject's private information. The predictions follow from Moldovanu and Sela's (2001) model of contest design. 
Interestingly, Müller and Schotter cannot discern evidence of bifurcation when effort levels are averaged across groups. However, they provide compelling visual evidence of bifurcation at the individual level (see Figure 2 in Müller and Schotter). They also construct a simple econometric model and estimate the cut-off level of the multiplicative coefficient measuring ability at which the empirical bidding function bifurcates.

At least two studies recognize that the feedback provided between periods may influence bidding. Barut et al. (2002) examine two different treatments with respect to information disclosure. In one treatment, the subjects learn the bids that were submitted during the last period. In the treatment with a richer information structure, the subjects learn the bids as well as the players' valuations. They find that revealing previous period valuations raises efficiency in two-player all-pay auctions. Hyndman et al. (2010) observe overbidding in two-player privatevalue all-pay auctions where they vary the feedback provided to subjects between auctions. Similar to Barut et al. (2002) and Noussair and Silver (2006) the subjects' valuations are uniformly distributed. In one treatment the winning bid is revealed to all players, while in another treatment it is not. This design allows the authors to examine whether information disclosure affects the dynamics of bidding based on a model of regret. The main finding is that information disclosure worsens the degree of overbidding. They attribute this finding to the behavior of regretting agents, who, upon learning that they lost to an "affordable" bid, raise their bid in order to increase their chance of winning the next auction.

Brookins and Ryvkin (2011) compare lottery contests with complete and incomplete information regarding the marginal cost of effort. Each player's marginal cost of effort is an i.i.d. draw from a uniform distribution. They show that with two players, whether or not information is complete does not affect equilibrium effort expenditure significantly. However, with four players, players with a low marginal cost (high marginal cost) submit lower (higher) effort bids under complete information than under incomplete information. These equilibrium predictions are borne out by the data, but not surprisingly, the authors also observe substantial overbidding.

In the papers mentioned above players are ex-ante symmetric, i.e., their values (or costs) are independently drawn from the same distribution. Wärneryd (2003) analyzes a two player lottery contest in which one contestant is informed of the common value of the prize prior to bidding, while the other player knows only the continuous distribution from which this value is drawn. Grosskopf et al. (2010) experimentally study asymmetric information contests reminiscent of Wärneryd (2003). In their two-player common value environment there is either symmetric information and uncertainty, as participants submit their bids before the value of the prize is determined, or asymmetric information, whereby one contestant knows the value of the prize but the other player only knows the distribution of the value. In a comprehensive comparison of lottery contests to all-pay auctions, the authors find that informed participants in asymmetric contests tend to overbid, while symmetrically informed participants in contests with uncertainty are more prone to restraint. In general, informed bidders tend to bid more aggressively than uninformed bidders. Interestingly, the average sum of bids in asymmetric information lottery contests and all-pay auctions are not statistically different, while they differ 
under symmetric information. The empirical result for asymmetric information contests does not conform to the theoretical prediction, which is that expected revenue in the all-pay auction is greater than expected revenue in the lottery contest.

\section{Dynamic Contests}

In this section we discuss contests with a dynamic structure. That is, contests in which some players can make decisions based on the actions of others. First, we discuss contests in which players move sequentially. Second, we discuss wars of attrition, which are multi-period contests of exit, which in some contexts can be interpreted as simultaneous move contests. Third, we examine a class of multi-stage contests with a finite horizon in which the set of players remains fixed. These include patent races and best-of- $n$ contests. Fourth, we discuss multi-stage elimination contests, in which a certain number of players are eliminated at each stage of the competition. Finally, we conclude with a discussion of endogenous timing and entry into contests.

\subsection{Sequential Contests}

In a sequential contest, the players make effort decisions in a sequence, with players moving later in the game observing the previous players' choices. Dixit (1987) derives theoretical predictions for two-player sequential contests under standard assumptions on the CSF which include the lottery CSF as a special case. If players are symmetric, then the simultaneous move Nash equilibrium effort levels constitute a subgame perfect Nash equilibrium (SPNE) outcome. By contrast, if the leader is a favorite, in the sense that his probability of winning the contest in the simultaneous move Nash equilibrium is greater than one half, then the leader's SPNE effort level in the sequential contest is higher than under simultaneous moves. Leininger and Yang (1994) show that with the Tullock CSF with $r>2$ and symmetric players, in the unique SPNE, the first-mover preempts the second-mover by expending an effort level that forces the second-mover to expend zero. ${ }^{19}$ In a game such as Dixit's (1987) in which the choice of timing is endogenized, Baik and Shogren (1992) show that in a SPNE, the favorite chooses to follow whereas the underdog chooses to lead. They use this result to argue that the favorite would not lead aggressively and, in fact, endogenous leadership by the underdog causes both players to expend less effort than under simultaneous moves. This theoretical prediction forms the basis for a number of related experiments.

First, Shogren and Baik (1992) investigate the form of exogenous leadership that does not arise in their game of timing, the case of the "favorite leader" - "underdog follower" sequential contest. They compare behavior in this dynamic game to behavior in the simultaneous move contest, with the lottery CSF. Their experiments identify several key behavioral departures from

\footnotetext{
${ }^{19}$ In fact, because Leininger and Yang (1994) allow for an arbitrary number of alternating moves, the preemption result does not rely on a simple sequence of one move for each player.
} 
Dixit's prediction. In the sequential contest, favorite first-movers submit effort levels that are no different from the favorites' expenditures in the simultaneous move game. Overall, secondmovers best respond to the first-movers' choices. Finally, the authors note that in their role as followers, underdogs sometimes seek to equalize the probability of winning across players rather than maximize their expected payoff.

Weimann et al. (2000) also examine a sequential two-player contest, but employ a design with symmetric players and the Tullock CSF with $r=8$. Recall that for such a value of the parameter $r$ the simultaneous move Nash equilibrium in the Tullock contest is in non-degenerate mixed strategies. However, as mentioned above, a unique SPNE exists in a sequential contest. In equilibrium, the first-mover preempts the second-mover by submitting the lowest effort level for which the second-mover's best response is to play zero. The experiment implements two-player games with random matching. In the first ten periods, leader-follower roles are reassigned in every period. The striking finding is the lack of evidence for a first-mover advantage in the data. In many instances, second movers earn average payoffs above those earned by first-movers. As Vogt et al. (2002) state when referring to Weimann et al.'s results, it appears as though secondmovers "punished preemptive attempts and exploited cooperative attempts" (pg. 74).

Fonseca (2009) reconsiders experimental sequential contests under both symmetric and asymmetric conditions. More specifically, his experiment allows for a two-by-two comparison of contests by varying both the degree of symmetry between players (symmetric versus asymmetric) and the timing (simultaneous versus sequential). In the treatment with asymmetric players, the CSF is such that the effort by one of the players has a greater marginal impact on his probability of winning than the other player's effort. However, both players have identical cost of effort functions in all treatments. In the contest with symmetric players but asymmetric timing, first-movers submit effort levels in excess of the prediction. In contests with asymmetric players and timing, Fonseca's findings replicate Shogren and Baik's (1992) results to some extent. Favorite first-movers often fail to exploit their theoretically predicted first-mover advantage. Although a large proportion of preemptive attempts succeed, such aggressive (equilibrium) behavior by first-movers sometimes engenders retaliation by the second-mover. Noting that social preferences could strongly influence behavior in contests with asymmetric players, the author also calculates the optimal effort levels for inequality-averse players (Fehr and Schmidt, 1999). Indeed underdog second-movers often submit rather large effort levels, a behavior that can be rationalized by inequality aversion.

Vogt et al. (2002) study contests in which players alternate in submitting bids and each player's bids add up across the duration of the contest to determine a player's overall or total bid. At each point in time, previously submitted bids are public information and the window of opportunity during which contestants may submit bids closes after a randomly determined number of rounds. This design is broadly similar to that in Weimann et al. (2000) and is meant to experimentally implement Leininger and Yang's (1994) infinite horizon alternating move model. In that model there exists a Markov perfect equilibrium in which tit-for-tat strategies are employed, generating a path of play on which bidding ends with the second mover (who bids 
zero). The experimental data exhibit patterns reminiscent of this equilibrium. Contestants stop accumulating effort relatively quickly (after 6 to 10 periods) so that bidding never escalates. As a result, average earnings are higher than in Weimann et al.'s simple leader-follower games. These findings suggest that alternating-move contests with uncertain final period yield more efficient outcomes than one-shot leader-follower contests.

The experiments discussed above involved either exogenously specified leader-follower roles or alternating moves. Baik et al. (1999) examine the natural extension of the leaderfollower setting to a game where the choice of timing is endogenous. ${ }^{20}$ In the first stage of the game, the players simultaneously choose either to commit to an effort level or to wait. ${ }^{21}$ If one player, referred to as the leader, immediately commits to an effort level and the other player, referred to as the follower, waits, then the follower learns the leader's effort level and must choose his own effort level. If both subjects choose to wait, then they play a simultaneous contest. Note that this extensive form corresponds to Hamilton and Slutsky's (1990) game of action commitment. Baik et al.'s (1999) design includes a few noteworthy features. First, they use a payoff matrix with only five actions at the effort choice stage. The payoffs are expected payoffs based on a Tullock lottery contest and asymmetric players (the "favorite" player is more efficient in generating "effective effort" than the "underdog"). Hence the contest is actually one with a deterministic proportional prize rather than a standard lottery contest. As in the Fonseca (2009) study discussed above, the asymmetry is due to superior ability by one of the players as reflected in the underlying CSF. Second, they use the strategy method. ${ }^{22}$ The subjects must fill out a form where they describe a complete strategy for this extensive form game. Third, in one of the treatments, the subjects were given two days to formulate a strategy. In the control treatment, the subjects had twenty minutes to formulate their strategy. Finally, the actual game in the experiment is an elimination tournament whereby each stage is a two-player game of action commitment. After each stage of the elimination tournament, the winners of that stage's twoplayer contests move on to the next stage. Before the new stage begins, they are matched into new pairs who then compete in a two-player contest with action commitment. Turning to the findings, subgame perfection predicts actual timing choices rather well. In particular, when subjects are given up to two days to think about their strategy, favorites endogenously choose to follow and underdogs choose to lead in an overwhelming majority of cases.

\footnotetext{
${ }^{20}$ We note that parts of the experiment and results in Baik et al. (1999) are similar to those in Shogren and Hurley (1997).

${ }^{21}$ Liu (2011) also conducts an experiment to study a sequential all-pay auction in which, prior to the auction, each bidder decides whether to enter the auction early or late. Experimental results indicate that across treatments, players learn to enter the all-pay auction late, even in the case where SPNE predicts that players should be indifferent between entering early and late.

${ }^{22}$ Brandts and Charness (2011) define the strategy method as a method of eliciting decisions in which "subjects make contingent decisions for all nodes at which they may have to play," as opposed to the direct-response method in which subjects only "make decisions whenever it is their time to do so" (pg. 1).
} 


\subsection{Wars of Attrition}

Ever since Maynard-Smith (1974) introduced the model known as the "war of attrition", it has been applied extensively in the field of biology. Experiments on animal contests abound but a comprehensive review of these studies is beyond the scope of this survey. As recognized by Hörish and Kirchamp (2010), economics experiments on the war of attrition are scarce. Before we describe the few economics experiments that have been conducted, we briefly review Austad's (1983) study of male spider contests. His study appears to be the first experimental test of the war of attrition. He implements simple two-player games, where the design varies the value of the prize (low and high) and the asymmetry between contestants (symmetric cost of effort, low asymmetry and high asymmetry). Some of the notable results are that observed contest duration is inversely related to the degree of cost asymmetry. Contests between two highly asymmetric contestants end the soonest and as expected, high-cost males are more likely to stop fighting first than low-cost males. Moreover, raising the value of the prize increases the observed duration of the contest. This treatment effect is observed both in symmetric and in asymmetric contests, where high-cost males do not give in as quickly when the value of the prize is higher.

In the economics literature, the first experimental study of the war of attrition is Bilodeau et al. (2004). ${ }^{23}$ They test a dynamic model of the volunteer's dilemma in which the clock stops as soon as one participant volunteers. ${ }^{24}$ This model is similar to a discrete time war of attrition with complete information and a finite horizon. It is useful to describe the model in some detail. In every period until a final period $T$, if no player has volunteered yet, each player must decide whether to volunteer or wait. Player $i$ receives a payoff of $v_{i}$ per unit of time until at least one player volunteers, after which player $i$ 's payoff increases to $u_{i}>v_{i}$. For player $i$, the cost of volunteering is a one-time cost equal to $c_{i}$. Therefore, given that no other player has volunteered before $t$, if player $i$ volunteers in period $t$, his payoff is $(T-t) u_{i}+t v_{i}-c_{i}$. If some player other than $i$ volunteers in period $t$, then player $i$ 's payoff is $(T-t) u_{i}+t v_{i}$. In this game, the volunteer is the sole participant to incur a cost but every player receives a prize. Equilibrium behavior may be characterized as follows. Define the cutoff period $t_{i}=T-c_{i} /\left(u_{i}-v_{i}\right)$ as the period beyond which for player $i$, volunteering is dominated by not volunteering. For the specific parameters in the experiment, these cutoffs are between 0 and $T$ for every player. If player $i$ is the sole player with

\footnotetext{
23 The first experimental study of a competitive environment resembling a war of attrition is Phillips and Mason (1997). However, in the dynamic Cournot game they analyze, players do not choose the time at which they wish to exit. Rather, a player remains in the game until he is forced to exit when his cumulative profit falls to zero.

${ }^{24}$ The static volunteer's dilemma is a simultaneous move game in which each of $n$ players has two actions, "volunteer" and "not volunteer". Any player who volunteers incurs a cost, $c$. If at least one player volunteers then all players receive an identical prize, $v$. If none of the players volunteer, then all players earn a payoff of zero. If $v-c>$ 0 , the game has multiple Nash equilibria, including pure strategy equilibria in which one player volunteers and $n-1$ players do not volunteer, as well as a symmetric equilibrium in non-degenerate mixed strategies. Diekmann (1985, 1986) experimentally studies symmetric games and the effect of the number of players on the probability of volunteering, and finds that a player's likelihood of volunteering is decreasing in the number of players. Diekmann (1993) experimentally studies an asymmetric version of the game where players differ in their cost of volunteering, and finds that the players with the lowest cost of volunteering are more likely to volunteer.
} 
the largest value of $t_{i}$, then there is a unique SPNE in which player $i$ volunteers immediately and all other players free-ride. If more than one player has the largest cutoff value, there are multiple equilibria, but in every equilibrium, the clock is stopped immediately. In the experiment, groups of three subjects each engage in the war of attrition. Subjects make decisions for 12 periods, each consisting of a separate war of attrition, and there is random matching across periods. In five different treatments, the authors consider various parameters that influence the players' benefit and cost of public good provision. Subgame perfection accurately predicts the identity of the volunteer only $41 \%$ of the time. One of the key departures from subgame perfection is that subjects rarely volunteer immediately. However, behavior responds to incentives in a sensible manner. For instance, other things equal, players with a greater benefit from volunteering (in the sense of a larger $u_{i}-v_{i}$ ) do volunteer more often than other players. Similarly, other things equal, players with a lower cost of volunteering are more likely to stop the clock first. These qualitative predictions are consistent with a descriptive model in which contestants have "first-order beliefs" (see for instance, Nagel 1995). In this model, the contestants believe their opponents' volunteering times are random draws from an identical distribution and they choose their volunteering time to maximize their expected payoff. ${ }^{25}$

Hörish and Kirchkamp's (2010) experiment offers a direct comparison of the all-pay auction, the static representation of the war of attrition (i.e., the second-price all-pay auction) and the dynamic war of attrition (where an actual clock runs and the loser is the first player to stop it). In contrast to Bilodeau et al. (2004), Hörish and Kirchamp set up an environment with private costs drawn independently from an identical distribution. One of the main qualitative implications is that in the symmetric equilibrium of the war of attrition, almost all player types do not stop immediately. Moreover, the static and dynamic wars of attrition have the same symmetric equilibrium, which is that of the second-price all-pay auction. In the laboratory, the authors find that overbidding prevails in the all-pay auction and the static war of attrition. However, subjects tend to undersupply effort in the dynamic war of attrition by stopping the clock earlier than predicted. For all treatments, the authors test for evidence of bifurcation in empirically estimated bidding functions, but even in the all-pay auction, they find no significant evidence of the commonly-observed behavioral pattern (see Section 3.6).

Oprea et al. (2012) design an experiment based on the duopoly model of Fudenberg and Tirole (1986). In this model, two firms must decide whether or not to remain in a market or to exit. A player's cost per unit of time of remaining in the market is private information and for a

\footnotetext{
${ }^{25}$ The experiment by Otsubo and Rapoport (2008) also implements a finite horizon, complete information war of attrition (framed as a dynamic volunteer's dilemma), but focuses on symmetric players. The authors consider threeplayer games with random matching across rounds of the experiment and vary the cost of volunteering between sessions. As in Bilodeau et al. (2004) they find little support for the predictive power of asymmetric SPNE in which one player stops the clock immediately. However, because players are symmetric, there exist multiple such asymmetric equilibria, whereas the equilibrium is unique in Bilodeau et al.'s asymmetric games. Hence, the lack of support for asymmetric equilibria may be due to a coordination failure in Otsubro and Rapoport's experiment. Moreover, the game also has a symmetric equilibrium, which is in non-degenerate mixed strategies. However, this equilibrium also fails to accurately predict behavior. In the experiment, subjects tend to volunteer earlier than predicted by the symmetric equilibrium and there is substantial heterogeneity in behavior across subjects: some of the subjects tend to always stop early, while others rarely volunteer.
} 
large range of these unit costs, duopoly profit is negative whereas monopoly profit is positive. For such unit cost values, remaining in a duopoly market has an instantaneous cost equal to duopoly profit and a future benefit to a surviving firm equal to the monopoly profit. Oprea et al.'s design varies the dispersion in the distribution of costs to induce more or less uncertainty regarding the rival's cost. They also consider two different frames. In one treatment, the cost of remaining in the market is an explicit fixed cost, while in an alternative treatment, it is framed as an opportunity cost (that is, a contestant may earn an amount equal to cost per unit of time by exiting the market). Observed behavior conforms rather well to the point prediction for exit times. As expected, there is a negative relationship between cost and exit time overall. Furthermore, when the degree of cost asymmetry between firms is high, high-cost firms tend to exit earlier than low-cost firms. The authors refer to these two findings as a Darwinian property in the data. Finally, framing does not have a significant effect on behavior.

DeScioli and Wilson (2011) observe behavior in an experiment that requires selfselection into an asymmetric war of attrition. Unlike the above economic experiments, in their study, the experimental procedures are contextualized and meant to replicate the environment found in typical animal behavior experiments. Each subject controls an "avatar," a virtual character that competes with other avatars over scarce resources located at various points of a virtual field. In one of the treatments, the resources are uniformly distributed across the field and in another treatment, they are clustered in patches. When encountering a rival avatar, a subject may "fight" (equivalent to a constant positive bid), "smile" (equivalent to a zero bid) or "travel" to another location. There are two types of players, large and small, and fights may arise between participants of equal size or between asymmetric participants. When fighting, a large player requires fewer resources than a small player in order to inflict a given amount of harm (equivalent to the bid) on his opponent. Furthermore, an endogenous source of asymmetry arises because when an encounter occurs at a given location, one of the avatars is a resident who has already begun exploiting resources at that location. In the experiment the authors find that fights are much more frequent in the patchy than in the uniform treatment. Moreover, their experimental results indicate that an ownership convention develops in the patchy treatment because, in the resulting wars of attrition, residents are more likely to win than intruders, even after controlling for size. In contrast, no such convention is observed in the uniform treatment. ${ }^{26}$

\footnotetext{
${ }^{26}$ In a recent paper, Caldara (2012) examines complete information common value pay-to-bid auctions, which resemble wars of attrition. In a pay-to-bid auction, there is a fixed cost that must be paid in order to raise the maximum bid by one unit. If a player does so, he is an active bidder. At any given maximum current bid, players must simultaneously decide whether or not to pay the cost of increasing the maximum bid and remaining active. If at least one player does so, the price of the object increases by one unit. At the end of each stage, a player is randomly selected among the subset of active bidders and that player becomes the leader (who automatically remains active through the next stage). In the next stage, each active player but the leader submits a bid or stays out and then a new leader is selected. The auction ends when no one submits a bid and the current leader wins the object. Caldara finds that overbidding relative to the symmetric Markov Perfect equilibrium occurs, but it decreases with subject experience. Subjects who obtain low earnings early in an experimental session tend to stay out of future auctions, so that within a session, attrition occurs based on the subjects' relative ability to play the game.
} 


\subsection{Races}

Seminal work by Harris and Vickers $(1985,1987)$ on races provides a rich set of predictions in the theory of dynamic contests. In their models, two players each start at a finite distance from the finish line. In Harris and Vickers (1985), the two players take turns advancing a continuous amount, with a convex per unit cost of advancing within each period and progress that is deterministic. By contrast, in Harris and Vickers (1987), players engage in a sequence of component contests and each firm must win a certain (potentially different) number of contests in order to win the race. Progress is stochastic, with the outcome of each contest determined by a type of modified Tullock lottery contest in which the cost of bidding is not only a function of the player's own effort, but is decreasing in the other player's effort (reflecting the reduced form of an R\&D model due to Lee and Wilde (1980). Harris and Vickers (1987) also examine a dynamic contest that they describe as a "tug-of-war," in which a player wins if and only if he accumulates a certain critical difference between the number of component contests he wins and the number his opponent wins. This number may vary across players and the first player to achieve the critical difference wins the overall contest, whereas the other loses the contest. The outcome of each component contest is determined by the same modified lottery contest applied to the race.

Zizzo's (2002) experiment seeks to implement Harris and Vickers's (1987) multi-stage race in the laboratory. Harris and Vickers provide a limited set of analytical results which can be used as point predictions, but provide several qualitative results. Zizzo (2002) derives several hypotheses based on their analysis. First, one implication of the Harris and Vickers analysis is that the leader (the player requiring the smaller number of consecutive component contest wins to win the contest) expends more than the follower in a given component contest. Second, the correlation between the gap (the difference between the number of consecutive wins needed to win the contest by the leader and by the follower) and component contest expenditure is more negative for the follower than for the leader. Third, as the gap increases, a threshold is reached beyond which the leader incurs almost all of the component contest expenditure. To test these hypotheses, Zizzo implements races with two subjects and a Tullock lottery CSF in each component contest. ${ }^{27}$ In the Zizzo experiment, unlike the Harris and Vickers (1987) model, players are budget constrained, which may constrain behavior in a way not accounted for by the theoretical model. However, the author is careful to control for the tightness of a subject's budget constraint. One of the key findings is that leaders do not invest significantly more than followers, unless the gap is extremely wide (that is, followers are five or more steps behind). Therefore, the first hypothesis is rejected, while the data exhibit mitigated support for the third hypothesis. The data provide better support for the second hypothesis, suggesting that as the gap increases, discouragement affects the laggard's behavior.

The best-of-three contest examined by Mago et al. (2011) is similar to a race. Two players compete in a contest lasting at most three stages. The first player to win two stages

\footnotetext{
${ }^{27}$ It is important to note that in the experiment, a subject's starting balance was equal to half of the value of the
} prize. That is, a subject could guarantee earnings equal to half of the value of the prize by not joining the race at all. 
obtains the final prize. ${ }^{28}$ As in Zizzo (2002), in Mago et al. (2011), two players engage in a simultaneous move Tullock component contest in each stage. There is perfect observability between stages. In Zizzo's set-up, the winner is the first player to achieve ten successes, while in Mago et al., the winner is the first player to achieve two successes. Another key difference is that in Mago et al., a player obtains an intermediate prize for winning a stage, while there is no such prize in Zizzo. Moreover, Mago et al. vary $r$ in the CSF in two separate treatments, $r=1$ and $r=$ $0.4{ }^{29}$ Finally, Mago et al. consider a linear cost of effort, whereas in Zizzo the cost function is quadratic. In contrast to Zizzo, Mago et al. (2011) find that leaders expend more effort than followers. That is, stage 1 winners invest more than stage 1 losers, an effect they refer to as strategic momentum. They also find that including intermediate prizes increases both overall effort and the length of the race, results which both conform with the relevant theory. Finally, increasing the role of chance by lowering $r$ decreases the likelihood of the race ending in two rounds.

The above studies provide evidence on behavior in races where opportunities for cooperation are nonexistent. Silipo (2005) sets up an experiment to examine the incentives for cooperation that may arise before the start of a patent race or emerge during its course. His model is based on Fudenberg et al. (1983) but allows for collusion. In the experiment, subjects engage in a two-player race for a given prize. A player wins the race by completing 30 discrete steps before his rival. If both players reach 30 steps in the same period, then they share the prize equally. The cost of advancing is convex and progress is deterministic. Each period is a twostage game. In the first stage, the players decide whether or not to cooperate. If one subject turns down cooperation, then in the second stage, the two players make investment decisions independently. Specifically, each player chooses how many discrete steps he wishes to take $(0,1$ or 2 steps) and these decisions are made simultaneously. If both players vote in favor of cooperation, then in the second stage, they jointly choose the number of steps and both players advance by the chosen number. With cooperation, each player incurs half of the cost of advancing.

Silipo employs a three-by-two design that varies the degree of asymmetry in starting positions and the value of the prize. He observes rather high rates of cooperation, but mostly when the players are symmetric. With asymmetries, in the sense that one of the subjects has a head start in the race, cooperation does not emerge as often. Furthermore, when the prize value is low, any cooperation typically breaks down as contestants approach the finish line. Like the Harris and Vickers models, Fudenberg et al.'s (1983) model exhibits the property that once a player has established a sufficient lead, this player makes all the investment while the laggard gives up. For duopolies that do not cooperate, Silipo does find evidence that points to such a

\footnotetext{
${ }^{28}$ Irfanoglu et al. (2011) also investigate a best-of-three contest and compare its performance with a static contest. Mago and Sheremeta (2012) examine the best-of-three contest modeled as an all-pay auction. Their results are qualitatively similar to the findings of Mago et al. (2011).

${ }^{29}$ As $r$ decreases, the CSF becomes less responsive to effort choices and luck plays a bigger role. In the limit as $r$ goes zero, the probability of winning is 0.5 regardless of effort choices.
} 
discouragement effect. Indeed, "leaders are more likely than trailers to make a greater effort" (p. 23).

Finally, Deck and Sheremeta (2012) employ a special case of a model of a race due to Konrad and Kovenock (2009) in which each component contest is an all-pay auction. Deck and Sheremeta interpret the model as a game in which an attacker of a resource and the resource's owner engage in what is potentially a sequence of $n>1$ component contests over the resource. The defender must win each of the contests to secure the resource and the attacker need only win one contest to capture the resource. The nature of the unique SPNE of this model depends on the ratio of valuations of the defender and attacker, and how this ratio relates to the number of consecutive contests the defender must win in order to secure the resource. For the pair of defender prize values chosen in their experiment, the defender's optimal strategy is either to fight all battles by employing the same mixed strategy in every component contest or to give up and expend no effort. In the former case, the attacker responds by lowering his expected effort expenditure with each new battle. The qualitative findings of the experiment correspond to the theoretical predictions except for one key pattern. When fighting, rather than expending the same (respectively, lowering) expected effort in each new component contest, the defender (respectively, attacker) increases effort. Moreover, the authors observe substantial overexpenditure relative to the equilibrium benchmark, particularly in later stages.

In the above experimental races, at the end of each period the contestants receive full feedback regarding the outcome of the stage game and their position in the race. We devote Section 6.2 to experiments on dynamic contests which specifically address the effect of informational feedback on behavior in such contests.

\subsection{Multi-Stage Contests with Carryover}

An important aspect of multi-stage contests is that effort may carry over from one stage to the next. In the models of races in Section 4.3, the effort expended in a given stage could not be used in subsequent stages. An early study of a contest in which effort from previous stages is carried over to later periods is Sbriglia and Hey's (1994) real-task experiment. In the experiment, the subjects must discover a seven letter code. The first subject to discover the seven letter code wins a prize of fixed value. In every period, subjects buy letters at a cost that is linear in the number of letters bought. If a subject buys $x$ letters that are indeed part of the secret code, then this subject advances $x$ steps towards the finish line. The treatment variables are the marginal cost of letters (low or high) and whether or not a subject's cost is private information. Sbriglia and Hey find that players who are ahead in the contest tend to raise their investment to secure a win. Many subjects drop out of the contest entirely when they realize they are lagging behind. This pattern is similar to the discouragement effect observed in multi-stage races.

A number of recent studies have used the Tullock CSF to examine contests with carryover. In Schmitt et al. (2004) the same bidders interact in a sequence of contests. A participant's bids accumulate over time but they depreciate at a constant, non-negative depreciation rate. Therefore a participant's effective bid in a given contest is the sum of his 
(exponentially) depreciated bids in all previous contests. In every stage contest, the Tullock CSF has an exponent $r=1$. The number of participants remains the same throughout the game. The key treatment variable is the size of the depreciation or "carryover rate". If the carryover rate is equal to zero, then bids depreciate immediately and thus are not carried over. In this case, the multi-stage contest is simply a finitely repeated single-stage contest. Regardless of the carryover rate, total equilibrium effort across all stages is identical. That is, total equilibrium effort is the same whether or not any amount of effort in a given period is carried over to the next period. However, an increase in the carryover rate results in contestants shifting effort from later to earlier stages. Schmitt et al. (2004) consider three values for the carryover rate and they also vary feedback conditions. The main finding is that, contrary to equilibrium, carryover reduces overall expenditure. Furthermore, carryover induces contestants to expend more effort in the first than in the second stage. Interestingly, in a two-stage elimination contest and a related design, Sheremeta (2010a) also finds that the effect of carryover is to increase first-stage effort levels and decrease second-stage effort. However, contrary to Schmitt et al. (2004), the total effort increases in the carryover rate. Hence, the efficiency effect of allowing effort carryover can be either positive or negative depending on whether the multi-stage contest has an elimination structure. $^{30}$

Ryvkin (2011) investigates another aspect of effort carryover, namely fatigue. In the model, players may choose one of two effort levels, high and low, and players who choose the high effort in the earlier component contests decrease their probability of winning in later component contests in a best-of- $n$ overall contest. The model is constructed in such a way that in the absence of fatigue choosing high effort in all stages is a dominant strategy. When fatigue is possible, high effort in all stages of the contest is no longer an equilibrium. In the experiment, Ryvkin tests the major predictions of the model and finds that subjects strategically respond to changes in the parameters of the contest in a manner predicted by equilibrium behavior.

Tong and Leung (2002) add to the literature by comparing behavior in static LazearRosen tournaments to behavior in dynamic tournaments. Tong and Leung's treatment with static tournaments is similar to the two-player games in Bull et al. (1987) and their findings replicate those of Bull et al. Tong and Leung also consider a number of dynamic tournaments. In all dynamic tournaments implemented, players make simultaneous effort choices in a series of stages. In one of the treatments, the number of stages is uncertain and in the other treatments, there are 10 stages. At the end of each stage, the players learn their rival's output for the stage. Upon completing the ten stages (or when the final stage occurs in tournaments with uncertain ending), realized output levels are summed up across stages to determine the winner. The prizes

\footnotetext{
${ }^{30}$ In multi-stage contests, with or without carryover, the discount rate that players apply to future payoffs affects the intertemporal allocation of effort. Deck and Jahedi's (2011) experiment seeks to test whether individual contestants discount future gains and whether they strategically anticipate that others also discount future payoffs. In the experiment, subjects appear neither to discount the future, nor to act as if anticipating that others would do so. Zhong and Tang (2010) use an all-pay auction with accumulating valuation to study whether subjects underestimate the potential outcomes of current decisions. They find evidence of myopic bidding behavior, where subjects consistently underestimate the future value of their bids.
} 
in the dynamic tournaments are equal to their static tournament values multiplied by the number of stages or the expected number of stages (in the treatment with an uncertain number of stages). They find that effort levels are significantly higher in dynamic tournaments than in static tournaments and are also higher in dynamic tournaments with a mean preserving spread of the terminal number of stages than in the benchmark ten-round dynamic tournaments. To predict behavior in the dynamic tournaments, Tong and Leung employ a non-equilibrium model whose prediction relies on the "hare-tortoise heuristic". This model predicts that the "trailing contestant will exert more effort to catch up, whereas the leading contestant will slack off' (p. 404). This is in sharp contrast with the discouragement effect arising in the perfect equilibria of races examined by Harris and Vickers $(1985,1987)$. However, the simple hare-tortoise model provides a reasonably good fit of Tong and Leung's data.

Finally, Breitmoser et al. (2010) examine a dynamic contest which is labeled a race, but which differs from the Harris and Vickers framework. In their model the contest is perpetual because the horizon is infinite and the player who is ahead receives a prize in every period. In each period, contestants invest in order to increase the probability that they will be successful. Cumulative success determines a player's relative position in the contest. The laggard bears an instantaneous cost equal to minus the value of the prize. Hence, unless investment cost is prohibitively high, the incentive is to become the leader and to remain ahead at all times. The players discount future payoffs using a common discount rate. In the laboratory, the authors implement the contest with a random ending in order to induce an infinite horizon with discounting. The authors choose four sets of parameters to define four treatments that capture a variety of predicted behaviors. The data show a tendency for subjects to over-invest as compared to the Markov Perfect Equilibrium prediction. On average, subjects invest roughly three times more than the equilibrium prediction. The quantal response equilibrium explains overinvestment rather well. The key finding is evidence for an "absorbing equilibrium pattern." As the gap increases, laggards give up, while leaders also reduce their investment but by less of an extent. Eventually, the leader settles into a safe quasi-monopoly position.

\subsection{Multi-Stage Elimination Contests}

Many contests in practice consist of multiple players and multiple stages. In each stage contestants exert efforts in order to advance to the final stage and win a prize. At the end of each stage, a specific number of contestants are eliminated from participation in the subsequent stages

of the contest. Such contests are prevalent in real life; however, empirical studies of multi-stage elimination contests are hard to conduct due to endogeneity and selection problems (Szymanski, 2003). For this reason, beginning with Shogren (1997), many multi-stage elimination contests have been studied in a laboratory setting.

Parco et al. (2005) and Amaldoss and Rapoport (2009) investigate a symmetric two-stage elimination lottery contest, where each player has a budget constraint that constrains his total expenditure of effort across the two stages. In the first stage, players compete by expending efforts within their own groups, and the winner of each group proceeds to the second stage. In 
the second stage, players compete with one another to win a prize by expending additional effort subject to their overall budget constraints. Parco et al. (2005) study this model with a two-group two-player experimental design, and find significantly higher efforts than predicted in the first stage and, as a consequence, significantly lower efforts in the second stage. Parco et al. conjecture that a non-monetary value of winning and misperception of the probabilities of winning play a crucial role in explaining these findings. Amaldoss and Rapoport (2009) further test this conjecture in a similar symmetric two-stage elimination contest with larger group sizes: a three-group eight-player and an eight-group three-player contest. As before, they find firststage effort levels that are significantly higher than predicted. The results also suggest that the utility of winning, rather than misperception of the probabilities of winning, plays a crucial role in explaining the data. ${ }^{31}$

Sheremeta (2010b) investigates a symmetric two-stage elimination contest with a lottery CSF and constant unit cost of effort (without budget constraints). He compares the performance of this contest to a revenue equivalent one-stage contest. Contrary to the theoretical predictions of Gradstein and Konrad (1999), the two-stage contest generates higher aggregate effort than the corresponding one-stage contest, and efforts are higher than predicted by a SPNE in both stages of the two-stage contest. Additionally, rather than attempting ex-post to estimate the nonmonetary utility of winning, Sheremeta elicits this utility from subjects. Specifically, after 60 periods of playing the actual contests, subjects participate in a simple one-stage lottery contest in which the value of the prize is zero. As before, subjects' efforts are costly, and so any efforts greater than zero may be interpreted as indicating that subjects derive some non-monetary value from winning. Roughly $40 \%$ of the subjects exert positive efforts in the contest with a prize value of zero. Sheremeta shows that a simple behavioral model featuring a non-monetary utility of winning explains both efforts higher than the theoretical benchmark and the difference between the efforts expended in the one-stage and two-stage contests.

A follow up study by Sheremeta (2010a) investigates a symmetric two-stage elimination lottery contest with effort carryover. The key difference from previous studies is that the winning players' first-stage efforts are partially or fully carried over to the second stage. The experimental results support all major theoretical predictions: the first-stage efforts increase, while the second-stage efforts decrease in the carryover rate. Consistent with the theory, the aggregate effort increases in the number of players and the number of groups.

Although the studies examined so far have involved symmetric players, there have also been contributions in which players are asymmetric. Höchtl et al. (2011) study a two-stage lottery contest similar to Sheremeta $(2010 \mathrm{a}, 2010 \mathrm{~b})$. The main difference, however, is that instead of being homogeneous, players are one of two types: strong or weak (low or high marginal cost). Höchtl et al. show both theoretically and experimentally that total effort is maximized if strong players compete against each other in the first stage of the contest. On the

\footnotetext{
${ }^{31}$ Chark et al. (2011) study two-stage elimination lottery contests with large group sizes, no binding constraints, and groups that are of unequal sizes. Qualitatively, their results are similar to Parco et al. (2005) and Amaldoss and Rapoport (2009), although Chark et al. find little evidence for over-expenditure in the first stage.
} 
other hand, a strong player is more likely to win the elimination contest if strong players compete against weak players in the first stage of the contest.

Amegashie et al. (2007) study a two-stage elimination all-pay auction with heterogeneous players and budget constraints. In the experiment there are four players, each with a different valuation for the prize. In the first stage, all players place their bids and the two highest bids proceed to the second stage. The two winners of the first stage place their bids in the second stage, subject to the remaining budget constraint. Amegashie et al. find that subjects behave according to the SPNE, which involves "burning out" by using all of the available budget in the first stage. They also find that subjects exert significantly higher bids when groups are larger, thus concluding that more competition leads to higher bids, and that burning out is a competitive phenomenon.

Finally, Altmann et al. (2012) conduct an experimental investigation of a two-stage elimination rank-order tournament and compare its performance to a revenue equivalent onestage tournament. Consistent with previous findings on rank-order tournaments (Bull et al., 1987), average effort in a one-stage tournament is close to the Nash equilibrium. In contrast, subjects in the two-stage tournament exert a higher effort in the first stage than in both the SPNE benchmark and the equivalent one-stage tournament. This finding is robust to a pointwise increase in the marginal cost of effort obtained by making the cost function more convex. Combined with the findings of Sheremeta (2010b), the fact that the over-expenditure of effort is significantly higher in the two-stage contest than in the one-stage contest suggests that there is a fundamental difference between subjects' behavior in two-stage and one-stage elimination contests. Whether this pattern is due to a non-monetary utility of winning, sunk cost fallacy, misperception of the probabilities, or yet another behavioral anomaly remains an open question.

\subsection{Endogenous Entry}

There is a growing interest in endogenous participation in contests. One of the first experimental studies to address this issue is Fullerton et al. (1999), who base their experimental design on Taylor's (1995) innovation tournament model. (Baye and Hoppe (2003) show that the innovation tournament is strategically equivalent to a Tullock contest with an endogenous prize.) Fullerton et al. (1999) find substantial support for the model's comparative statics predictions, indicating that subjects optimally choose to participate in research contests by employing effort expenditures that are influenced by the number of contestants, the value of the prize and the cost of effort.

Anderson and Stafford (2003) build their experimental design on the theoretical model of Gradstein (1995), which extends Tullock's (1980) model by introducing an entrance fee and asymmetric cost structure. They find that, consistent with theoretical predictions, low ability (high cost) contestants frequently choose not to participate in the lottery contest and instead opt out for a fixed payment. In a related study, Morgan et al. (2012a) design an experiment using the Tullock lottery contest where subjects may choose whether to participate in a contest or obtain a fixed payment as an outside option. Morgan et al. examine cases with both relatively large and 
small contest prizes. They find that, consistent with theory, contest entry and effort expenditures increase with the size of the prize. However, they also find that when the prize is small, there is more participation than predicted (over-entry) and contest participants earn less than the outside option. ${ }^{32}$ On the other hand, when the prize is large, there is under-entry and contest participants earn more than predicted. ${ }^{33}$

Eriksson et al. (2009b) conduct an experiment where subjects can choose to enter the Lazear-Rosen rank-order tournament or be paid according to a payoff equivalent piece-rate incentive scheme. They find that subjects choose tournaments about $50 \%$ of the time. Risk aversion is one of the main predicting factors of tournament entry. Using Holt and Laury's (2002) elicitation procedure for risk preferences, Eriksson et al. show that the more risk-averse subjects are, the less likely they are to enter tournaments. Dohmen and Falk (2011) use a similar approach by letting subjects self-select into one of the four payment schemes, including a fixed payment, piece-rate, tournament and a revenue-sharing scheme. The results of the experiment demonstrate that subjects systematically sort into different payment schemes. When the choice is between a fixed payment and a tournament, subjects are more likely to enter the tournament if they are less risk-averse, more productive and more optimistic. Bartling et al. (2009) use a realeffort experiment to study how subjects' distributional preferences influence their decisions to enter a tournament or a piece-rate incentive scheme. They find that inequality-averse subjects are less likely to enter the tournament. Similarly, Balafoutas et al. (2012) document that, controlling for beliefs, inequality-averse and spiteful subjects are less likely to enter tournaments. Finally, Niederle and Vesterlund (2007) document that men enter tournaments significantly more often than women. In summary, all of these findings highlight the importance of endogenous sorting when players are allowed to choose other opportunities and the tendency for rank-order tournaments to systematically attract people with specific individual characteristics, including people that are less risk or inequality averse.

Several studies examine entry decisions into alternative contest structures. Vandegrift et al. (2007), for example, report a real-effort experiment in which subjects choose between a piece-rate, a single-prize and multiple-prize lottery contests. They find that, holding total payments constant across contests, effort is higher in the single-prize contest than in a multiprize contest. However, entry rates into the single-prize contest are lower than into the multiprize contest. Consequently, Vandegrift et al. conclude that the single-prize contest is more efficient in generating higher effort but less efficient in inducing entry and identifying the most capable players from the given pool of participants.

Another experimental study that compares entry into alternative contest structures is Cason et al. (2010). Cason et al. employ a real-effort experiment in which subjects can choose between a piece-rate, a single-prize and proportional-prize contest, each with the same total prize

\footnotetext{
${ }^{32}$ This result is similar to the findings of Fischbacher and Thöni (2008), who also investigate endogenous entry into contests (with opportunity cost being an outside option) and find that often contests elicit excessive entry relative to the SPNE.

${ }^{33}$ A follow up study by Morgan et al. (2012b) shows that there is neither over nor under-entry when the lottery contest is replaced with the proportional-prize contest.
} 
value. They find that a proportional-prize contest attracts more entrants and generates more aggregate effort than a single-prize contest. The proportional-prize contest performs better by encouraging entry and a performance of low ability players, without discouraging entry or the performance of high ability players.

Finally, Büyükboyac1 (2012) compares theoretically and experimentally a single-prize contest with a game that involves self-selection into one of two parallel contests, one with a high prize and the other a low prize (maintaining identical total prize value). There is incomplete information about players' types (i.e., high or low cost). The contest and effort choices in the latter game are simultaneous, so that effort is not chosen contingent upon the players' contest choice. Contest winners are determined by an auction CSF. Büyükboyacı predicts that when the heterogeneity of types is large, the two parallel contests generate higher effort than the singleprize contest. When heterogeneity is low, the single-prize contest outperforms the two parallel contests. Experimental results mainly comply with these predictions.

\section{Static Multi-Battle Contests}

In a wide range of disciplines, including computer science, political science, economics, management science, and the military sciences, there are environments that may be characterized as games of multiple contests with linkages (Kovenock and Roberson, 2012). Examples include innovation races that involve obtaining multiple, interrelated patents, counterterrorism and information systems security efforts that involve allocating resources to the defense of networks of targets, multi-battle military conflicts involving allocating forces across space or time, and models of redistributive politics in which a budget is allocated across different constituencies in order to secure their political support. In each of these examples the total payoff across the entire set of contests depends on how the individual contests enter into the players' objectives and how the underlying technology links expenditures across the contests. These games have long attracted the attention of theorists and, more recently, have been the subject of experimental investigation.

\subsection{Constant-Sum Colonel Blotto Games}

The Colonel Blotto game has its roots in a paper by Borel (1921) in which two players must simultaneously select an ordered triple of three nonnegative numbers which sum to a common constant and the winning player is the player who chooses the higher number in two of the three components of the triple. Borel viewed this game as having many applications including military, where the natural interpretation is to view each component as a battlefield and the nonnegative numbers as the amount of a nonnegative resource allocated. In this interpretation, each player's resource has no alternative use and the objective of each player is to maximize the probability of winning two of the three battlefields.

According to McDonald and Tukey (1949), Colonel Blotto games were examined in the

process of solving practical military problems by Charles P. Winsor and Tukey at Princeton 
during World War II. Since then, substantial theoretical work on these games was undertaken in the context of military operations research, computer science, political science, management science, and economics (for a review see Kovenock and Roberson, 2012). These theoretical contributions have spurred a host of experimental tests of Colonel Blotto models. ${ }^{34}$

Avrahami and Kareev (2009) study a discrete constant-sum Colonel Blotto game as in Hart (2008) in which players maximize the expected number of battlefields won subject to a budget constraint. They look at both symmetric and asymmetric budgets. In their experiment, pairs of subjects participate in eight repetitions of a discrete Colonel Blotto game using a partners matching protocol. In the symmetric treatments, the two players are endowed with 24$24,18-18$, and 12-12 units of a discrete resource. In the asymmetric treatments, the players are endowed with 24-12, 18-12, and 24-18 units of a resource. The results of the experiment support the qualitative predictions of the theory. Specifically, as predicted, the weaker players (with lower budgets) allocate zero resources to a subset of battlefields. The number of battlefields to which the weaker players allocate zero resources increases in the relative strength of their opponents.

Chowdhury et al. (2012) provide an experimental test of the theoretical predictions of Roberson (2006) in the Colonel Blotto game with a continuous strategy space in which players maximize the expected number of battlefields won subject to asymmetric budgets. In their experiment, the stronger player has 200 units of a divisible resource and the weaker player 120 units, which must be simultaneously allocated to eight battlefields. The experiment has separate treatments with an auction CSF and a lottery CSF. Due to the constant-sum nature of the game, the experiment also compares a fixed matching protocol (where subjects are paired for all 15 rounds) and a random matching protocol (where subjects are randomly re-matched after each round). The results of the experiment provide surprising support for the main qualitative predictions of the theory. In the auction treatments, the weaker players often use a "guerilla warfare" strategy which stochastically allocates zero resources to a subset of battlefields. The stronger players often employ a "stochastic complete coverage" strategy, allocating random, but positive, resource levels to each battlefield. However, subjects also exhibit significant serial correlation across periods in allocations to a given battlefield, which is not predicted by the theory. This correlation is reduced under the fixed matching protocol, but it is not entirely eliminated. Under the lottery treatments there is support for the equilibrium prediction of a constant allocation across all battlefields for both players.

Arad and Rubinstein (2012) examine a version of the Colonel Blotto game between symmetric players using a combination of a large scale web-based experiment and classroom experiments. In their experiment, players are symmetric, each having 120 units of a divisible resource which they can allocate across 6 battlefields. Players choose their strategies once and these strategies are played in a tournament against the strategies of all other players in the

\footnotetext{
${ }^{34}$ Recently, the Colonel Blotto game became available on Facebook, known as Project Waterloo (Kohli et al., 2012). The Facebook application allows people to participate in a symmetric version of a Colonel Blotto game. In the game, each player has 100 troops and five battlefields to conquer. In order to win, a player needs to conquer a majority of the five battlefields.
} 
player's "group," and players with the most battlefields won against the group as a whole win the overall game (the "group" consists of players within the same classroom in the classroom experiments; the group consists of all web-based participants in the case of the web-based tournament). In each group, three "winners" are chosen and the reward these winners receive is to have their names announced to the group. Within each battlefield an auction CSF is used, but in the case of a tie neither of the players is awarded the battlefield. Thus, the standard constantsum Colonel Blotto game is transformed into a non-constant-sum game due to possible ties. Arad and Rubinstein provide a theoretical prediction for subjects' behavior based on multidimensional iterative reasoning, and discuss in details the type of strategies that are most successful in achieving the highest payoff in the Colonel Blotto game. These strategies generally involve the almost complete neglect of two battlefields, often the endpoint (first and last) battlefields, with moderately high allocations to four battlefields. They also involve the frequent use of a 1 or 2 in the unit digit place in individual battlefield bids.

Cinar and Goksel (2012) compare Colonel Blotto games where players have either symmetric resources (180 versus 180 ) or asymmetric resources (180 versus 50 ). They also vary the number of battlefields from 6 to 10. An interesting feature of their design is that in each treatment, subjects play for 12 periods against a computer which is programmed to play an optimal strategy derived from the theory. The results of the experiment indicate that in all treatments the aggregate behavior of all subjects is well predicted by the theory. Similar to Chowdhury et al. (2012), subjects' payoffs are relatively close to the theoretical benchmarks. Nevertheless, in the asymmetric case, computer generated strategies outperform strategies chosen by subjects and thus, in this case, subjects usually receive lower payoffs than predicted by the theory.

Finally, Arad (2012) examines a Colonel Blotto game between symmetric players, in which resources cannot be allocated continuously, but instead, are clustered into several partitions, which represent different levels of force. The player who allocates a greater level of force to a battlefield wins that battle. Arad motivates this game as a "tennis coach problem," where a coach has to allocate four tennis players of different skills (resources of different values) among four positions (battlefields). The objective is to win a majority of the battlefields. The results of the experiment show that most subjects use only a small number of strategies, disregarding a large set of potential strategies. The behavior of some subjects can be explained by an adapted level- $k$ model of iterating reasoning (Stahl and Wilson, 1994).

\subsection{Non-Constant-Sum Blotto-like Games}

The classical formulation of the Colonel Blotto game provides an important benchmark for studying multi-battle contests. In the original formulation of the game, players are budget constrained and any unused resources have no value; that is, resources are "use it or lose it." However, there are a number of relevant applications in which unused resources have positive

value, and the corresponding multi-battle contest is a non-constant-sum game (Szentes and Rosenthal, 2003; Klumpp and Polborn, 2006; Kvasov, 2007, Roberson and Kvasov, 2012). 
Mago and Sheremeta (2012) investigate the non-constant-sum multi-battle contest that is the all-pay auction special case of the chopstick-auction examined by Szentes and Rosenthal (2003). In their contest two players simultaneously expend effort in three battles. The player expending the highest effort in a battle wins that battle with certainty (i.e., the auction CSF) and the player who wins the majority of the battles (two or more) wins the contest. Players pay an identical constant unit cost of effort in each battle. Consistent with other experimental findings on single-battle contests, Mago and Sheremeta (2012) find significant over-expenditure of resources relative to the Nash equilibrium benchmark. Consistent with the theory, subjects make positive but random allocations in each battle and allocations fall within the theoretically predicted univariate supports. Contrary to the theory, subjects often make positive allocations in only two out of three battles (instead of all three) and they significantly overuse moderately high allocations.

Irfanoglu et al. (2011) also investigate a three-battle contest similar to Mago and Sheremeta (2012). However, the main difference is that the probability of winning the battle is determined by the lottery CSF. Nash equilibrium requires that subjects allocate an equal expenditure across the three battles (Klumpp and Polborn, 2006). However, contrary to this prediction, none of the subjects employ a uniform expenditure strategy. Most subjects vary their expenditure between battles in a given period and within battles over time, although such dispersion of expenditure decreases as the game is repeated (with random matching).

\subsection{Asymmetric Objectives}

Often players may have asymmetric objectives when participating in multi-battle contests (Clark and Konrad, 2007, Kovenock and Roberson, 2010, Kovenock et al. 2010, Deck and Sheremeta, 2012). For example, in patent races firms often must obtain a cluster of patents in order to produce a commercially viable product. Also, in military battles, the attacker's objective is often to successfully attack only one target, or a subset of targets, and the defender's objective is to successfully defend all targets.

Kovenock et al. (2010) experimentally investigate a two-player multi-battle contest in which players have asymmetric objectives. In this game a risk-neutral attacker and defender simultaneously allocate a scarce resource obtained at constant unit cost across the set of battlefields. The battlefields form a weakest-link network for the defender. The attacker receives a prize if he wins at least one battle. The defender receives a prize if he wins all battles. For each player, the probability of winning any given battle is determined either by the auction CSF (Kovenock and Roberson, 2010) or the lottery CSF (Clark and Konrad, 2007). For both CSF's, the Nash equilibrium depends on the ratio of the defender's valuation of the prize to the attacker's valuation. There is a key distinction between equilibria under the auction CSF and the lottery CSF. With the auction CSF, the attacker employs a "guerilla warfare" strategy by exerting effort in attacking at most one randomly chosen target. On the other hand, the defender either exerts random amounts of effort defending all targets or gives up on all of them. In contrast, with the lottery CSF, the attacker exerts the same level of effort at every target. Although the 
theoretical predictions associated with the auction CSF are, on the whole, supported by the data, the last prediction of the lottery CSF is not borne out by the data. The experimental evidence shows that not only do attackers employ stochastic guerilla warfare strategies in most of the games with the auction CSF, but surprisingly, they also do so in about half of the games with the lottery CSF.

Montero et al. (2012) investigate both discrete and continuous constant-sum Colonel Blotto games where battlefields have asymmetric values and values are the same for both players. The authors systematically vary the number of battlefields from 3 to 5 , with one battlefield having higher value than the others, and the resource budgets from 5 (the discrete case) to 120 (the continuous case). The objective is majoritarian, i.e., the player who accumulates the highest sum of battlefield values wins the game. The results of the experiment indicate that subjects often use strategies that allocate resources to a subset of battlefields that is minimum necessary for winning. Moreover, within this subset, resources are allocated proportionally to the value of the battlefield, contrary to the theoretical prediction of Young (1978) that the more important battlefield should receive a disproportionally higher allocation than the less important battlefields.

Finally, Horta-Vallve and Llorente-Saguer (2010) examine a discrete Colonel Blotto game with incomplete information concerning the players' values of the individual battlefields. Players have identical budgets which they simultaneously allocate across the set of battlefields and each player's vector of battlefield values is independently drawn from a discrete distribution over positive vectors whose components sum to a fixed constant. The objective of each player is to maximize the expected sum of battlefield values won. The authors systematically vary the number of battlefields from 2 to 6 . The results of the experiment indicate that subjects do not play truthful strategies, i.e., strategies that reveal subjects' preferences for winning specific battlefields. Nevertheless, in the aggregate subjects attain more than $80 \%$ of the efficient level of welfare, i.e., the sum of both players' payoffs is maximized.

\section{Extensions}

\subsection{Sabotage in Contests}

Sabotage occurs whenever a contestant invests in reducing the effectiveness of a rival's effort. Other things constant, sabotage increases the saboteur's probability of winning. Such destructive activities typically require using scarce resources so that, in general, sabotage is a costly and welfare-reducing endeavor. Lazear (1989), in the context of a rank-order tournament, shows that reducing the spread between winner and loser prizes decreases sabotage activities. For a specific type of lottery contest in which the effective effort of a player is increasing and concave in the player's effort and decreasing and convex in rivals' sabotage efforts, Konrad (2000) provides some comparative statics of effort with respect to constraints on sabotage and shows that, in the presence of sabotage, aggregate effort may not be increasing in the number of players. In the context of an elimination tournament with all-pay auction component contests, 
Amegashie and Runkel (2007) examine the incentive to invest in sabotage activity at the precontest stage. They find that for some initial seedings in the elimination tournament, the player with the highest valuation (who they term the most able player) has incentive to invest in sabotage.

As noted by Carpenter et al. (2010), despite the importance of sabotage to the efficiency properties of tournaments, relatively little experimental work has been devoted to it. Harbring and Irlenbusch and their co-authors $(2005,2007,2008,2011)$ have provided a large share of the findings in this area. Several studies show that sabotage activities increase as the spread between winner and loser prizes widens (Harbring and Irlenbusch, 2005; Falk et al., 2008; Harbring and Irlenbusch, 2011). These studies focus on the role of the contest designer (the principal) in mitigating the incidence of sabotage through the judicious choice of incentive contracts. With sabotage, a contest designer who seeks to maximize total effort expended should optimally reduce the spread between winner and loser prizes (as compared to the optimal spread when sabotage is not possible).

In Harbring and Irlenbusch (2005) groups of four agents compete in a rank-order tournament. In one of the treatments, a fifth agent acts as a principal who determines winner and loser prizes. In this treatment, subjects play the following two-stage game. The principal, or contest designer, first offers a wage contract to the four agents. Then, in the second stage, the four agents choose their effort levels simultaneously in a rank-order tournament. In the baseline treatment where the prize structure is exogenous, contestants simply engage in a simultaneous move rank-order tournament. The results of the experiment indicate that both productive effort and sabotage increase in the winner's prize. Moreover, sabotage is higher when the prize structure is not exogenous but chosen by the principal, especially when the winner's prize is relatively low. Falk et al. (2008) run a similar experiment, but they implement two-player tournaments. Comparing environments with and without sabotage opportunities, they find that when sabotage is possible, principals tend to choose smaller prize spreads. With sabotage, the empirical relationship between the prize spread and productive effort is non-monotonic. Effort and the prize spread are positively correlated when the prize spread is small and negatively correlated when the prize spread is high. Harbring and Irlenbusch (2011) extend this line of inquiry by allowing for communication between participants (both contestants and the principal) as well as a broader choice of contracts for the principal. With fixed matching of contestants and principals, they find that communication helps curb sabotage because the principal and the agents manage to agree to small prize spreads in exchange for relatively high output. Harbring and Irlenbusch also find that sabotage is lower when the instructions frame the experimental tasks as an employer-employee relationship and refer to the action of lowering other participants' effort as "sabotage".

Harbring and Irlenbusch (2008) consider additional aspects of contest design that may influence sabotage activities, namely, the number of contestants and the number of winner prizes to be awarded. The underlying model is a rank-order tournament with up to eight players. The findings are mixed as neither design feature has a significant impact on the amount of sabotage 
exerted. Interestingly, increasing the number of winner prizes does have a significant effect on effort in the sense that effort is higher when the proportion of winner prizes is even (i.e., there are as many winner prizes as there are loser prizes). However, participants do not seem to respond to this higher effort with increased sabotage activity.

Harbring et al. (2007) examine how asymmetries between players affect the level of sabotage that takes place in a contest. Their experiment implements a set of three-player Tullock lottery contests. They compare sabotage behavior in symmetric contests to behavior in asymmetric contests, wherein underdogs compete with favorites. In asymmetric contests, players differ in their marginal cost of effort, which can be either high (underdogs) or low (favorites). All player types have identical sabotage cost functions. One of the key results is that the existence of asymmetries increases the frequency of sabotage. The composition of the group of contestants matters as favorites tend to sabotage each other's effort more than they sabotage underdogs. However, underdogs engage in sabotage with other underdogs as frequently as they do with favorites. Harbring et al. also examine the effect of different information structures on sabotage effort. They find that revealing the identity of the saboteur leads to less sabotage. They also observe that contestants often retaliate against saboteurs in a tit-for-tat fashion.

Gürtler et al. (2010) show theoretically that sabotage is not only counterproductive but it also imposes an indirect cost of weakening incentives. They examine a two-stage game with a simultaneous binary choice of effort in the first stage followed by a simultaneous binary choice of sabotage activities, contingent on the profile of efforts, in the second stage. In the equilibrium, leaders (those exerting high effort in the first stage) are sabotaged more than followers (those exerting low effort) and thus there is less incentive to exert the high effort to be a leader. Gürtler et al. further demonstrate that this problem can be solved by concealing intermediate information on the players' performances. These theoretical predictions are supported by complementary experimental studies.

Carpenter et al. (2010) add context and a real-effort task to the experimental study of sabotage. Due to the socially unacceptable nature of sabotage, it is important to ask whether sabotage occurs if it truly involves actions that any participant would consider cheating or lying. In the experiment, participants engage in a clerical task whose output is measured along two dimensions: quantity and quality. Participants privately evaluate each other's performance along these two dimensions. Underreporting both of quantity and quality, i.e., sabotage, is thus feasible at no monetary cost. The authors examine two compensation schemes: piece-rate and tournament, expecting that sabotage would occur only under the tournament scheme. The results are clear-cut: objectively measured output is highest under tournament incentives when sabotage is not feasible and lowest under tournament with sabotage. The possibility of sabotage does not affect output under piece-rate incentives.

Vandegrift and Yavas (2010) also use a real-effort experiment to examine the effect of contestant heterogeneity on the occurrence of sabotage. The subjects engage in two-player games where each contestant must forecast the price of a fictitious stock after observing two signals that are correlated to the actual price. After submitting their forecast, the contestants may alter their 
opponent's forecast at a cost. The contestant with the best forecast (after accounting for sabotage) wins a high value prize and the other contestant wins a low value prize. The authors consider two matching protocols, fixed and random matching, as well as various prize spreads. They also measure contestants' abilities in a few practice periods by having the players make forecasts in a non-competitive setting. The results are that under fixed matching subjects perform worse than under random matching and this is mainly because of poor performance by lowability subjects. Fixed matching also reduces the rate at which subjects choose sabotage, but it also causes higher sabotage levels given that the sabotage option is selected. Finally, the authors find that a higher spread in prizes increases the frequency as well as the level of sabotage under both matching protocols.

\subsection{Feedback in Contests}

There has been relatively little recent theoretical work on the impact of feedback on individual performance in contests (For exceptions, see Kräkel, 2008; Ederer, 2010). Nevertheless, there are many studies in the lab and in the field investigating how feedback about the relative performance of contestants impacts their behavior in contests (Ederer and Fehr, 2009; Eriksson et al., 2009a; Gürtler and Harbring, 2010; Berger and Pope, 2011; Fershtman and Gneezy, 2011; Gill and Prowse, 2012; Kuhnen and Tymula, 2012; Mago et al., 2012). The findings are mixed, with different studies often providing contrasting results.

Eriksson et al. (2009a) experimentally investigate the impact of feedback on individual performance in real-effort rank-order tournaments and under piece-rate incentive schemes. The three feedback conditions are: no feedback about relative performance, discrete feedback given halfway through the production period, and continuous feedback. The results of the experiment indicate that neither discrete nor continuous feedback has any effect on effort under a piece-rate scheme. In contrast, in the rank-order tournament there are some positive peer effects of feedback, with players who lag behind never quitting and players who are ahead not slacking during the contest. Similarly, Fershtman and Gneezy (2011) study how feedback impacts quitting behavior in tournaments by conducting a field experiment with high school students running athletics races. In the two treatments of interest, students either run side by side (feedback) or separately (no feedback). In contrast to Eriksson et al. (2009a), Fershtman and Gneezy (2011) find that students often quit the tournament with continuous feedback, while there is significantly less quitting with no feedback.

Gill and Prowse (2012) study a sequential-move tournament in which the first mover completes a real-effort task and the second mover observes the first mover's effort before choosing how much effort to expend. A prize is awarded to one of the paired subjects based on their relative performance and some element of luck. The key feature of the experiment is that, over the relevant range, the probability of winning the prize is linear in the difference in the subjects' efforts, so the marginal impact of the second mover's effort on the probability of

winning does not depend on the effort of the first mover. The results of the experiment provide evidence of a discouragement effect: second movers decrease their effort after observing a high 
effort by the first movers. The authors interpret this discouragement effect as a consequence of disappointment aversion, and estimate both the level and heterogeneity of disappointment aversion using structural methods. Interestingly, Berger and Pope (2011) document the exact opposite effect in a sequence of simultaneous move real-effort tournaments, in which players observe their relative performance in the previous tournament before choosing effort in the current tournament. They find evidence that being slightly behind in the previous tournament increases (rather than decreases) effort. One possible reason for the difference in findings between Gill and Prowse (2012) and Berger and Pope (2011) is the prize allocation rule, i.e., probabilistic versus deterministic. Another possibility is that Gill and Prowse (2012) employ a sequential tournament, while Berger and Pope (2011) employ a sequence of simultaneous move tournaments.

Kuhnen and Tymula (2012) design a real-effort tournament experiment in which subjects work on multiplication problems during a 90-second round. A subject's score is displayed on his screen throughout the round and is updated after every correct answer. In one treatment subjects also receive feedback about their relative performance at the end of each round. Kuhnen and Tymula find that subjects work harder and expect to rank better when they are told they will learn their ranking, relative to cases where they are told feedback will not be provided. After receiving feedback, subjects who ranked better than expected decrease their performance but they expect an even better rank in the future rounds, while subjects who ranked worse than expected increase their performance and lower their future rank expectations. Similarly, Ludwig and Lünser (2012) find that in a chosen-effort two-stage rank-order tournament, contestants who lag behind tend to increase effort in the second stage, while those who lead tend to reduce effort. Nevertheless, the authors find no significant difference in total effort between the feedback and the no feedback treatments. Hence, while providing feedback changes the timing of effort expenditure, it does not alter the overall performance of the tournament. In a chosen-effort lottery contest, Mago et al. (2012) also find that ex-post feedback about relative performance does not affect aggregate effort in contests, but it significantly affects the dynamics of individual behavior similar to the real-effort experiments of Ludwig and Lünser (2012) and Kuhnen and Tymula (2012). ${ }^{35}$

Given that feedback can sometimes have a significant effect on effort, the principal may have an incentive to misreport intermediate information to the contestants (Ederer, 2010). Ederer and Fehr (2009) design a two-stage rank-order tournament between two agents in which total output across stages is used to determine the winner. In one of the treatments, the agents are not told their first-stage output levels while the principal learns that information. Before the second stage begins, the principal may report effort levels to each of the agents. In the treatment of interest, the principal's message is cheap talk and thus, should be ignored in equilibrium. Furthermore, using backward induction, it is clear that even a truthful message (known to be

\footnotetext{
${ }^{35}$ Fallucchi et al. (2012) also investigate the role of information feedback in a chosen-effort lottery contest. In contrast to Mago et al., they find that giving subjects additional feedback about rivals' efforts reduces aggregate effort. A potential explanation for the different findings in the two studies is that Mago et al.'s experiment lasts for 20 periods, while Fallucchi et al.'s experiment lasts for 60 periods, giving subjects more time to learn.
} 
truthful) should not affect second-stage effort levels. Equipped with these predictions the authors find that subjects expend similar effort when the principal provides either no feedback or feedback that is known to be truthful. Furthermore, these effort levels are not significantly different from the SPNE prediction. By contrast, when the principal's feedback is cheap-talk, effort is lower than in the other two treatments. Similar to Ederer and Fehr (2009), Gürtler and Harbring (2010) analyze a principal's optimal feedback policy in tournaments. They show that in equilibrium the principal reveals intermediate information regarding the agents' previous performances if these performances are relatively similar, and agents react to the principal's feedback decision. The experimental findings provide some support for the theoretical predictions of the model. As predicted, agents exert lower efforts when principals reveal intermediate information about relatively uneven performance of the agents. Principals correctly anticipate this behavior and, as a consequence, they are less likely to reveal information about agents' intermediate performance if this performance is relatively uneven.

\subsection{Bias in Contests and Affirmative Action}

In Section 3.2 we discussed that greater heterogeneity between players may lead to lower aggregate effort in contests because of the "discouragement effect": the ability and willingness of a stronger player to bid aggressively to win the contest discourages a weaker player from bidding aggressively for fear of losing his bid. As a result, the weaker player reduces his effort. Therefore, a contest designer wishing to maximize aggregate effort may decide to resort to a policy of biasing the contest in favor or against one or more of the candidates. This bias may be implemented either through discounting or "handicapping" the effort of stronger players or through augmenting the efforts of weaker players. The primary application of the study of bias in contests is to the examination of affirmative action policies in hiring or education. There may be many motivations for inducing bias in contests, but our focus here is on that coming purely from the theory of contests: that bias may in fact induce greater aggregate effort in equilibrium. Probably one of the first laboratory studies of affirmative action was done by Schotter and Weigelt (1992). Without affirmative action, Schotter and Weigelt find that disadvantaged players usually drop out of rank-order tournaments. However, this discouragement effect decreases when affirmative action, designed as a head-start advantage for the disadvantaged player, is implemented. As a result, the aggregate performance in the tournament increases, although the magnitude of this effect depends on the degree of heterogeneity and the level of affirmative action.

Michelitch (2009) points out a potential disadvantage of affirmative action policies such as quotas, i.e., dividing the set of all contestants into subsets that compete for separate sets of prizes. A common criticism is that quota-eligible individuals exert less effort in a tournament, while quota-ineligible individuals exert more effort. In a tournament experiment, Michelitch (2009) finds that quota-eligible individuals indeed exert less effort than quota-ineligible individuals. Niederle et al. (2010) and Balafoutas and Sutter (2012) examine how affirmative action affects competitive entry and performance in tournaments by men and women. Niederle et 
al. (2010) find that, although affirmative action (directed towards women) encourages entry by women into tournaments, it may come at the cost of discouraging entry by men. Similarly to Niederle et al., Balafoutas and Sutter (2012) find that affirmative action leads to significantly higher entry by women; however, it does not discourage entry by men. Moreover, affirmative action leads to higher aggregate performance in tournaments.

Finally, Calsamiglia et al. (2012) use a field experiment to study affirmative action policies among children. Similarly to the two studies mentioned above, they find that an affirmative action policy significantly increases the chance of disadvantaged players winning the tournament, without discouraging the performance of other players. We discuss the study of Calsamiglia et al. (2012) in more detail in Section 7.2.

\subsection{Collusion and Communication}

In all three canonical contest formats discussed in this paper, the players could raise their total expected payoffs by jointly lowering their individual efforts below the Nash equilibrium level. Clearly, the total expected payoffs are maximized when all contestants expend zero effort (with a suitable tie-break). Therefore, there is a strong incentive for collusion among participants. While collusion does not seem relevant in some of the applications of contest theory (e.g., political competition), in other cases, its occurrence in the field is a real possibility (e.g., military conflict, labor tournaments, R\&D competition).

The study of collusion in experimental contests is even more important given that subjects tend to overbid. Imperfectly collusive behavior may in fact bring effort levels closer to the static non-cooperative equilibrium levels. For the all-pay auction, Lugovskyy et al. (2010) find that this is indeed the case by comparing behavior under random matching to behavior under fixed matching. Although the number of periods is known, thereby making the game a finitely repeated game, bids are lower with fixed matching than with random matching. In a multipleprize discrete all-pay auction, Harbring and Irlenbusch (2003) vary the number of contestants from two to six and employ fixed matching. They find that effort levels are lower in two-player than in six-player contests because a greater fraction of players bid zero. Such seemingly collusive behavior is significantly less frequent with a greater number of contestants. ${ }^{36}$

Even with repeated interactions, collusion may be difficult to sustain if it is to remain tacit. Therefore, it is crucial to analyze the way communication affects effort levels. Several studies do so. Harbring (2006) compares the total effort in a standard two-player rank-order tournament setting with a winner and a loser prize to a non-competitive team compensation scheme where total output is shared equally between the two players. The design varies the compensation scheme, whether or not communication is possible between contestants and the type of communication. In one of the communication treatments, the contestants are restricted to messages about their intended actions. In another communication treatment, the contestants may

\footnotetext{
${ }^{36}$ In a related experiment with sabotage, Harbring and Irlenbusch (2008) fail to replicate the finding that two-player contests are prone to collusive behavior.
} 
use a chat program. All sessions use a fixed matching protocol and the findings are as follows. While restricted communication only has a weak collusive effect on effort, chat communication increases effort under the team compensation scheme and it dramatically lowers effort under tournament incentives. Both findings suggest a strong effect of communication on cooperative play.

Sutter and Strassmair (2009) compare the effect of communication between teams of players to communication within a team of players. They employ a rank-order tournament between teams. Participants are matched in teams of three players each, competing with one other team under a fixed matching protocol. Communication is implemented using a chat application. They consider a number of communication treatments. One of the treatments allows for within-team communication only. Another treatment allows for between-team messages only and does so by restricting access to the chat window to a single player per team. Finally, they implement between-team communication where all messages are public. The analysis yields a rich set of findings about the role of communication. Within-team communication leads to higher effort and average earnings than in the absence of communication, which lends support to the conjecture that communication helps coordination within teams. However, as in Harbring (2006), communication between teams tends to lower effort, so that this type of communication helps teams collude. Allowing for both types of communication simultaneously, with all messages being public, has an ambiguous effect on effort. Interestingly, collusion between teams often leads to "effort rotation" schemes whereby teams take turns expending effort and winning the tournament.

Cason et al. (2012) also compare within-group communication to between-group communication. When between-group communication is allowed, the subjects may exchange messages between group members as well as between groups. The within-group messages are private information for the group members, whereas the between-group messages are public information. The game is a weakest-link contest, where the performance of a team corresponds to the effort of the team's worst performer. Specifically, two groups of three players each engage in a finitely repeated lottery contest, where a group's effort level is equal to the minimum of its members' expenditures. The weakest-link nature of the team's performance implies that multiple equilibria exist and that groups must solve a coordination problem to reach the preferred equilibrium. All communication occurs via a chat application, with separate chat windows for within and between-group messages in the "between-group" treatment, and the matching is fixed. Cason et al. find that simple within-group communication does improve coordination, but with the undesirable side effect of substantially raising (wasteful) effort levels. Groups compete so intensely when within-group communication is available that average earnings are lower than without communication. ${ }^{37}$ On the other hand, extending communication opportunities to allow both for within and between-group communication helps collusion by lowering effort levels and

\footnotetext{
${ }^{37}$ In a related study, Leibbrandt and Saaksvuori (2012) document similar results in contests between groups, where individual efforts are aggregated based on perfect substitutes and not a weakest-link technology.
} 
thus raising average earnings. An important finding is that allowing for voluntary between-group communication has a positive impact on within-group coordination.

Even when communication is not possible, there are other mechanisms through which subjects can still learn to reduce their efforts. Savikhin and Sheremeta (2012), for example, show that subjects learn to reduce efforts in a lottery contest if they simultaneously participate in a separate cooperative voluntary contribution mechanism (VCM). Interestingly, the cooperative nature of the VCM spills over to the lottery contest but the competitive nature of the lottery contest does not affect contributions to the VCM. ${ }^{38}$ Mago et al. (2012) show that subjects exert lower efforts in lottery contests when their identities are reveled through photo display. The authors argue that photo display reduces social distance and enhances pro-social behavior, leading subjects to behave more cooperatively.

\subsection{Alliances in Contests}

The formation and performance of alliances in conflicts is a topic as old as the study of conflict and much of the recent modeling in this area has employed contest theory (for a survey, see Bloch 2012). The renewed theoretical interest in alliances has seen a parallel interest in experiments on alliance behavior. A host of questions have been addressed in this experimental literature: If contestants have the opportunity to pool resources together in order to fight a common opponent, will they do so? How do alliances behave in comparison to single players? How does the sharing rule within the alliance affect alliance formation and behavior? In this section we provide an answer to the first question, while Section 6.6 addresses the second and third.

Amaldoss et al. (2000) consider contests played by teams of two players. The contest success function is the auction CSF except for the tie-breaking rule which specifies that no player wins a prize in case of a tie. Each alliance's pure strategy space has three possible effort levels, including zero. In one of the treatments, the alliance's effort is the maximum of its members' efforts (best-shot), whereas in other treatments the alliance's effort is the sum of the efforts of its members (perfect substitutes). The authors consider two sharing rules for the victorious alliance: equal sharing and sharing that is proportional to effort (as in the deterministic proportional-prize contest). Finally, the authors vary the size of the prize across treatments and there is random matching of contestants both within and between alliances. For both types of alliances (best-shot and perfect substitutes), regardless of the sharing rule, the mixed strategy equilibrium explains aggregate frequencies of play rather well for high and medium prizes. However, when the prize value is low, subjects tend to overbid relative to the Nash equilibrium. The sharing rule has no significant effect on effort. The key finding is that best-shot contests generate significantly less effort than alliances in which effective effort is the sum of the

\footnotetext{
38 Note that the experimental literature on the application of contests to fundraising for charity originated with Morgan and Sefton (2000). We devote Section 8.6 to this topic.
} 
members' expenditure. This behavior is consistent with the mixed strategy equilibrium prediction.

Sheremeta and Zhang (2010) study lottery contests between teams (alliances), each comprised of two players who must decide upon a single team effort, and compare team effort to the effort in a properly normalized contest between two (single) players. The team members can communicate before the contest. While single players and teams over-expend effort compared to the predicted levels, teams perform better by exerting efforts that are closer to Nash equilibrium. ${ }^{39}$ One interpretation of this finding is that alliances can make better decisions than individuals. Deck et al. (2012) also examine alliances in a model in which an attacker selects among two targets after observing the level of defense at each. The attacker attacks the weakest target, meaning that if each target is defended separately, one defender's expenditure imposes a negative externality on the other. Deck et al. examine experimentally whether this externality provides incentive for the defenders to form an alliance and the alliance's impact on equilibrium expenditures. One implication of the model is that if the defenders form an alliance then their expected payoffs increase despite the fact that a successful attack is more likely given the overall reduction in defense. Experimentally, alliances yield higher payoffs to defenders as predicted, but also reduce the likelihood of a successful attack, counter to the theoretical prediction.

$\mathrm{Ke}$ et al. (2012b) consider a setting in which an alliance of two players fights a single opponent in a lottery contest. The key treatment variable is the sharing rule within the alliance. In one treatment, the members of a victorious alliance share the prize equally. In the other treatment, they engage in a within-alliance lottery contest in order to determine which alliance member earns the prize. In the latter case, the contest is a two-stage game. Ke et al. (2012b) emphasize their comparison of within-alliance contests to contests between two strangers. Theory predicts that there should be no difference in behavior when the contest is between fellow group members as compared to a contest between strangers. The data provide evidence for this prediction. However, there is no evidence in favor of the hypothesis that an exogenously given equal sharing rule results in higher alliance effort than the contest sharing rule. In a related study, Ke et al. (2012a) find that alliances are more likely to break down if the sharing rule is not the equal sharing rule. Finally, Ke (2011) finds that when allies share the prize proportionally (as in the deterministic proportional-prize contest), instead of probabilistically (as in the lottery contest), efforts are significantly lower by both allies and stand-alone opponents, resulting in higher payoffs to all competing parties. Therefore, $\mathrm{Ke}$ (2011) finds that alliance formation can be beneficial to both allies and stand-alone players.

The endogenous formation of alliances is the topic of the recent paper by Herbst et al. (2012). Their experiment implements three-player lottery contests with random matching. In a two-by-two design they vary whether alliance formation is exogenous or endogenous, as well as the cost of forming an alliance (in one of the treatments, this cost is negative so that alliance formation is subsidized). In the baseline treatment with exogenous alliance formation, a random

\footnotetext{
${ }^{39}$ Sheremeta and Zhang (2010) attribute part of this finding to lower risk-aversion by teams and to better learning from communication and negotiation between team members.
} 
draw determines whether an alliance is formed between two of the three players. In the endogenous treatment, an alliance results from mutual agreement between two randomly selected players. In both treatments, the outcome of the alliance formation process becomes public information, after which all three players choose effort simultaneously. The within-alliance sharing rule specifies equal sharing of the prize. Herbst et al. find that contestants who expend relatively lower effort levels in contests where no alliance is formed display a greater willingness to form alliances. Despite this observed self-selection of less aggressive subjects into alliances, endogenous alliances tend to generate higher effort than exogenously formed alliances.

\subsection{Contests between Groups}

Many contests are characterized by competition between groups (e.g., boards of directors, teams of researchers, or committees), and not individuals. Examples include competitions between corporate consortia, $\mathrm{R} \& \mathrm{D}$ and patent competitions between firms and election campaigns by political parties. As group contests unfold, conflicts arise within each group and between groups. Members of the same group have incentives to cooperate with each other by contributing individual efforts in order to win a contest. Since effort is costly, each member also has an incentive to abstain from contributing any effort and instead free-ride on the efforts of other members. Theoretically, the amount of free-riding that occurs within a group depends on the composition of the group, the technologies of group performance, and the rules that regulate the competition (Baik, 1993; Chowdhury et al., 2011; Lee, 2012).

One of the first experimental studies of contests between groups is Nalbantian and Schotter (1997). ${ }^{40}$ In their experiment, there are two identical groups, consisting of six players each, and the performance of the group is the sum of all individual efforts. The best performing group receives the prize and all players of the winning group split the prize equally. Nalbantian and Schotter (1997) found that, compared to other incentive schemes (i.e., profit sharing, revenue sharing, or gain sharing), a contest between groups increases efforts and mitigates the withingroup free-rider problem. Similar qualitative results are obtained in an information gathering experiment by Vasilaky (2011) and a real-effort experiment by van Dijk et al. (2001). Follow-up studies by Sutter and Strassmair (2009), Cason et al. (2012), and Leibbrandt and Saaksvuori (2012) show that the introduction of within-group communication can further reduce the freeriding incentives within a group. However, as pointed out by Cason et al. (2012), enhanced within-group coordination may lead to extensive and inefficient competition between groups.

Abbink et al. (2010, 2012) and Ahn et al. (2011) study lottery contests between symmetric groups as in Katz et al. (1990). They also investigate treatments in which individuals compete, respectively, against individuals and against groups. All three studies document very high rates of overbidding, with the highest bids reaching up to five times the Nash equilibrium level. This overbidding is observed in all treatments, regardless of whether individuals compete

\footnotetext{
${ }^{40}$ The experimental literature on political voting, which originated with Rapoport and Bornstein (1987), is also related to contests between groups. For a review of this literature see Bornstein (2003). Here we focus only on contests between groups where individual players can make continuous effort choices.
} 
against individuals, groups compete against groups, or individuals compete against groups. Abbink et al. (2010) further document that when group members are allowed to punish freeriders, the overbidding is even higher (up to nine times higher than the Nash equilibrium). Such high rates of overbidding are troubling and are hard to reconcile with standard economic theories. Abbink et al. (2012) suggest that such behavior in intra-group contests can be explained by parochial altruism - altruism towards group members along with hostility towards nonmembers. $^{41}$

Cherry and Cotten (2011) extend the theoretical analysis of Katz et al. (1990) by introducing the possibility that the two competing groups may be interdependent (i.e., individuals can be part of both sides of a contest). Theoretical and experimental results indicate that strategic individual behavior, and the resulting rent dissipation, is affected by the relative size of the groups. Specifically, Cherry and Cotten (2011) find that individual efforts by group members decrease and individual efforts of those outside the group increase in the relative size of the group. These results are consistent with one of the Nash equilibria of the group contest with interdependent groups.

Most studies on contests between groups assume identical players within each group. One notable exception is Sheremeta (2011b), who investigates contests between groups, where each group has one strong player, with a higher valuation for the prize, and two weak players, with lower valuations. The experiment examines three contests: a perfect-substitutes contest in which all efforts are perfect substitutes (Baik, 1993), a best-shot contest in which group performance depends on the best performer (Chowdhury et al., 2011), and a weakest-link contest in which group performance depends on the worst performer (Lee, 2012). Sheremeta (2011b) finds that in perfect-substitutes contests, all players expend significantly higher efforts than predicted by theory. In best-shot contests, most of the effort is expended by strong players while weak players free-ride. Finally, in weakest-link contests, there is almost no free-riding and all players expend similar positive efforts conforming to the group Pareto dominant equilibrium.

So far, all of the contests between groups discussed share the feature that all players within the winning group split the prize equally. Such an egalitarian sharing rule creates incentives for some group members to free-ride on the effort of others. One possible solution is a proportional sharing rule, where players of the winning group split the prize in proportion to the efforts that they contributed to the group performance. Two experimental studies by Gunnthorsdottir and Rapoport (2006) and Kugler et al. (2010) compare the effectiveness of the proportional sharing rule to the egalitarian rule. Gunnthorsdottir and Rapoport (2006) experimentally study contests between two symmetric groups and find that efforts are higher under the proportional sharing rule than under the egalitarian sharing rule. Kugler et al. (2010)

\footnotetext{
${ }^{41}$ Andersson et al. (2012) examine a rank-order team tournament in which subjects are assigned to a pro-social, proself, or neutral organizational culture. The organizational culture is primed by letting subjects solve scrambles in which words have pro-social connotation, pro-self connotation, or no connotation. The results of the experiment indicate that pro-social personal preferences (measured by a pre-test) and organizational culture (primed by the scrambles) reinforce each other - pro-socially oriented subjects exert significantly higher and pro-self oriented subjects exert significantly lower efforts in the pro-social primed condition than in the other conditions.
} 
extend this setting to contests between asymmetric groups and more than two groups. They replicate the findings of Gunnthorsdottir and Rapoport by showing that, even in more complex settings, the proportional sharing rule elicits higher individual efforts than the egalitarian rule. In a slightly different environment, Sutter (2006) studies group performance where the prize is either split equally or determined endogenously through a bargaining process between group members. Consistent with theoretical predictions, the results of the experiment indicate that subjects exert higher efforts under the bargaining scheme than under the egalitarian sharing rule. Jointly, the findings from the experiments by Gunnthorsdottir and Rapoport (2006), Sutter (2006) and Kugler et al. (2010) strongly confirm that individual efforts are higher when members of the group are rewarded proportionally to their performance.

Cadigan (2007) points out that many naturally-occurring contests involve sequential (and not simultaneous) decisions by players on a team. It is then possible that team members who make decisions early in the game have an incentive to precommit to free-ride on their teammates' anticipated later choices. Cadigan sets up an experiment to examine this free-riding problem. Teams of two players compete in the following sequential manner. One member of each team expends effort in the first stage. Then, after observing the first-stage choices by their teammate and rival first-mover, second-stage players simultaneously choose an effort level. The two teams play a lottery contest in which the sum of the efforts of the team members represents the team's effort. The prize is non-excludable between members of the winning team so that both players receive the same prize. In equilibrium, first-stage players free ride by choosing zero effort. In the experiment, free-riding by first-stage players does not occur to the extent predicted by the model, but it increases slightly with experience (i.e., in later periods). Cadigan also introduces a treatment in which first-stage and second-stage efforts enter multiplicatively in determining team effort. In the equilibrium of the two-stage game, free-riding is avoided as both first and second-movers expend identical, strictly positive amounts of effort. However in the experiment, higher effort by first-movers tends to lower the effort expended by second-movers, which suggests that free-riding occurs in this treatment as well.

\section{Real-Effort and Field Experiments}

\subsection{Real-Effort Experiments}

The vast majority of laboratory studies examining contest theory are based on choseneffort experiments, where each subject is asked to choose a number, representing an effort level or a bid, from a set of available options. In most of such chosen-effort experiments subjects are informed about their relative strength, the distribution of noise (if any) which impacts individual effort and the cost of effort function. This provides the experimenter with great control over the essential parameters of the theories of contests under investigation. Nevertheless, such laboratory experiments inherently lack external validity since in the field economic agents have to perform real tasks with unobserved cost functions and incomplete information about their relative abilities. Because in the following section we review field experiments, in this section we focus 
mainly on the real-effort experiments that are performed in the laboratory and are designed to test contest theory.

In one of the first real-effort experiments on contests, van Dijk et al. (2001) examine the performance of a rank-order tournament relative to other payment schemes. They use a task which consists of solving two-variable optimization problems by trial and error. This type of task was chosen because it is similar to a common naturally-occurring setting, as it is requires concentration while still providing an exact measure of performance. During the experiment subjects performed this task for 50 periods. One of the main findings related to our interest is that efforts are higher in rank-order tournaments than in piece-rate or team payment schemes, but they are also more variable. Overall, the findings from the real-effort experiment of van Dijk et al. echo similar findings from the chosen-effort experiments of Nalbantian and Schotter (1997) and Eriksson et al. (2009b).

There are a growing number of experimental studies investigating contest theory using real-effort experiments. For instance, Carpenter et al. (2010) employ a real-effort task in studying sabotage, reviewed in Section 6.1. The real-effort task employed had subjects printing letters, placing them into envelopes and handwriting addresses on envelopes. Vandegrift et al. (2007) use a forecasting task and Cason et al. (2010) employ an adding numbers task to study endogenous entry in tournaments (for details see Section 4.6). ${ }^{42}$ Freeman and Gelber (2010) employ a maze-solving task to examine the optimal prize structure in tournaments. Other realeffort tasks used to test contest theory include multiplying numbers (Kuhnen and Tymula, 2012), pressing keys as quickly as possible (Berger and Pope, 2011), and moving sliders (Gill and Prowse, 2012). These three papers are discussed in more detail in Section 6.2.

\subsection{Field Experiments}

Field experiments differ from their laboratory counterparts in many respects (Harrison and List, 2004). Not only do field experiments use real-effort tasks, but these tasks are performed in their natural environment by professionals (experts). Beginning with the now famous Erev et al.'s (1993) orange grove experiment, many researchers have used field experiments to test various predictions of contest theory. First, a number of studies use field experiments to examine the basic incentive effects of tournaments (Fershtman and Gneezy, 2011; Leuven et al., 2010, 2011; De Paola et al., 2012; Hossain et al., 2011; Delfgaauw et al., 2012). Second, field experiments are used to study predictions of contest theory regarding bias with asymmetric contestants (Calsamiglia et al., 2012), the number of contestants (Casas-Arce and MartinezJerez, 2009; List et al., 2010) and the number of prizes (Lim et al., 2009). Third, several field studies investigate different dynamic structures in tournaments: sequential versus simultaneous all-pay auctions (Liu et al., 2011), dynamic contests (Casas-Arce and Martinez-Jerez, 2009) and elimination tournaments (Delfgaauw et al., 2011). There are also field experiments that compare

\footnotetext{
${ }^{42}$ Eriksson et al. (2009a) also employ the adding numbers task to study feedback in tournaments (for details see Section 6.2), while Hammond and Zheng (2011) employ the same task to study the effect of heterogeneity on subjects' performance in tournaments (for details see Section 3.2).
} 
tournaments with alternative payment schemes (Bandiera et al., 2005, 2006, 2012). Finally, a few studies show how tournaments with symbolic awards (non-pecuniary prizes) can be used as incentive mechanisms in the field (Kosfeld and Neckermann, 2011; Barankay, 2011).

Erev et al.'s (1993) orange grove experiment is arguably the first experiment to test contest theory in the field. The focus of the study is on the incentives to free-ride in teams of fruit pickers. The authors view effort contribution to the team as a voluntary contribution mechanism (VCM). Hence, if each team member is paid an equal share of the team's output, free-riding is an equilibrium strategy. In one of the treatments, the teams of four workers are split into pairs that compete against each other for a reward. The within-team contest should provide an incentive for each pair to contribute effort and thus avoid free-riding. Erev et al. find that tournament incentives lead to significantly higher output (a 35\% gain). Furthermore, output tends to increase over time in the contest treatment, while it tends to fall in the VCM condition. These findings indicate that tournament incentives help teams overcome the free-riding problem. Blimpo (2010) and Bigoni et al. (2011) replicate this result in the setting of secondary schools in Benin and the University of Bologna in Italy, suggesting that tournaments can be effective mechanisms in increasing team performance and school achievement.

Leuven et al. (2011), conduct a field experiment using students at the University of Amsterdam in the Netherlands. Students could self-select into tournaments with one of three types of prizes: low $(€ 1000)$, medium $(€ 3000)$ and high $(€ 5000)$. In the data, performance increases with the size of the prize, but the authors show that this positive effect of tournament incentives is due to sorting. Controlling for sorting and heterogeneity of students, there is no significant effect of tournament incentives on aggregate performance of students. Similarly, very little in the way of incentive effects are documented by Leuven et al. (2010). One possible reason for the insignificant findings in both of these studies is that the ratio of the number of prizes to the number of students is very low (i.e., less than 1 to 25). De Paola et al. (2012) conduct a field experiment, involving undergraduates at a university in southern Italy, where the number of prizes to the number of students is relatively high (i.e., around 1 to 5). Students are randomly assigned to one of the three treatments: a control group, a small prize $(€ 250)$ and a large prize $(€ 700)$. They find that, as predicted by theory, more valuable prizes significantly increase student performance both in terms of the number of credits earned and the grades obtained on exams. High ability students, who are very likely to win the tournament, increase their performance the most, while low ability students do not change their performance.

Hossain et al. (2011) conduct a field experiment at a large-sized Chinese manufacturing company. During the eight-week long experiment, workers on the team with the higher per-hour productivity were provided a weekly prize (bonus). The prize was framed either positively as a reward or negatively as a punishment (although both framings are theoretically equivalent). Prizes increased the average weekly productivity by $14 \%$, indicating a strong incentive effect of tournaments. Moreover, the team for which prize was framed as a punishment was at least $35 \%$ more likely to produce at a rate higher than the team for which prize was framed as a reward. 
Delfgaauw et al. (2012) find that tournament incentives have a significant effect on sales performance. They implement a sales competition between grocery stores belonging to the same retail chain. The rank-order tournament between stores is based on sales growth as the performance measure. There are two treatments, one in which two winner prizes are awarded to the two top performers and one in which there is no prize. In the latter treatment, stores simply provide feedback on relative performance. In the data, sales growth is higher in both treatments than in the baseline without relative performance information. Surprisingly, simple feedback is as effective in increasing sales growth as the monetary reward.

Fershtman and Gneezy (2011) also highlight the importance of feedback in tournaments. They design a field experiment involving schoolchildren who participate in a 60-meter footrace. The design varies matching (assortative by skill versus random), the power of tournament incentives (none, low, high) and the information condition (contestants either run side by side or on separate tracks). The main finding is that the likelihood a contestant will give up during the race is highest in the high reward treatment. Hence, high-reward tournaments seem to induce more "quitting in the middle," particularly when contestants run side by side. By contrast, such quitting behavior barely occurs under low or no reward. Another finding is that tournaments with no reward draw little participation. That is, a significantly larger number of students opt out of the tournament race when no reward is offered than in the other treatments. Finally, the authors conclude that the overall winner of the race performs better in the high reward treatment than with either no or a small reward.

Field experiments have also been used to study different predictions from contest theory. Calsamiglia et al. (2012), for example, design pair-wise tournaments among children from two similar schools in Spain. Students in one school (experienced) are taught how to solve simple numerical puzzles or "sudokus" as part of their regular mathematics courses, while students in the other school (inexperienced) are not. In the experiment, students from the two schools competed in pair-wise tournaments for 30 minutes by solving sudokus. The findings confirm that the asymmetry in experience is reflected in subjects' performance, with experienced subjects solving significantly more than inexperienced subjects. A policy which biases tournament rules in favor of inexperienced students, only marginally reduces performance of experienced subjects, while significantly increasing the chances of inexperienced subjects to win the tournament.

List et al. (2010) conduct both a laboratory and a field experiment to study how the number of contestants impacts individual efforts in tournaments. The field experiment uses nonprofessional fishermen as subjects. One of the notable characteristics of the experimental setting is that it allows the authors to measure inputs, while most field studies on tournaments only measure output (they demonstrate empirically that the input measure has a large and significant effect on fish caught). The design varies the number of contestants between two and eight within session. Furthermore, the authors argue that because the stock of fish in the pond decreases with each catch, the density of the noise is decreasing. In this case, effort is predicted to decrease with the number of contestants (see a more detailed discussion in Section 3.1). Experimental data provide strong support for this prediction. Casas-Arce and Martinez-Jerez (2009) analyze the 
sales contests organized by a commodities firm and, similarly to List et al., find that individual efforts decrease in the number of contestants.

Another design issue in tournaments is the number of prizes (see Sections 3.4 and 3.5). Lim et al. (2009) conduct a field experiment among salespeople which is also accompanied by a chosen-effort experiment (for details see Section 8.5). In the experiment, salespeople were asked to either sell sponsorships to the business community through a golf tournament or to solicit donations from companies to raise funds for the university. Salespeople were assigned either to a 15 -salespeople contest with one prize of $\$ 300$ or to a 15 -salespeople contest with five prizes of $\$ 60$. Consistent with the theoretical predictions of Kalra and Shi (2001), the authors find that the five-prize contest elicits higher performance (average sales) than the equivalent single-prize contest.

Many tournaments in the field have a dynamic structure (see Section 4). Liu et al. (2011) design a field experiment to study the performance of sequential and simultaneous all-pay auctions with incomplete information. The experiment is conducted on a crowdsourcing website Taskcn.com, one of the largest Q\&A sites in China. Consistent with theoretical predictions, tasks with high prizes attract more submissions and higher quality answers than tasks with low prizes. Also, as expected, in the sequential case early entry of a high quality answer deters the entry of users. Delfgaauw et al. (2011) conduct a field experiment in a retail chain to test basic predictions of tournament theory regarding the prize spread and noise in two-stage elimination tournaments. Tournaments differ in the distribution of prize money across the respective winners of the first and second stages of the tournament, while keeping total prize money constant. The modified model of Lazear and Rosen (1981) predicts that a more convex prize structure leads to better second-stage performance at the expense of first-stage performance. It also predicts that noise weakens incentives to perform, as it reduces the marginal effect of effort on the probability of winning. The findings indicate that, as predicted by theory, a more convex prize spread increases performance in the second stage at the expense of first-stage performance. Also, as predicted by theory, noise has a negative effect on the response to tournament incentives.

There are several field experiments that compare tournaments with alternative payment schemes (Bandiera et al., 2005, 2006, 2012). Bandiera et al. (2005) exploit an exogenous change in the compensation scheme of workers at a large farm to compare piece-rate and relative performance pay. Under the relative performance pay, workers are paid according to how their productivity compares to average productivity in the field; thus, a worker's expected payoff is similar to the expected payoff in a lottery contest. The main finding of interest is that for the average worker, productivity increases by at least 50\% when moving from tournament-type incentives to a piece-rate scheme. The authors conclude that workers behave as if they have social preferences and are thus reluctant to impose negative externalities on other workers by exerting higher effort in tournaments. In the follow up study, Bandiera et al. (2006) find substantial evidence of collusive behavior in tournaments, which can further explain why piecerates may sometimes outperform tournaments. In the same line of research, Bandiera et al. (2012) design a field experiment to evaluate the effects of piece-rate, tournament and rank 
incentives (i.e., simply displaying the rank of each team's productivity) on the productivity and composition of teams. They find that the introduction of tournament and rank incentives leads to significant changes in team composition, making workers more likely to form teams with others of similar ability instead of with their friends. Introducing rank incentives reduces average productivity by $14 \%$, whereas introducing a tournament increases it by $24 \%$. However, the effects are heterogeneous: rank incentives only reduce the productivity of low ability teams, and tournaments only increase the productivity of high ability teams. Finally, teams that remain intact after the introduction of incentives do not change their productivity under rank incentives but increase their productivity by $25 \%$ under tournament incentives. In summary, these findings suggest that tournaments affect firm performance through both the endogenous changes in team composition and changes in behavior within the same team.

Finally, several studies show how tournaments with no monetary prizes can be used as incentive mechanisms in the field (Kosfeld and Neckermann, 2011; Barankay, 2011). ${ }^{43}$ Kosfeld and Neckermann (2011), for example, design an experiment to study how symbolic awards impact individual behavior in the field. In the experiment, students enter data for three weeks as part of a non-governmental organization project. The treatment is to honor the best performance publically with a symbolic award. Kosfeld and Neckermann find that the award treatment raises performance by $12 \%$. Barankay (2011) designs a field experiment on a crowdsourcing website to see how feedback about ranking (in terms of performance compared to others) affects the behavior of employees. Although rank has no real implication for compensation, compared to a control group with no rank feedback, employees who receive feedback about their rank are $30 \%$ less likely to return to work and also $22 \%$ less productive on the job. Although the studies of Kosfeld and Neckermann (2011) and Barankay (2011) are not directly comparable, the striking difference between their findings further highlights the importance of conducting field experiments.

\section{Applications}

Contest theory may be used to examine a wide range of topics, from sports competitions and the competition for admission to college, to political campaigns, innovation races, and world military conflict. In this section we review laboratory experiments addressing a few of the many potential applications. We start with the study of litigation and legal systems.

\subsection{Litigation and Legal Systems}

Theoretical models of contests have been used to analyze expenditure on legal services in litigation. In this context, the players are litigants and their bids represent expenditures on legal services. The contest success function is interpreted as a production function of legal outcomes.

\footnotetext{
${ }^{43}$ For a laboratory experiment on tournaments used as an intrinsic motivation for giving see Duffy and Kornienko (2010). Also, see Sheremeta (2010a, 2010b).
} 
Because field data on legal expenditures are difficult to obtain, researchers have turned to laboratory experiments.

Two experimental studies have applied contest models to legal battles in order to compare the effect of different fee allocation rules on legal expenditure. Coughlan and Plott's (1997) experiment compares the American rule to the British rule of allocating expenditure. In the experiment, each legal dispute is a two-stage game. First, one of the litigants (the plaintiff) must decide whether or not to go to trial. Second, if the plaintiff does not go to trial, the two litigants receive fixed payoffs. If the plaintiff goes to trial, the ensuing legal battle is specified as a modified lottery contest, where a litigant's probability of winning the case is a convex combination of the lottery CSF and a parameter representing the merit of the case. Under the American rule, each litigant pays his own expenditure whereas under the British rule, the loser must not only pay his own expenditure but also reimburse the winner. We note that Coughlan and Plott (1997) use random matching. The key finding is that, as predicted, conditional on the occurrence of a trial, the British rule generates substantially greater total expenditure than the American rule. Furthermore, Coughlan and Plott observe that under the British rule, plaintiffs are much less likely to go to trial, but the average total expenditure is nonetheless greater than under the American rule.

Dechenaux and Mancini (2008) obtain similar findings by employing the generalized contest payoff function in (5) and the auction CSF. The experiment follows the theoretical model in Baye et al. (2005). In this model, the American system results from setting $\alpha=1$ and $\beta=1$ and the British system results from setting $\alpha=1$ and $\beta=0$ (although in the experiment, Dechenaux and Mancini set $\beta=0.2$ to approximate the British system). Similar to Coughlan and Plott (1997), pairs of subjects participate in 40 rounds which represent different two-player legal battles and the matching protocol is random matching. The experimental design induces private values whereby the valuations are drawn from a uniform distribution at the beginning of every period. Again, conditional on the occurrence of a legal battle, expenditures are higher under the British rule than under the American rule, but the British rule generates fewer trials than the American rule. Contrary to the prediction, but similar to Coughlan and Plott, the British rule also results in higher average total expenditure, even when factoring in the lower frequency of legal battles. Therefore the application of contest models to the legal process and their implementation in the laboratory point to the policy relevance of the over-dissipation finding common to many contest experiments. Under the British rule, the rate of over-dissipation is magnified to such an extent that this legal system results in extremely high average legal expenditure. ${ }^{44}$

Deck and Farmer (2009) also study the behavior of litigants with respect to expenditure on legal services, but their focus is on final-offer arbitration. An uncertain sum of money is in

\footnotetext{
${ }^{44}$ Additionally, Dechenaux and Mancini (2008) collect data for the parameterization that Baye et al. (2005) refer to as Quayle system $(\alpha=2$ and $\beta=1$ in equation (5)) and a specific parameterization of the Continental system $(\alpha=1$ and $\beta=0.6)$. A key finding is the lack of "expenditure equivalence" between the American and Quayle systems predicted by the model (Baye et al., 2005). The Quayle system results in higher average expenditure than the American system, which is also contrary to the arguments put forward by the 1991 President's Council on Competitiveness.
} 
dispute and the litigants invest in order to influence its distribution. The theoretical model resembles a rank-order tournament because the effect of legal service expenditure on the probability of winning is subject to random noise (affecting the arbiter's preferences). The baseline model is a two-stage game in which litigants first simultaneously expend resources to influence the arbiter's decision and then simultaneously submit their bids (or claims). The arbiter chooses the claim that is closest to his preferred sum of money. The SPNE depends on whether a litigant chooses legal expenditure before submitting a bid or the opposite is true (in which case bids are public information). Interestingly, Deck and Farmer find that across treatments, subjects underinvest compared to the equilibrium prediction. When bids are placed after committing to legal expenditure, average investment is roughly equal to one third of the predicted amount.

\subsection{Political Competition and Lobbying}

Arguably one of the most direct applications of contest theory is to political competition and lobbying. Tullock's (1980) seminal work that introduced the canonical Tullock contest is an analysis of rent-seeking behavior. Moreover, in the United States in particular, elections resemble contests in which candidates spend effort and money on advertising in order to increase their chance of winning. Hence contest theory naturally applies to electoral competition. In this context, laboratory experiments are a useful complement to empirical studies using field data. For an excellent review of political science experiments see Morton and Williams (2010). Here, we only discuss those studies which explicitly employ one of the three contest mechanisms that are the focus of this survey.

Millner and Pratt's (1989) experiment, which we review in Section 2.1, is a test of Tullock's (1980) model and thus the authors cite lobbying as the primary application of their results. We also refer the reader to Section 2.1 for a discussion of the studies that followed directly from Millner and Pratt's (1989) study (Shogren and Baik, 1991; Millner and Pratt, 1991; Potters et al., 1998). These studies examine symmetric Tullock contests and focus on the effect of the parameter $r$ on expenditure in such contests. Davis and Reilly (1998) motivate their experiment by using a model of lobbying in which four sellers compete in order to appropriate monopoly rents. In some treatments a buyer also expends effort in order to keep the firms from obtaining monopoly power (see Ellingsen (1991) for the theoretical model). Davis and Reilly's design introduces player asymmetries because the single buyer's valuation of the prize is higher than the firms' valuations. They also compare behavior in simultaneous Tullock contests to behavior in a two-stage contest. In the two-stage contest, the sellers first compete in an elimination stage and the first-stage winner then engages in a Tullock contest with the buyer. The findings of this study are discussed in Section 3.2.

Experiments on electoral competition include Öncüler and Croson (2005) who set up a contest model with a lottery contest success function. In their model, the value of the prize is uncertain at the time candidates commit to campaign expenditure. Furthermore, there are two stages (say, a primary and a general election) to which resources drawn from a fixed budget must be allocated. In the first stage, players participate in a lottery contest in order to win a risky rent. 
In the second stage, the winner of the first stage engages in a contest against "nature", which determines the actual value of the rent. The experimental design varies the degree of symmetry between players (the size of their budget) and the number of players. Not surprisingly, when players are symmetric, over-expenditure is observed. However, advantaged players do not overinvest in the asymmetric treatment. Regardless of the degree of asymmetry, total expenditure is higher in four-player games than in two-player games, as predicted by the model.

Kräkel et al. (2012) analyze a two-player electoral contest, where candidates first decide on their political program (high or low risk) and then spend money (exert effort) conveying these programs. Theory predicts that the low-quality candidate should always choose high risk political programs. The high-quality candidate should choose either high or low risk programs, depending on the interaction of a discouragement effect, a cost effect and a likelihood effect. Intuitively, the high-quality candidate should prefer a risky agenda, either to prevent aggressive campaigning or to discourage his opponent. ${ }^{45}$ Experimental findings mostly confirm the theoretical predictions. ${ }^{46}$

Other experiments on political competition include Sheremeta (2010a), who studies an elimination political contest with effort carryover, Irfanoglu et al. (2012), who analyze a best-ofthree contest designed to gain insight into the so-called New Hampshire effect (Klumpp and Polborn, 2006), and Cadigan (2007), who focuses on contests between groups. These studies are discussed in more detail in Section 4.4, Sections 5.2 and Sections 6.6, respectively.

\subsection{War}

Wars are an extreme form of a contest. Standard contest models, in particular those based on the lottery contest success function, have been employed to analyze the strategic choices made by the parties to a conflict. Abbink (2012) offers a review of the literature on experimental conflicts and we refer the reader to his article. Here, we focus on papers that are relevant to this survey.

Arguably, one of the first war applications of contest theory is the Colonel Blotto game introduced by Borel (1921). We discuss experimental papers related to this literature in Section 5. The two most relevant studies that investigate the behavior of attackers and defenders in war games are Kovenock et al. (2010) and Deck and Sheremeta (2012). Kovenock et al. (2010) compare behavior across simultaneous attacker-defender games under two different CSFs, the lottery CSF and the auction CSF. In the experiment, all contests are two-player four-target games with random matching. The attacker wins a prize if he wins at least one target and the defender wins a prize if he wins all targets. The details of the theoretical predictions and experimental

\footnotetext{
${ }^{45} \mathrm{~A}$ high-quality candidate may also choose a more risky agenda if the outcomes are perfectly correlated (Nieken and Sliwka, 2010).

${ }^{46}$ Bullock and Rutström's (2007) experiment also considers an environment where lobbyists compete for a prize of endogenous value. The model is due to Becker $(1983,1985)$. While their work is clearly related to the research surveyed in this paper, this model does not fit one of our three contest structures (i.e., lottery contest, all-pay auction or rank-order tournament).
} 
results are provided in Section 5.3. Deck and Sheremeta (2012) also employ an auction CSF to examine a similar, but sequential, game of attack and defense in which the defender needs to win all targets, while the attacker needs to win only one target to secure the prize. The details of this paper are provided in Section 4.3.

Linster et al. (2001) examine the incentive to invest in military deterrence faced by two members of a coalition fighting a common opponent. Formally, the authors set up a simultaneous move contest with a lottery CSF, in which all three players expend effort. Unlike the Ke et al. (2011) study discussed in Section 6.5 on alliances, the contest in Linster et al. is one with identity-dependent externalities. Specifically, the single contest winner earns a prize. If the winner is a coalition member, then her fellow coalition member also earns a fraction of the winning prize, while the opponent earns zero. If the opponent wins, then both coalition members earn zero. Moreover, unlike Ke et al., Linster et al. do not examine post-victory conflicts that may arise within the coalition. The set up introduces an incentive for the smaller coalition member to free-ride on the large player, where size refers to the valuation of the winning prize. A subject's size and whether or not the subject belongs to a coalition are fixed throughout the sessions, but there is random matching. The qualitative comparative static predictions are supported by the data. Interestingly, there is little, if any over-dissipation. The key finding is the significant and predicted decrease in expenditure as effort becomes more of a public good within the alliance.

Lacomba et al. (2011) study a series of two-stage and three-stage games meant to model a variety of post-conflict scenarios. The first stage of each game is a Tullock lottery contest. If both contestants invest zero, then neither obtains the prize, which the authors interpret as making peace. Furthermore, contestants face an endowment constraint. In one treatment, the second stage is a dictator game where the winner of the first stage decides how much of the loser's remaining endowment to expropriate (complete surrender). In another treatment, there is an interim stage where the loser may destroy part or all of her remaining endowment (scorched earth). In a third stage, the winner decides how much of the leftover endowment to expropriate. In yet another treatment, following the contest, the winner first commits to an expropriation rate and then, the loser decides how much of the remaining endowment she wishes to destroy (resistance). The authors also vary the matching protocol between partners and strangers within each session. The authors find that the post-conflict scenario matters. For strangers, the ranking of expenditures in the first stage contest is as follows: complete surrender $>$ scorched earth $>$ resistance. Under partners matching, expenditure is lower under all post-conflict scenarios as compared to strangers, but the ranking between treatments remains the same. Other interesting findings are related to the frequency of peaceful interactions and the dynamics that lead to peace.

Smith et al. (2011) investigate theoretically and experimentally how the costs of conflict affect the probability of a settlement. Their study is based on a model by McBride and Skaperdas (2009). Smith et al.'s extension is the following game with $n$ rounds. The first round consists of two stages. In the first stage, two players precommit to an effort level. This first-stage effort level is referred to as "arms". The first-stage effort choices or arms then become public information 
and in the second stage, the two players simultaneously decide to either settle or engage in conflict. Settlement results in the players sharing a prize in proportion to their first-stage efforts. With settlement, the players make no further decisions, but in each of the remaining $n-1$ rounds each earns his share of the prize minus his cost of first-stage effort. In the absence of a settlement, the players' first-stage efforts are used in a lottery contest. The winner of the contest in the first round earns the prize in all $n$ rounds. However the players only incur their cost of effort in the first round, but not in the remaining $n-1$ rounds. In fact, the players make no further decisions after the first round. Also, with conflict, the prize is equal to a fraction of its value had the two players settled ("the cost of conflict"). A comparative static prediction of the model is that settlement is more likely when the cost of conflict depends on first-stage efforts than when the cost of conflict is exogenous. In a laboratory experiment subjects first choose how heavily to invest in arms and then choose whether to cooperate or engage in conflict. Consistent with the SPNE, Smith et al. (2011) find that when the conflict's costs depend on the subjects' arms investments, subjects cooperate more. Moreover, when arms are cheaper, and thus subjects are better armed, they are more likely to cooperate.

\subsection{Conflict Avoidance}

Given the high costs of conflict documented by experimental studies, a natural question that arises is how one could avoid a potential conflict. Since the seminal book by Schelling (1960), a number of mechanisms for avoiding conflicts have been proposed, ranging from deterrence via extensive armament to contractually binding side-payments. Recently, different conflict resolution mechanisms have been examined in the laboratory (Bolle et al., 2010; Lacomba et al., 2011; Kimbrough et al., 2011; Smith et al., 2011; Abbink and Brandts, 2012; Kimbrough and Sheremeta, 2012a, 2012b).

Kimbrough and Sheremeta (2012a) examine a two-stage conflict game with sidepayments, where conflict is modeled as a Tullock lottery contest. The equilibrium of the game predicts that with binding stage-one offers, proposers make and responders accept sidepayments, thereby always avoiding conflicts. Laboratory experiments confirm that binding sidepayments reduce conflicts. Nevertheless, conflicts still occur and they are more costly than predicted. ${ }^{47}$ When side-payments are non-binding, the equilibrium of the game predicts that proposers offer nothing and conflicts always arise. Surprisingly, contrary to this prediction, laboratory experiments show that non-binding side-payments significantly reduce conflicts. When comparing efficiency of binding versus non-binding contracts, with binding sidepayments, most of the efficiency gains come from avoided conflicts through contracting.

\footnotetext{
47 Abbink and Brandts (2012) extend the analysis to the case of competing groups instead of individuals. As in Kimbrough and Sheremeta (2012a), their experiments show frequent and more intense conflicts. Kimbrough and Sheremeta (2012b) further point out that when subjects earn their roles (i.e., proposer or responder), conflicts are more likely to be avoided than when roles are assigned randomly. However, when conflicts ensue, they are more intense than the baseline. Kimbrough and Sheremeta conclude that earned rights have no impact on the total welfare, since the positive welfare effects of reduced conflict frequency are offset by higher conflict intensity.
} 
However, with non-binding side-payments, gains come from both avoided conflicts and from reduced contest expenditures.

Kimbrough et al. (2011) study conflict resolution via a random device. They model conflict as a two-player Tullock contest between asymmetric players. Before conflict arises, both players may agree to allocate the prize by coin flip to avoid the costs of conflict. In equilibrium, sufficiently symmetric players agree to resolve the conflict by a flip of a coin. However, with sufficiently asymmetric players, conflicts are unavoidable because the stronger players always prefer to fight. Laboratory experiments confirm that the availability of the random device partially eliminates conflicts between relatively symmetric players; however, the device also reduces conflict between relatively asymmetric players.

Another mechanism that seems to partially resolve conflict is retaliation (or a possibility of it). Lacomba et al. (2011) find that when losers of a lottery contest are given an opportunity to destroy some of their resources before winners get hold of them, many defeated contestants do so. Given this, incentives to invest in a conflict change and in some cases conflicts are avoided. Bolle et al. (2010) further demonstrate the importance of emotions in conflict resolution mechanisms with the possibility of retaliation. In a related study, Smith et al. (2011) show theoretically that when a conflict's costs are effort-dependent, conflict is more costly and settlement is more likely. Experimental findings confirm this intuition. These papers are discussed in more detail in Section 8.3.

McBride and Skaperdas (2009) develop and experimentally test a dynamic model of conflict (modeled as a repeated Tullock contest), in which players in each stage can choose either a conflict or a settlement. In their model, winning the conflict changes the future strategic positions of adversaries. Therefore, there is a tradeoff between paying a high cost to win the conflict in the current stage and enjoying higher payoff in the consecutive stages. McBride and Skaperdas show that under such assumptions, as the future becomes more important (i.e., a lower discount rate), open conflict becomes more likely than settlement. The behavior of subjects in the experiment is qualitatively consistent with the predictions of the theory, suggesting that a longer "shadow of the future" induces more conflict and less settlement. In a similar study, Tingley (2011) investigates a dynamic model of conflict with declining bargaining power. As in McBride and Skaperdas (2009), the model predicts a negative relationship between the likelihood of repeated interaction and social efficiency, and laboratory experiments confirm this intuition. The theoretical and experimental findings of McBride and Skaperdas (2009) and Tingley (2011) show that conflicts are less likely to be avoided in the long-run than in the short-run interactions.

\subsection{Sales Contests}

According to Lim et al. (2009), sales contests are "short-term incentives that managers use to raise sales effort." With a few exceptions, like the field experiments discussed in Section 7.2, the inability to manipulate contest rules in the field and the paucity of field data on sales contests has led researchers in marketing to use laboratory experiments to examine their effects. 
Lim et al. (2009) seek to advance the study of contest design with an experiment that focuses on the number of prizes to be awarded from a fixed budget. Based on a model by Kalra and Shi (2001), they predict that the optimal prize structure is one with multiple prizes with distinct values. The authors report results from two studies, one laboratory experiment and one field experiment. A novel aspect of the design of the laboratory experiment is the endogenous selection of optimal parameters (in this case, the prize values) based on the subjects' estimated degrees of risk aversion (using the Holt and Laury (2002) procedure). In the laboratory experiment, the authors find that, compared to tournaments with a single prize, introducing multiple winning prizes (holding the total value of prizes constant) generates both higher effort and higher performance. In the field experiment, where actual effort cannot be observed, introducing multiple winning prizes results in higher performance as compared to tournaments with a single prize. However, across studies, for a given number of winning prizes the contests with multiple distinct prizes do not result in significantly higher effort or performance than the contests with multiple, but identical, prizes.

Lim's (2010) study addresses the role of social preferences in influencing behavior in three-player rank-order sales tournaments. The experimental design varies the distribution of prizes. In one treatment there is one large winning prize and two losing prizes. In the other treatment, there are two winning prizes, but the value of the winning prizes is lower than in the first treatment. A key aspect of the design is that it varies the degree of social pressure present. In two of the treatments, the subjects know the identity of the other contestants in their group, thus resulting in a higher degree of social pressure than the baseline tournaments in which bidding is anonymous. Also, in the treatments with social pressure, contest outcomes are announced publicly. The results of the experiment provide substantial evidence that the social environment plays an important role in determining bidding behavior. Therefore, social preferences have a significant impact on the design of sales tournaments. Specifically, Lim (2010) finds that a contest designer may prefer to employ a distribution with two winning prizes, rather than one, especially when a certain amount of social pressure exists.

Finally, Chen et al. (2011) study the role of asymmetries by setting up three-player sales contests with asymmetric contestants and a social environment similar to treatments in Lim (2010) in which contestant identities and contest outcomes are announced publicly. In the experiment, some of the contestants are "favorites" whose performance is costlessly raised by a publicly known constant (as if they had a head start). The other contestants are referred to as "underdogs." In a two-by-two design the authors vary the number of favorites in the contest ( 1 or 2 ) and the number of prizes ( 1 or 2$)$. In all treatments of the experiment, they observe overexpenditure relative to the Nash equilibrium, both by favorites and underdogs. Chen et al. construct a behavioral model in which a contestant does not want to be seen as a "loser" compared to other contestants. In this environment with social pressure, the behavioral model explains the pattern of over-expenditure quite well and allows the authors to estimate the subjects' degree of loss. 


\subsection{Charity}

Lotteries or "charitable gambling" are a popular fundraising tool. There has been a recent surge in both laboratory and field experiments on fundraising contests. A number of experiments compare lotteries and all-pay auctions to the system of voluntary contributions employed by many charities. Hence, this application of contest theory to charitable giving intersects the vast literature on public goods experiments (Chaudhuri, 2011). When applying contest models to charitable giving, the key departure from standard models is that players receive utility from the amount of revenue that is raised. Most laboratory studies concur that lotteries and all-pay auctions are effective tools to raise revenue for charity. These findings support the theoretical results of Morgan (2000), who examines a lottery contest with common values and complete information, Davis et al. (2006), who extend Morgan's analysis to heterogeneous valuations of the prize (but complete information), and Goeree et al. (2005), who focus on comparisons between winner-pay and all-pay auctions in an independent private values environment.

Do lottery contests generate higher contributions to public goods than the well-known voluntary contribution mechanism (VCM)? Morgan and Sefton (2000) were the first to take up this question in the lab. Besides comparing the lottery mechanism to the VCM, their design also varies the size of the lottery prize (three different values) as well as the number of players (two and four). There is complete information and the players are homogeneous. Overall, they find that lotteries do increase contributions, as the model predicts. Lange et al. (2007) extend Morgan and Sefton's (2000) work by considering the role of contributor heterogeneity and risk aversion. In the theoretical model, contributors differ in their marginal valuation of the public good (or marginal per capita return) and may be risk-averse. ${ }^{48}$ When players are risk-neutral, then the lottery that raises the largest amount of contributions is one with a single winner prize. By contrast, when contributors are sufficiently risk-averse, multiple prizes are optimal. The results of the experiment largely confirm the theoretical predictions, indicating that the optimal fundraising mechanism critically depends on the heterogeneity of contributors and their risk preferences. Faravelli and Stanca (2012a) further extend the work of Lange et al. (2007) by investigating single- and multiple-prize all-pay auctions as fundraising mechanisms. ${ }^{49}$ They find that for a given total sum of prizes, a single prize all-pay auction generates higher contributions to the public good than a multiple-prize all-pay auction. This is mainly because a single prize induces higher contributions from high-income individuals, without discouraging low income individuals.

Davis et al. (2006) also introduce contributor heterogeneity in their comparison of English auctions to lottery contests (and various types of all-pay auctions) under complete information. The experimental auctions or contests have four bidders, 24 periods and fixed matching. Prize valuations are redrawn in every period, but the marginal per capita return is

\footnotetext{
${ }^{48}$ The marginal per capita return of a player refers to the (constant) per unit benefit that the player receives from the public good.

${ }^{49}$ Dickinson and Isaac (1998) and Dickinson (2001) were the first to show the effectiveness of an all-pay auction as an incentive mechanism in raising contributions to public goods.
} 
varied between sessions. Unsurprisingly, they find that the lottery mechanism always raises a greater amount of revenue than the English auction due to the typical over-dissipation result. Observed average revenue from the English auction is not significantly different from the predicted expected revenue.

Schram and Onderstal (2009) compare three fundraising mechanisms (an all-pay auction, a lottery and a winner-pay auction) that all involve bidding for a prize. Groups of three subjects, randomly rematched in every period, compete in 28 successive auctions with independent private values for the prize. The design also allows for the presence or absence of a public good to be funded within the session. The value of the public good is complete information and common across players. Hence, in half of the periods, the subjects are simply bidding for a private good. The authors find that the all-pay auction generates more revenue than the other mechanisms. The lottery and winner-pay auctions are indistinguishable in the aggregate. Furthermore, the all-pay auction is the only mechanism examined that raises significantly more revenue when revenue is used to fund a public good (charity), than in the private good treatment (no charity).

Orzen (2008) provides yet another comparison between several mechanisms. In his case, contest mechanisms (a lottery and various all-pay auctions) are pitted against the VCM. The experiment implements four-player games in which the funding mechanism is varied within session and there is random matching. The five alternative funding mechanisms are the firstprice and last-price all-pay auctions, the lottery contest, the VCM and a last-price all-pay auction with a zero prize (referred to as the "lowest common denominator"). ${ }^{50}$ Orzen finds that the firstprice all-pay auction raises substantially more revenue than any other format, followed by the last-price all-pay auction. Moreover, every contest raises more revenue than the VCM.

Corazzini et al. (2010) find that the revenue dominance of all-pay auctions is not robust when the contributors' endowments are private information (drawn from a uniform distribution). Their experiment implements the VCM, the lottery contest and the all-pay auction in four-player games with random matching. A key prediction is that in the VCM subjects should contribute nothing, while in the lottery contest all subjects should contribute the same amount regardless of the endowment (under their parameterization). In the all-pay auction, however, the subjects' contributions depend on the endowment level. Moreover, theoretically, the all-pay auction generates higher revenue than the lottery contest. Contrary to this theoretical prediction, Corazzini et al. find that the all-pay auction raises less revenue than the lottery contest. Similar to other experimental studies, over-expenditure is observed in all three mechanisms. However, over time, contributions tend to converge to equilibrium in the all-pay auction while they remain excessive in the lottery contest. Furthermore, over-expenditure in the lottery contest is quite pronounced for subjects with a high endowment even though equilibrium requires that contributions are the same regardless of the endowment. Duffy and Matros (2012) provide another reason why lotteries may outperform all-pay auctions. In their complete information setting, the public good is provided only if the participants' contributions are greater than the fixed-prize value. Under such conditions, theory predicts that lotteries may raise higher

\footnotetext{
${ }^{50}$ This last mechanism is a VCM in which players pay the lowest contribution.
} 
contributions than all-pay auctions (depending on the endowment relative to the prize value and the marginal per capita return). The experiments provide partial support for these predictions.

There are three studies that take experimental charity contests to the field: Landry et al. (2006), Carpenter et al. (2008), and Onderstal et al. (2011). Landry et al. (2006) study lottery contests as fund-raising mechanisms in a door-to-door fund-raising field experiment and find that lotteries are more effective than the VCM. Carpenter et al. (2008) compare first-price and second-price winner-pay auctions and all-pay-auctions as fund-raising mechanisms. The setting is an annual pre-school fundraiser where a variety of consumer products, ranging from $\$ 10$ to $\$ 275$ in value, are auctioned off. Interestingly, they find that the winner-pay auctions raise more revenue than the all-pay auction, contrary to standard theoretical predictions and experimental findings in the lab (Goeree et al., 2005; Schram and Onderstal, 2009). Carpenter et al. (2008) attribute their result to the fact that participants may be reluctant to enter the all-pay auction. ${ }^{51}$ Similarly, Onderstal et al. (2011) compare the all-pay auction to the lottery contest in Dutch door-to-door fundraising, and find that, contrary to the theoretical prediction, lotteries significantly outperform all-pay auctions in raising revenue. Like Carpenter et al. (2008), Onderstal et al. (2011) suggest that the inferior performance of the all-pay auction is caused by substantially lower participation rates.

\subsection{Behavior and Gender}

A number of contributions to the literature examine whether men and women behave differently in contests and tournaments. Gneezy et al. (2003) point out that the answer to this question is of great economic importance because tournaments are ubiquitous within firms, especially among top management. Furthermore, gender differences in many aspects of human activity have been a subject of study across a wide array of disciplines, ranging from biology to psychology (Gneezy and Rustichini, 2004). Economists have much to contribute to this large body of literature, in particular through the use of experimental methods.

A number of experimental studies do indeed find robust evidence that men and women behave differently in tournaments (Croson and Gneezy, 2009; Niederle and Vesterlund, 2011). In fact, this evidence is corroborated both by laboratory and field experiments. Generally speaking, women are less likely to enter tournaments than men are (women "shy away from competition"). ${ }^{52}$ Second, women do not perform as well as men under tournament incentives. Third, possible differences in attitudes toward risk can only partially explain these differences. ${ }^{53}$ An extensive survey of gender differences is beyond the scope of this paper and one is already available (Niederle and Vesterlund, 2011). Therefore, we simply highlight a handful of major contributions and some of their extensions.

\footnotetext{
${ }^{51}$ A similar finding is documented by Cason et al. (2010) in a real-effort lab experiment.

${ }_{53}$ Although, see Price (2010) and Balafoutas et al. (2012).

${ }^{53}$ Although gender differences in attitudes toward risk seem to exist, as women tend to be more risk-averse than men. A complete discussion of these gender differences can be found in Croson and Gneezy (2009).
} 
When studying gender related questions, laboratory experiments that use a real-effort task such as adding sequences of numbers or maze solving are common. Gneezy et al. (2003) have groups of men and women engage in a maze solving task. They find that women perform as well as men under a piece-rate scheme, but they solve significantly fewer mazes under tournament incentives. They are able to rule out differences in risk aversion as the factor causing the discrepancy and, instead, they argue that differing attitudes toward competition play a major role.

Gneezy and Rustichini (2004) use a field setting wherein pairs of schoolboys and schoolgirls compete in a footrace, first in a non-competitive and then in a competitive environment. When competing, children of equal ability are matched in pairs. In this pure field experiment, there are no monetary incentives. The general finding is that, when compared to a non-competitive setting, under competition boys improve in their performance relative to girls. In fact, as in Gneezy et al. (2003), when a girl is matched with a boy, a girl's performance tends to be lower in the competitive race than when there is no competition.

Niederle and Vesterlund (2007) design an experiment that focuses on selection into tournaments. The subjects engage in a number adding task under both piece-rate and tournament incentives. While the performances of men and women are not statistically different under either the piece-rate or tournament schemes, when asked which payment scheme they would like to participate in, men choose the tournament much more often than women. The authors attribute this result to gender differences in confidence and attitudes toward competition. ${ }^{54}$ We note that their study spearheaded a host of papers on the topic, most of which replicate their result (e.g., Cason et al., 2010; Niederle and Vesterlund, 2011; Balafoutas and Sutter, 2012). Notably, in a setting similar to Niederle and Vesterlund (2007), Healy and Pate (2010) find that competition in teams helps close the gender gap in entry by two thirds. A related finding is Delfgaauw et al.'s (2009) field experiment. In examining sales competitions between retail stores, they find that such competitions do raise sales, but only when the store's manager and a large fraction of team members share the same gender.

Gneezy et al.'s (2009) experiment seeks to get at the root cause of the competition gender gap. Their field experiment uses two populations of subjects, one drawn from a matrilineal society (Khasi) and the other drawn from a patriarchal society (Maasai). Women in the matrilineal society are more likely than men to enter the tournament, while the reverse is true and thus in line with findings based on Western subjects - in the patriarchal society. This

\footnotetext{
${ }^{54}$ Interestingly, several studies (Mago et al., 2011; Brookins and Ryvkin, 2011; Price and Sheremeta, 2012) find that women bid significantly more than men in lottery contests. As a result of significantly higher bids, women receive significantly lower earnings from the contest than men. The fact that women earn significantly lower payoffs in contests may suggest that the ex-ante decision to "shy away from competition" may be rational. Similarly, Ong and Chen (2012) find that women bid significantly more than men in all-pay auctions with complete information. Moreover, controlling for the gender of the bidder and the opponent, Ong and Chen argue that observed behavior is consistent with equilibrium behavior where women attach a higher valuation to winning the all-pay auction than men. Behavior is not consistent with an "errors in bidding" model in which errors are invariant with respect to the opponent's gender.
} 
experiment's findings highlight the role played by culture in shaping individuals' attitudes toward competition. ${ }^{55}$

We close this section with a brief discussion of Price's (2012) study. The author adds another dimension to the analysis of the gender gap in competition. In a setting similar to Niederle and Vesterlund (2007), he includes a treatment in which subjects are paired with other subjects whose gender they can observe and with whom they act as a manager. Specifically, managers select one of two compensation schemes for their workers, piece-rate or tournament. The results depend on whether information on productivity in a prior task is provided to the manager. Male managers who are informed about the productivity of their workers are less likely to assign female workers to the tournament scheme. When managers are not informed about productivity, there is no difference in the choice of compensation schemes. In this case, for managers of either gender, the manager's own preference for one compensation scheme or the other seems to guide the manager's choice. Importantly, when asked to evaluate the ability of workers, managers tend to rate women lower than men, suggesting that a stereotype exists.

\section{Conclusions and Future Directions}

There are several important lessons for the theory of contests that emerge from the papers that we surveyed. First, most of the experimental studies, both in the laboratory and in the field, find support for the comparative statics predictions of contest theory. Second, most studies on lottery contests and all-pay auctions find significant overbidding relative to the Nash equilibrium prediction. Third, in contrast to lottery contests and all-pay auctions, there is very little overbidding in rank-order tournaments and aggregate effort usually conforms to the theoretical predictions. Fourth, in all three canonical contests there is significant dispersion in the behavior of individual subjects. Finally, in lottery contests and rank-order tournaments bids are usually distributed around the equilibrium, while in all-pay auctions the distribution of bids is bimodal, with some subjects submitting very low and others submitting very high bids.

We see a number of fruitful avenues for future experimental research on the theory of contests. First, the sources of the phenomenon of overbidding in lottery contests and all-pay auctions is still an open question. Although there are numerous factors that may contribute to overbidding (such as a non-monetary utility of winning, mistakes, judgmental biases, spite, house money), it remains an open question as to whether some of these factors are related and which are the most important. For example, is it possible that the non-monetary utility of winning is driven by spite, or vice versa? Similarly, judgmental biases may be correlated with mistakes and loss-aversion. It would also be interesting to examine whether the patterns of overbidding in lottery contests and all-pay auctions are caused by the same underling attributes. For example, do the same subjects who overbid in lottery contests also overbid in all-pay auctions? If subjects make mistakes in lottery contests then does it imply that they are also more

\footnotetext{
${ }^{55}$ For a counterpoint to this argument, see the recent experiment by Buser (2012).
} 
likely to make mistakes in all-pay auctions? The answers to these questions would significantly advance our understanding of overbidding phenomenon.

Second, it is intriguing that there is almost no overbidding in rank-order tournaments. We conjecture that this striking difference when compared to lottery contests and all-pay auctions can be explained by the convex cost of effort and relatively large amount of noise, which are generally assumed in rank-order tournaments to insure the existence of a pure strategy Nash equilibrium. Convex cost functions make overbidding very costly and a large amount of noise reduces the predictability of the tournament outcome, again discouraging overbidding. It would be useful to see more research related to these issues.

Another avenue for future research is to continue to explore the relationship between the three canonical contest models. As we discuss in Section 2.4, there are many theoretical studies that establish common links between different contests in the literature. Nevertheless, there are only a few studies that compare different contest structures empirically. Moreover, there are virtually no experimental studies that directly address the issue of equivalence between different contests.

There appear to also be significant returns to continued experimental research on applications of contest theory. Since the work of Lazear and Rosen (1981), the theory has already taken an established place in the understanding of organizational incentives. The experimental work documented in Section 8.5 has barely touched the many issues in this line of research in the context of contests as incentive mechanisms in sales. The new and recent work on the use of contests in charity fundraising (Section 8.6) also appears to have generated a host of avenues for future research.

Contest theory is also an integral part of the theoretical study of conflict (see for instance the numerous contest theoretic contributions in Garfinkel and Skaperdas, 2012). Experimental research in this area is also in its infancy and we can expect the research outlined in Sections 8.3 and 8.4 to form the basis of continued study. Given the high costs of conflict documented by experimental studies, it is important to develop and investigate different mechanisms that could help avoiding potential conflicts. We discuss several papers that began this research endeavor in Section 8.4. Although there is substantial theoretical work, originating with Schelling (1960), addressing conflict resolution mechanisms, there are only a few experimental studies that test such mechanisms. We expect future experimental research to focus on issues such as deescalation, deterrence, and management and resolution of conflicts.

There are undoubtedly many other important applications of contest theory that have escaped our overview and will capture the interest of experimenters in the future. We very much look forward to revisiting the area in five years to see where the growth of the field, so evident in Figure 1, takes us. 


\section{References}

1. Abbink, K. (2012). Laboratory Experiments on Conflict. In Michelle R. Garfinkel and Stergios Skaperdas, (Eds.), Oxford Handbook of the Economics of Peace and Conflict. Oxford University Press, New York.

2. Abbink, K. \& Brandts, J. (2012). Political Autonomy and Independence: Theory and Experimental Evidence. Working Paper.

3. Abbink, K., Brandts, J., Herrmann, B. \& Orzen, H. (2010). Inter-Group Conflict and IntraGroup Punishment in an Experimental Contest Game. American Economic Review, 100, 420-447.

4. Abbink, K., Brandts, J., Herrmann, B. \& Orzen, H. (2012). Parochial Altruism in InterGroup Conflicts. Economics Letters, 117, 45-48.

5. Abrevaya, J. (2002). Ladder tournaments and underdogs: Lessons from professional bowling. Journal of Economic Behavior and Organization, 47, 87-101.

6. Agranov, M. \& Tergiman, C. (2012). Incentives and Compensation Schemes: An Experimental Study. International Journal of Industrial Organization, forthcoming.

7. Ahn, T.K., R, Isaac, M. \& Salmon, T.C. (2011). Rent Seeking in Groups. International Journal of Industrial Organization, 29, 116-125.

8. Altmann, S., Falk, A. \& Wibral, M. (2012). Promotions and Incentives: The Case of Multistage Elimination Tournaments. Journal of Labor Economics, 30, 149 - 174.

9. Amaldoss, W. \& Jain, S. (2002). David vs. Goliath: An Analysis of Asymmetric MixedStrategy Games and Experimental Evidence. Management Science, 48, 972-991.

10. Amaldoss, W. \& Rapoport, A. (2009). Excessive Expenditure in Two-Stage Contests: Theory and Experimental Evidence. In F. Columbus (Ed.), Game Theory: Strategies, Equilibria, and Theorems. Hauppauge, NY: Nova Science Publishers.

11. Amaldoss, W., Meyer, R.J., Raju, J.S. \& Rapoport, A. (2000). Collaborating to Compete. Marketing Science, 19, 105-126.

12. Amegashie, J.A. \& Runkel, M. (2007). Sabotaging Potential Rivals. Social Choice and Welfare, 28, 143-162.

13. Amegashie, J.A., Cadsby, C.B. \& Song, Y. (2007). Competitive Burnout: Theory and Experimental Evidence. Games and Economic Behavior, 59, 213-239.

14. Anderson, L.A. \& Freeborn, B.A. (2010). Varying the Intensity of Competition in a Multiple Prize Rent Seeking Experiment. Public Choice, 143, 237-254.

15. Anderson, L.A. \& Stafford, S.L. (2003). An Experimental Analysis of Rent Seeking under Varying Competitive Conditions. Public Choice, 115, 199-216.

16. Anderson, S.P., Goeree, J.K. \& Holt, C.A. (1998). Rent Seeking with Bounded Rationality: An Analysis of the All-Pay Auction. Journal of Political Economy, 106, 828-853.

17. Andersson, O., Huysentruyt, M., Miettinen, T. \& Stephan, U. (2012). Person-Organization Fit in Contests: Experimental Evidence. Working Paper.

18. Arad, A. (2012). The Tennis Coach Problem: A Game-Theoretic and Experimental study. The B.E. Journal of Theoretical Economics, 12, 10.

19. Arad, A. \& Rubinstein, A. (2012). Multi-Dimensional Iterative Reasoning in Action: The Case of the Colonel Blotto Game, forthcoming.

20. Audas, R., Barmby, T. \& Treble, J. (2004). Luck, Effort, and Reward in an Organizational Hierarchy. Journal of Labor Economics, 22, 379-396. 
21. Austad, S.N. (1983). A Game Theoretical Interpretation of Male Combat in the Bowl and Doily Spider (Frontinella Pyramitela). Animal Behaviour, 31, 59-73.

22. Avrahami, J. \& Kareev, Y. (2009). Do the Weak Stand a Chance? Distribution of Resources in a Competitive Environment. Cognitive Science, 33, 940-950.

23. Avrahami, J., Güth, W., Kareev, Y. \& Uske, T. (2012). On the Incentive Effects of Sample Size in Monitoring Agents - A Theoretical and Experimental Analysis. German Economic Review, forthcoming.

24. Baik, K. H. (1994). Effort levels in contests with two asymmetric players. Southern Economic Journal, 61, 367-378.

25. Baik, K.H. (1993). Effort Levels in Contests: The Public-Good Prize Case. Economics Letters, 41, 363-367.

26. Baik, K.H. \& Shogren, J.F. (1992). Strategic Behavior in Contests: Comment. American Economic Review, 82, 359-362.

27. Baik, K.H., Cherry, T.L., Kroll, S. \& Shogren, J.F. (1999). Endogenous Timing in a Gaming Tournament. Theory and Decision, 47, 1-21.

28. Balafoutas, L. \& Sutter, M. (2012). Affirmative Action Policies Promote Women and do not Harm Efficiency in the Lab. Science, 335, 579-582.

29. Balafoutas, L., Kerschbamer, R. \& Sutter, M. (2012). Distributional Preferences and Competitive Behavior. Journal of Economic Behavior and Organization, 83, 125-135.

30. Balafoutas, L., Lindner, F., Sutter, M. (2012). Sabotage in tournaments: Evidence from a natural experiment. Kyklos, forthcoming.

31. Bandiera, O., Barankay, I. \& Rasul, I. (2005). Social Preferences and the Response to Incentives: Evidence from Personnel Data. Quarterly Journal of Economics, 120, 917-962.

32. Bandiera, O., Barankay, I. \& Rasul, I. (2006). The Evolution of Cooperative Norms: Evidence from a Natural Field Experiment. The B.E. Journal of Economic Analysis and Policy, 6, 1-26.

33. Bandiera, O., Barankay, I. \& Rasul, I. (2012). Team Incentives: Evidence From a Firm Level Experiment. Journal of the European Economic Association, forthcoming.

34. Barankay, I. (2011). Rankings and Social Tournaments: Evidence from a Crowd-Sourcing Experiment. Working Paper.

35. Bartling, B., Fehr, E., Marechal, M.A. \& Schunk, D. (2009). Egalitarianism and Competitiveness. American Economic Review, 99, 93-98.

36. Barut, Y. \& Kovenock, D. (1998). The Symmetric Multiple Prize All-Pay Auction with Complete Information. European Journal of Political Economy, 14, 627-644.

37. Barut, Y. \& Kovenock, D. \& Noussair, C.N. (2002). A Comparison of Multiple-Unit AllPay and Winner-Pay Auctions Under Incomplete Information. International Economic Review, 43, 675-708.

38. Baye, M., Kovenock, D. \& de-Vries, C.G. (1994). The Solution to the Tullock RentSeeking Game When R Is Greater Than 2: Mixed-Strategy Equilibria and Mean Dissipation Rates. Public Choice, 81, 363-380.

39. Baye, M., Kovenock, D. \& de-Vries, C.G. (1996). The All-Pay Auction with Complete Information. Economic Theory, 8, 291-305.

40. Baye, M., Kovenock, D. \& de-Vries, C.G. (2012). Contests with Rank-Order Spillovers. Economic Theory, 51, 351-350.

41. Baye, M.R. \& Hoppe, H.C. (2003). The Strategic Equivalence of Rent-Seeking, Innovation, and Patent-Race Games. Games and Economic Behavior, 44, 217-226. 
42. Baye, M.R., de Vries, C.G. \& Kovenock, D. (2005). Comparative Analysis of Litigation Systems: An Auction-Theoretic Approach. Economic Journal, 115, 583-601.

43. Baye, M.R., Kovenock, D. \& de Vries, C.G. (1993). Rigging the lobbying process: an application of the all-pay auction. American Economic Review, 83, 289-294.

44. Becker, B.E. \& Huselid, M.A. (1992). The incentive effects of tournament compensation systems. Administrative Science Quarterly, 37, 336-350.

45. Becker, G.S. (1983). A theory of competition among pressure group for political influence. Quarterly Journal of Economics, 98, 371-400.

46. Becker, G.S. (1985). Public policies, pressure groups, and deadweight costs. Journal of Public Economics, 28, 329-347.

47. Berger, J. \& Pope, D.G. (2011). Can Losing Lead to Winning? Management Science, 57, 817-827.

48. Bergman, M., Olofsson, M., Wiklund, C. (2010). Contest Outcome in a Territorial Butterfly: The Role of Motivation. Proceedings of the Royal Society, 277, 3027-3033.

49. Bigoni, M., Fort, M., Nardotto, M., Reggiani, T. (2011). Teams or Tournaments? A Field Experiment on Cooperation and Competition in Academic Achievement. Working Paper, Università di Bologna.

50. Bilodeau, M., Childs, J. \& Mestelman, S. (2004). Volunteering a Public Service: An Experimental Investigation. Journal of Public Economics, 88, 2839-2855.

51. Blimpo, M.P. (2010). Team Incentives for Education in Developing Countries A Randomized Field Experiment in Benin. Stanford University, Working Paper.

52. Bloch, F. (2012). Endogenous Formation of Alliances in Conflicts. In Michelle R. Garfinkel and Stergios Skaperdas, (Eds.), Oxford Handbook of the Economics of Peace and Conflict. Oxford University Press, New York.

53. Bognanno, M.L. (2001). Corporate Tournaments. Journal of Labor Economics, 19, 290315.

54. Bolle, F., Tan, J.H.W. \& Zizzo, D.J. (2010). Vendettas. Centre for Behavioural and Experimental Social Science, Working Paper 10-04.

55. Bornstein, G. (2003). Intergroup conflict: Individual, group and collective interests. Personality and Social Psychology Review, 7, 129-145.

56. Brandts, J. \& Charness, G. (2011). The Strategy versus the Direct-response Method: A First Survey of Experimental Comparisons. Experimental Economics, 14, 375-398.

57. Breitmoser, Y., Tan, J. \& Zizzo, D. (2010). Understanding perpetual R\&D races. Economic Theory, 44, 445-467.

58. Brookins, P. \& Ryvkin, D. (2011). An Experimental Study of Bidding in Contests of Incomplete Information. Working Paper.

59. Bull, C., Schotter, A. \& Weigelt, K. (1987). Tournaments and Piece Rates: an Experimental Study. Journal of Political Economy, 95, 1-33.

60. Bullock, D. \& Rutström, E. (2007). Policy Making and Rent-Dissipation: An Experimental Test. Experimental Economics, 10, 21-36.

61. Buser, T. (2012). The Impact of the Menstrual Cycle and Hormonal Contraceptives on Competitiveness. Journal of Economic Behavior and Organization, 83, 1-10.

62. Büyükboyac1, M. (2012). Parallel Tournaments. Working Paper.

63. Cadigan, J. (2007). Two-Stage Team Rent-Seeking: Experimental Analysis. Southern Economic Journal, 74, 85-103. 
64. Caldara, M. (2012). Bidding Behavior in Pay-to-Bid Auctions: An Experimental Study. Working Paper.

65. Calsamiglia, C., Franke, J. \& Rey-Biel, P. (2012). The Incentive Effects of Affirmative Action in a Real-Effort Tournament. Working Paper.

66. Carpenter, J., Holmes, J. \& Matthews, P. (2008). Charity Auctions: A Field Experiment. Economic Journal, 118, 92-113.

67. Carpenter, J., Matthews, P. \& Schirm, J. (2010). Tournaments and Office Politics: Evidence from A Real Effort Experiment. American Economic Review, 100, 504-517.

68. Casas-Arce, P. \& Martinez-Jerez, F.A. (2009). Relative Performance Compensation, Contests, and Dynamic Incentives. Management Science, 55, 1306-1320.

69. Cason, T. N., Masters, W.A. \& Sheremeta, R.M. (2010). Entry into Winner-Take-All and Proportional-Prize Contests: An Experimental Study. Journal of Public Economics, 94, 604-611.

70. Cason, T.N., Sheremeta, R.M. \& Zhang, J. (2012). Communication and Efficiency in Competitive Coordination Games. Games and Economic Behavior, 76, 26-43.

71. Chark, R., Rapoport, A. \& Zwick, R. (2011). Experimental Comparison of Two MultipleStage Contest Designs with Asymmetric Players. Public Choice, 147, 305-329.

72. Charness, G. \& Kuhn, P. (2011). Lab labor: What can labor economists learn from the lab? In: Ashenfelter, O., Card, D. (Eds.), Handbook of Labor Economics, Elsevier, pp. 229-331.

73. Chaudhuri, A. (2011). Sustaining cooperation in laboratory public goods experiments: a selective survey of the literature. Experimental Economics, 14, 47-83.

74. Che, Y.K. \& Gale, I. (2000). Difference-form contests and the robustness of all-pay auctions. Games and Economic Behavior, 30, 22-43.

75. Chen, H., Ham, S.H. \& Lim, N. (2011). Designing Multiperson Tournaments with Asymmetric Contestants: An Experimental Study. Management Science, 57, 864-883.

76. Cherry, T.L. \& Cotten, S.J. (2011). Sleeping With The Enemy: The Economic Cost Of Internal Environmental Conflicts. Economic Inquiry, 49, 530-539.

77. Chowdhury, S.M. \& Sheremeta, R.M. (2011a). A Generalized Tullock Contest. Public Choice, 147, 413-420.

78. Chowdhury, S.M. \& Sheremeta, R.M. (2011b). Multiple Equilibria in Tullock Contests. Economics Letters, 112, 216-219.

79. Chowdhury, S.M. \& Sheremeta, R.M. (2012). Strategic Equivalence of Contests. ESI Working Paper.

80. Chowdhury, S.M., Kovenock, D. \& Sheremeta, R.M. (2012a). An Experimental Investigation of Colonel Blotto Games. Economic Theory, forthcoming.

81. Chowdhury, S.M., Sheremeta, R.M., Lee, D. (2011). Top Guns May Not Fire: Best-Shot Group Contests with Group-Specific Public Good Prizes. ESI Working Paper.

82. Chowdhury, S.M., Sheremeta, R.M., Turocy, T.L. (2012b). Overdissipation and Convergence in Rent-Seeking Experiments: Cost Structure and Prize Allocation Rules. ESI Working Paper.

83. Chung, T.Y. (1996). Rent-Seeking Contest when the Prize Increases with Aggregate Efforts. Public Choice, 87, 55-66.

84. Cinar, Y. \& Goksel, T., (2012). An Experimental Analysis of Colonel Blotto Games Under Alternative Environments. İktisat İşletme ve Finans, 27, 39-57.

85. Clark, D.J. \& Konrad, K.A. (2007). Asymmetric Conflict: Weakest Link against Best Shot. Journal of Conflict Resolution, 51, 457-469. 
86. Clark, D.J. \& Riis, C. (1998). Influence and the Discretionary Allocation of Several Prizes. European Journal of Political Economy, 14, 605-625.

87. Coffey, B. \& Maloney, M.T. (2010). The Thrill of Victory: Measuring the Incentive to Win. Journal of Labor Economics, 28, 87-112.

88. Cohen, C. \& Shavit, T. (2012). Experimental tests of Tullock's contest with and without winner refunds. Research in Economics, 66, 263-272.

89. Cohen, C., Shavit, T. \& Rosenboim, M. (2012). The overweight of unfair tie in all-pay contest: An experimental study. International Journal of Economic Theory, 8, 301-311.

90. Corazzini, L., Faravelli, M. \& Stanca, L. (2010). A Prize To Give For: An Experiment on Public Good Funding Mechanisms. Economic Journal, 120, 944-967.

91. Coughlan, P.J. \& Plott, C. (1997) An Experimental Analysis of the Structure of Legal Fees: American Rule vs. English Rule. California Institute of Technology, Social Science Working Paper.

92. Croson, R. \& Gneezy, U. (2009). Gender Differences in Preferences. Journal of Economic Literature, 47, 448-474.

93. Dasgupta, P. (1986). The Theory of Technological Competition. In J. E. Stiglitz and G. F. Mathewson, (Eds.), New Developments in the Analysis of Market Structure. Cambridge, MIT Press.

94. Davis, D. \& Reilly, R. (1998). Do Many Cooks Always Spoil the Stew? An Experimental Analysis of Rent Seeking and The Role of A Strategic Buyer. Public Choice, 95, 89-115.

95. Davis, D., Razzolini, L., Reilly, R. \& Wilson, B.J. (2006). Raising Revenues for Charity: Auctions versus Lotteries. In D. D. Davis and M. Isaac, eds., Research in Experimental Economics, Volume 11. Greenwich: JAI Press.

96. De Paola, M., Scoppa, V. \& Nisticò, R. (2012). Monetary Incentives and Student Achievement in a Depressed Labor Market: Results from a Randomized Experiment. Journal of Human Capital, 6, 56-85.

97. Dechenaux, E. \& Mancini, M. (2008). Auction-Theoretic Approach to Modeling Legal Systems: An Experimental Analysis. Applied Economics Research Bulletin, 2, 142-177.

98. Dechenaux, E., Kovenock, D. \& Lugovskyy, V. (2003). A Comment on "David and Goliath: An Analysis on Asymmetric Mixed-Strategy Games and Experimental Evidence." Purdue University, Working Paper.

99. Dechenaux, E., Kovenock, D. \& Lugovskyy, V. (2006). Caps on Bidding in All-Pay Auctions: Comments on the Experiments of A. Rapoport and W. Amaldoss. Journal of Economic Behavior and Organization, 61, 276-283.

100. Deck, C. \& Sheremeta, R.M. (2012). Fight or Flight? Defending Against Sequential Attacks in the Game of Siege. Journal of Conflict Resolution, forthcoming.

101. Deck, C., Foster, J., Song, H. (2012). Alliances in Defense Against an Opportunistic Opponent: Theory and Experiments. Working Paper.

102. Deck, C. \& Farmer, A. (2009). Strategic Bidding and Investments in Final Offer Arbitration: Theory and Experimental Evidence. Journal of Economic Behavior and Organization, 70, 361-373.

103. Deck, C. \& Jahedi, S. (2011). Time Discounting in Strategic Contests. Working Paper.

104. Delfgaauw, J., Dur, R., Sol, J. \& Verbeke, W. (2011). The Effects of Prize Spread and Noise in Elimination Tournaments: A Natural Field Experiment. Working Paper.

105. Delfgaauw, J., Dur, R., Sol, J. \& Verbeke, W. (2012). Tournament Incentives in the Field: Gender Differences in the Workplace. Journal of Labor Economics, forthcoming. 
106. DeScioli, P. \& Wilson, B.J. (2011). The Territorial Foundations of Human Property. Evolution and Human Behavior, 32, 297-304.

107. DeVaro, J. (2006). Internal Promotion Competition in Firms. Rand Journal of Economics, $37,521-542$.

108. Dickinson, D.L. (2001). The Carrot vs. the Stick in Work Team Motivation. Experimental Economics, 4, 107-124.

109. Dickinson, D.L. \& Isaac, M.R. (1998). Absolute and Relative Rewards for Individuals in Team Production. Managerial and Decision Economics, 19, 299-310.

110. Diekmann, A. (1985). Volunteer's Dilemma. Journal of Conflict Resolution, 29, 605-610.

111. Diekmann, A. (1986). Volunteer's Dilemma: A Social Trap without a Dominant Strategy and Some Empirical Results. In Paradoxical Effects of Social Behavior: Essays in Honor of Anatol Rapoport, ed. by A. Diekmann, and P. Mitter. Heidelberg: Physica-Verlag, 187-197.

112. Diekmann, A. (1993). Cooperation in Asymmetric Volunteer's Dilemma Game: Theory and Experimental Evidence. International Journal of Game Theory, 22, 75-85.

113. Dixit, A.K. (1987). Strategic Behavior in Contests. American Economic Review, 77, 89198.

114. Dohmen, T. \& Falk, A. (2011). Performance Pay and Multidimensional Sorting: Productivity, Preferences, and Gender. American Economic Review, 101, 556-90.

115. Drago, R. \& Heywood, J.S. (1989). Tournaments, Piece Rates, and the Shape of the Payoff Function. Journal of Political Economy, 97, 992-998.

116. Duffy, J. \& Kornienko, T. (2010). Does competition affect giving? Journal of Economic Behavior and Organization, 74, 82-103.

117. Duffy, J. \& Matros, A. (2012). All-Pay Auctions vs. Lotteries as Provisional Fixed-Prize Fundraising Mechanisms: Theory and Evidence. Working Paper.

118. Ederer, F. \& Fehr, E. (2009). Deception and Incentives: How Dishonesty Undermines Effort Provision. IZA discussion paper No. 3200.

119. Ederer. F. (2010). Feedback and Motivation in Dynamic Tournaments. Journal of Economics and Management Strategy, 19, 733-769.

120. Ehrenberg, R.G. \& Bognanno, M.L. (1990). Do Tournaments Have Incentive Effects? Journal of Political Economy, 98, 1307-24.

121. Eisenkopf, G. \& Teyssier, S. (2010). Envy and Loss Aversion in Tournaments. Working Paper.

122. Eisenkopf, G. \& Teyssier, S. (2012). Horizontal and Vertical Social Preferences in Tournaments. Working Paper.

123. Ellingsen, T. (1991). Strategic buyers and the social cost of monopoly. American Economic Review, 81, 648-657.

124. Erev, I., Bornstein, G. \& Galili, R. (1993). Constructive Intergroup Competition as A Solution to The Free Rider Problem: A Field Experiment. Journal of Experimental Social Psychology, 29, 463-478.

125. Ericsson, K.A. \& Charness, N. (1994). Expert performance: Its structure and acquisition. American Psychologist, 49, 725 - 747.

126. Eriksson, T. (1999). Executive compensation and tournament theory: Empirical tests on Danish data. Journal of Labor Economics, 17, 262-280.

127. Eriksson, T., Poulsen, A. \& Villeval, M.C. (2009a). Feedback and Incentives: Experimental Evidence. Labour Economics, 16, 679-688. 
128. Eriksson, T., Teyssier, S. \& Villeval, M.C. (2009b). Self-Selection and The Efficiency of Tournaments. Economic Inquiry, 47, 530-548.

129. Ernst, C. \& Thöni, C. (2009). Bimodal Bidding in Experimental All-Pay Auctions. Working Paper.

130. Falk, A. Fehr, E. \& Huffman, D. (2008). The Power and Limits of Tournament Incentives. Working Paper.

131. Fallucchi, F., Renner, E. \& Sefton, M. (2012). Information feedback and contest structure in rent-seeking games. Working Paper.

132. Faravelli, M. \& Stanca, L. (2012a). Single versus Multiple-Prize All-Pay Auctions to Finance Public Goods: An Experimental Analysis. Journal of Economic Behavior and Organization, 81, 677-688.

133. Faravelli, M. \& Stanca, L. (2012b). When Less is More: Rationing and Rent Dissipation in Stochastic Contests. Games and Economic Behavior, 74, 170-183.

134. Fehr, D. \& Schmidt, J. (2011). Exclusion in the All-Pay Auction: An Experimental Investigation. WZB Working Paper.

135. Fehr, E. \& Schmidt, K. (1999). A theory of fairness, competition, and cooperation. Quarterly Journal of Economics, 114, 817-868.

136. Ferrall, C. \& Smith, A. (1999). A sequential game model of sports championship series: theory and estimation. Review of Economics and Statistics, 81, 704-719.

137. Fershtman, C. \& Gneezy, U. (2011). The Trade-off between Performance and Quitting in High-Power Tournaments. Journal of the European Economic Association, 9, 318-336.

138. Fischbacher, U. \& Thöni, C. (2008). Excess Entry in an Experimental Winner-Take-All Market. Journal of Economic Behavior and Organization, 67, 150-163.

139. Fonseca, M.A. (2009). An Experimental Investigation of Asymmetric Contests. International Journal of Industrial Organization, 27, 582-591.

140. Freeman, R.B. \& Gelber, A.M. (2010). Prize Structure and Information in Tournaments: Experimental Evidence. American Economic Journal: Applied Economics, 2, 149-64.

141. Fu, Q. \& Lu, J. (2009). The Beauty of "Bigness": on Optimal Design of Multi Winner Contests. Games and Economic Behavior, 66, 146-161.

142. Fu, Q. \& Lu, J. (2012). Micro Foundations for Generalized Multi-Prize Contest: A Noisy Ranking Perspective. Social Choice and Welfare, 38, 497-517.

143. Fudenberg, D. \& Tirole, J. (1986). A Theory of Exit in Duopoly. Econometrica, 54, 943960.

144. Fudenberg, D., Gilbert, R., Stiglitz, J. \& Tirole, J. (1983). Preemption, Leapfrogging and Competition in Patent Races. European Economic Review, 22, 3-31.

145. Fullerton, R., Linster, B.G., McKee, M. \& Slate, S. (1999). An Experimental Investigation of Research Tournaments. Economic Inquiry, 37, 624-636.

146. Fullerton, R., Linster, B.G., McKee, M. \& Slate, S. (2002). Using Auctions to Reward Tournament Winners: Theory and Experimental Investigations. The RAND Journal of Economics, 33, 62-84.

147. Galton, F. (1902). The Most Suitable Proportion Between The Values Of First And Second Prizes. Biometrika, 1, 385-390.

148. Garfinkel, M.R. \& Skaperdas, S. (2012). Oxford Handbook of the Economics of Peace and Conflict. Oxford University Press, New York.

149. Gerchak, Y. \& He, Q.M. (2003). When will the range of prizes in tournaments increase in the noise or in the number of players? International Game Theory Review, 5, 151-166. 
150. Gill, D. \& Prowse, V. (2012). A Structural Analysis of Disappointment Aversion in a Real Effort Competition. American Economic Review, 102, 469-503.

151. Gneezy, U. \& Rustichini, A. (2004). Gender and Competition at a Young Age. American Economic Review, 94, 377-381.

152. Gneezy, U. \& Smorodinsky, R. (2006). All-Pay Auctions - An Experimental Study. Journal of Economic Behavior and Organization, 61, 255-275.

153. Gneezy, U., Leonard, K.L. \& List, J.A. (2009). Gender Differences in Competition: Evidence from a Matrilineal and a Patriarchal Society. Econometrica, 77, 1637-1664.

154. Gneezy, U., Niederle, M. \& Rustichini, A. (2003). Performance in Competitive Environments: Gender Differences. Quarterly Journal of Economics, 118, 1049-1074.

155. Goeree, J.K., Maasland, E., Onderstal, S. \& Turner, J.L. (2005). How (Not) to Raise Money. Journal of Political Economy, 113, 897-926.

156. Gradstein, M. (1995). Intensity of competition, entry and entry deterrence in rent seeking contest. Economics and Politics, 7, 79-91.

157. Gradstein, M. \& Konrad, K.A. (1999). Orchestrating rent seeking contests. Economic Journal, 109, 536-545.

158. Grosskopf, B., Rentschler, L. \& Sarin, R. (2010). Asymmetric Information in Contests: Theory and Experiments. Working Paper, Texas A\&M University.

159. Gunnthorsdottir, A. \& Rapoport, A. (2006). Embedding Social Dilemmas in Intergroup Competition Reduces Free-Riding. Organizational Behavior and Human Decision Processes, 101, 184-199.

160. Gürtler, O. \& Harbring, C. (2010). Feedback in Tournaments under Commitment Problems: Experimental Evidence. Journal of Economics and Management Strategy, 19, 771-810.

161. Gürtler, O., Münster, J. \& Nieken, P. (2012). Information Policy in Tournaments with Sabotage. Scandinavian Journal of Economics, forthcoming.

162. Güth, W., Kocher, M.G. \& Strasser, S. (2009). Optimal Monitoring Schemes in Principal Agent Games. Working Paper.

163. Hamilton, J.H. \& Slutsky, S.M. (1990). Endogenous timing in duopoly games: Stackelberg or cournot equilibria. Games and Economic Behavior, 2(1), 29-46.

164. Hammond, R.G. \& Zheng, X. (2011). Heterogeneity in Tournaments with Incomplete Information: An Experimental Analysis. Working Paper.

165. Harbring, C. (2006). The Effect of Communication in Incentive Systems - An Experimental Study. Managerial and Decision Economics, 27, 333-353.

166. Harbring, C. \& Irlenbusch, B. (2003). An Experimental Study on Tournament Design. Labour Economics, 10, 443-464.

167. Harbring, C. \& Irlenbusch, B. (2005). Incentives in Tournaments with Endogenous Prize Selection. Journal of Institutional and Theoretical Economics, 127, 636-663.

168. Harbring, C. \& Irlenbusch, B. (2008). How Many Winners are Good to Have? On Tournaments with Sabotage. Journal of Economic Behavior and Organization, 65, 682-702.

169. Harbring, C. \& Irlenbusch, B. (2011). Sabotage in Tournaments: Evidence from a Laboratory Experiment. Management Science, 57, 611-627.

170. Harbring, C. \& Lünser, G.K. (2008). On the Competition of Asymmetric Agents. German Economic Review, 9, 373-395. 
171. Harbring, C., Irlenbusch, B. Krakel, M. \& Selten, R. (2007). Sabotage in Corporate Contests - An Experimental Analysis. International Journal of the Economics of Business, $14,367-392$.

172. Harris, C. \& Vickers, J. (1985). Perfect equilibrium in a model of a race. Review of Economic Studies, 52, 193-209.

173. Harris, C. \& Vickers, J. (1987). Racing with uncertainty. Review of Economic Studies, 54, $1-21$.

174. Harrison, G.W. \& List, J.A. (2004). Field Experiments. Journal of Economic Literature, 42, 1009-1055.

175. Hart, S. (2008). Discrete colonel Blotto and general Lotto games. International Journal of Game Theory, 36, 441-460.

176. Healy, A. \& Pate, J. (2010). Can Teams Help to Close the Gender Competition Gap? Economic Journal, 155, 1192-1204.

177. Herbst, L., Konrad, K.A. \& Morath, F. (2012). When the weak stand together and the strong stand alone - on group formation in contests. Working Paper.

178. Herrmann, B. \& Orzen, H. (2008). The Appearance of Homo Rivalis: Social Preferences and the Nature of Rent Seeking. University of Nottingham, Working Paper.

179. Hillman, A. \& Riley, J.G. (1989). Politically contestable rents and transfers. Economics and Politics, 1, 17-40.

180. Hirshleifer, J. \& Riley, J.G. (1978). Elements of the Theory of Auctions and Contests. UCLA Economics Working Papers 118.

181. Hirshleifer, J. \& Riley, J.G. (1992). The Analytics of Uncertainty and Information. New York, Cambridge University Press.

182. Höchtl, W., Kerschbamer, R., Stracke, R. \& Sunde, U. (2011). Incentives vs. Selection in Promotion Tournaments: Can a Designer Kill Two Birds with One Stone? Working Paper.

183. Holt, C.A. \& Laury, S.K. (2002). Risk Aversion and Incentive Effects. American Economic Review, 92, 1644-1655.

184. Hörisch, H. \& Kirchkamp, O. (2010). Less Fighting than Expected - Experiments with Wars of Attrition and All-Pay Auctions. Public Choice, 144, 347-367.

185. Hortala-Vallve, R. \& Llorente-Saguer, A. (2010). A Simple Mechanism for Resolving Conflict. Games and Economic Behavior, 70, 375-391.

186. Hossain, T., Hong, F. \& List, J.A. (2011). Framing Manipulations in Contests: A Natural Field Experiment. Working Paper.

187. Hyndman, K., Ozbay, E.Y. \& Sujarittanonta, P. (2010). Rent Seeking with Regretful Agents: Theory and Experiment. Working Paper.

188. Irfanoglu, B., Mago, S.D. \& Sheremeta, R.M. (2011). Sequential versus Simultaneous Election Contests: An Experimental Study. Working Paper.

189. Jackson, D. (1993). Independent trials are a model for disaster. Applied Statistics, 42, 211 220.

190. Jia, H. (2008). A stochastic derivation of the ratio form of contest success functions. Public Choice, 135, 125-130.

191. Kahneman, D. \& Tversky, A. (1979). Prospect Theory: An Analysis of Decision Under Risk. Econometrica, 47, 263-291.

192. Kalra, A. \& Shi, M. (2001). Designing Optimal Sales Contests: A Theoretical Perspective. Marketing Science, 20, 170-193. 
193. Kareev, Y. \& Avrahami, J. (2007). Choosing between adaptive agents: Some unexpected implications of level of scrutiny. Psychological Science, 18, 636-641.

194. Katz, E., Nitzan, S. \& Rosenberg, J. (1990). Rent-Seeking for Pure Public Goods. Public Choice, 65, 49-60.

195. Ke, C. (2011). Fight Alone or Together? The Need to Belong. Working Paper.

196. Ke, C., Konrad, K.A. \& Morath, F. (2012a). Alliances in the Shadow of Conflict. Working Paper.

197. Ke, C., Konrad, K.A. \& Morath, F. (2012b). Brothers in Arms - An Experiment on the Alliance Puzzle. Games and Economic Behavior, forthcoming.

198. Kimbrough, E.O. \& Sheremeta, R.M. (2012a). Side-Payments and the Costs of Conflict. International Journal of Industrial Organization, forthcoming.

199. Kimbrough, E.O. \& Sheremeta, R.M. (2012b). Why Can't We Be Friends? Entitlements and the Costs of Conflict. ESI Working Paper.

200. Kimbrough, E.O., Sheremeta, R.M. \& Shields, T. (2011). Resolving Conflicts by a Random Device. Chapman University, Working Paper.

201. Klose, B. \& Sheremeta, R.M. (2012). Behavior in All-Pay and Winner-Pay Auctions with Identity-Dependent Externalities. Working Paper.

202. Klumpp, T. \& Polborn, M.K. (2006). Primaries and the New Hampshire effect. Journal of Public Economics, 90, 1073-1114.

203. Knoeber, C.R. \& Thurman, W.N. (1994). Testing the Theory of Tournaments: An Empirical Analysis of Broiler Production. Journal of Labor Economics, 12, 155-179.

204. Kohli, P., Bachrach, Y., Stillwell, D., Kearns, M., Herbrich, R. \& Graepel, T. (2012). Colonel Blotto On Facebook: The Effect of Social Relations On Strategic Interaction. ACM Web Sciences 2012, ACM Conference on Web Sciences.

205. Kong, X. (2008). Loss Aversion and Rent-Seeking: An Experimental Study. University of Nottingham, Working Paper.

206. Konrad, K.A. (2000). Sabotage in Rent-Seeking Contests. Journal of Law, Economics and Organization, 16, 155-65.

207. Konrad, K.A. (2009). Strategy and Dynamics in Contests. New York, NY: Oxford University Press.

208. Konrad, K.A. \& Kovenock, D. (2009). Multi-battle contests. Games and Economic Behavior, 66, 256-274.

209. Kosfeld, M. \& Neckermann, S. (2011). Getting More Work for Nothing? Symbolic Awards and Worker Performance. American Economic Journal: Microeconomics, 3, 86-99.

210. Kovenock, D. \& Roberson, B. (2010). The Optimal Defense of Networks of Targets. Purdue University, Working Paper.

211. Kovenock, D. \& Roberson, B. (2012). Conflicts with Multiple Battlefields. In Michelle R. Garfinkel and Stergios Skaperdas, (Eds.), Oxford Handbook of the Economics of Peace and Conflict. Oxford University Press, New York.

212. Kovenock, D., Roberson, B. \& Sheremeta, R.M. (2010). The Attack and Defense of Weakest-Link Networks, Chapman University, Working Paper.

213. Kräkel, M. (2008). Emotions in tournaments. Journal of Economic Behavior and Organization, 67, 204-214.

214. Kräkel, M. \& Nieken, P. (2012). Relative Performance Pay in the Shadow of Crisis. Working Paper. 
215. Kräkel, M., Nieken, P. \& Przemeck, J. (2012). Risk Taking and Investing in Electoral Competition. Working Paper.

216. Krebs, J.R. (1982). Territorial Defence in the Great Tit (Parus Major): Do residents always Win? Behavioral Ecology and Sociobiology, 11, 185-194.

217. Krishna, V. \& Morgan, J. (1997). An Analysis of the War of Attrition and the All-Pay Auction. Journal of Economic Theory, 72, 343-362.

218. Krishna, V. \& Morgan, J. (1998). The winner-take-all principle in small tournaments. In M.R. Baye (ed.), Advances in Applied Microeconomics. Stamford, CT: JAI Press.

219. Krueger, A.O. (1974). The Political Economy of the Rent-Seeking Society. American Economic Review, 64, 291-303.

220. Kugler, T., Rapoport A. \& Pazy, A. (2010). Public Good Provision in Inter-Group Conflicts: Effects of Asymmetry and Profit-Sharing Rule. Journal of Behavioral Decision Making, 23, 421-438.

221. Kuhnen, C.M. \& Tymula, A. (2012). Feedback, Self-Esteem and Performance in Organizations. Management Science, forthcoming.

222. Kvasov, D. (2007). Contests with limited resources. Journal of Economic Theory, 136, 738-748.

223. Lacomba, J.A., Lagos, F.M., Reuben, E. \& van Winden, F. (2011). On the Escalation and De-escalation of Conflict. Working Paper.

224. Landry, C., Lange, A., List, J.A., Price, M.K. \& Rupp, N. (2006). Toward an Understanding of the Economics of Charity: Evidence from a Field Experiment. Quarterly Journal of Economics, 121, 747-782.

225. Lange, A., List, J.A. \& Price, M.K. (2007). Using Lotteries to Finance Public Goods: Theory and Experimental Evidence. International Economic Review, 48, 901-927.

226. Lazear, E.P. (1999). Personnel economics past lessons and future directions - presidential address to the society of labor economists. Journal of Labor Economics, 17, 199-236.

227. Lazear, E.P. (2000). Performance pay and productivity. American Economic Review, 90, 1346-1361.

228. Lazear, E.P. \& Rosen, S. (1981). Rank-Order Tournaments as Optimum Labor Contracts. Journal of Political Economy, 89, 841-864.

229. Lee, D. (2012). Weakest-link Contest with Group-Specific Public Good Prizes. European Journal of Political Economy, 28, 238-248.

230. Lee, T. \& Wilde, L. (1980). Market structure and innovation: A reformulation. Quarterly Journal of Economics, 94, 429-436.

231. Leibbrandt, A. \& Saaksvuori, L. (2012). More than Words: Communication in Intergroup Conflicts. European Economic Review, forthcoming.

232. Leininger, W. \& Yang, C.L. (1994). Dynamic rent-seeking games. Games and Economic Behavior, 7, 406-427.

233. Leininger, W. (1991). Patent Competition, Rent Dissipation, and the Persistence of Monopoly: The Role of Research Budgets. Journal of Economic Theory, 53, 146-172.

234. Leuven, E., Oosterbeek, H. \& van der Klaauw, B. (2010). The Effect of Financial Rewards on Students' Achievement: Evidence from a Randomized Experiment. Journal of the European Economic Association, 8, 1243-1265.

235. Leuven, E., Oosterbeek, H., Sonnemans, J. \& van der Klaauw, B. (2011). Incentives versus Sorting in Tournaments: Evidence From a Field Experiment. Journal of Labor Economics, 29, 637-658. 
236. Lim, N. (2010). Social Loss Aversion and Optimal Contest Design. Journal of Marketing Research, 47, 777-787.

237. Lim, N., Ahearne, M. \& Ham, S.H. (2009). Designing Sales Contests: Does the Prize Structure Matter? Journal of Marketing Research, 46, 356-371.

238. Lim, W., Matros, A. \& Turocy, T. (2012). Bounded rationality and group size in Tullock contests: Experimental evidence. Working Paper.

239. Lin, J.C. (2009). Contests of Status: An Experimental Study. Working Paper.

240. Linster, B.G., Fullerton, R.L., Mckee, M. \& Slate, S. (2001). Rent-Seeking Models of International Competition: An Experimental Investigation. Defence and Peace Economics, $12,285-302$.

241. List, J.A., van Soest, D., Stoop, J. \& Zhou. H. (2010). On the Role of Group Size in Tournaments: Theory and Evidence from Lab and Field Experiments. Working paper, University of Chicago, Chicago.

242. Liu, T.X. (2011). Sequential vs. Simultaneous All-pay Auction: An Experimental Study. University of Michigan, Working Paper.

243. Liu, T.X., Yang, J., Adamic, L.A. \& Chen, Y. (2011). Crowdsourcing with All-pay Auctions: a Field Experiment on Tasken. Working Paper.

244. Long, N.V. \& Vousden, N. (1987). Risk-averse rent seeking with shared rents. Economic Journal, 97, 971-985.

245. Ludwig, S., \& Lunser, G.K. (2012). Observing your competitor - The role of effort information in two-stage tournaments. Journal of Economic Psychology, 33, 166-182.

246. Lugovskyy, V., Puzzello, D. \& Tucker, S. (2010). An Experimental Investigation of Overdissipation in the All Pay Auction. European Economic Review, 54, 974-997.

247. Lynch, J. \& Zax, J. (2000). The Rewards to Running: Prize Structure and Performance in Professional Road Racing. Journal of Sports Economics, 1, 323-340.

248. Mago, S.D. \& Sheremeta, R.M. (2012). Multi-Battle Contests: An Experimental Study. ESI Working Paper.

249. Mago, S.D., Savikhin, A.C. \& Sheremeta, R.M. (2012). Facing Your Opponents: Social Identification and Information Feedback in Contests. ESI Working Paper.

250. Mago, S.D., Sheremeta, R.M. \& Yates, A. (2011). Best of Three Contests: Experimental Evidence. ESI Working Paper.

251. Main, B., O'Reilly, C.A. \& Wade, J. (1993). Top Executive Pay: Tournament or Teamwork? Journal of Labor Economics, 11, 606-28.

252. Maloney, M.T. \& McCormick, R.E. (2000). The Response of Workers to Wages in Tournaments: Evidence From Foot Races. Journal of Sports Economics, 1, 99-123

253. Malueg, D. \& Yates, A. (2010). Testing contest theory: evidence from best-of-three tennis matches. Review of Economics and Statistics, 92, 689-692.

254. Masiliunas, A., Mengel, F. Reiss, J.P. (2012). (Strategic) Uncertainty and the Explanatory Power of Nash Equilibrium in Tullock Contests. Working Paper.

255. Matros, A. \& Armanios, D. (2009). Tullock contest with reimbursements. Public Choice, $141,49-63$.

256. Maynard Smith, J. (1974). Theory of games and the evolution of animal contests. Journal of Theoretical Biology, 47, 209-221.

257. McBride, M. \& Skaperdas, S. (2009). Conflict, Settlement, and the Shadow of the Future. University of California-Irvine, Working Papers. 
258. McDonald, J. \& Tukey, J. (1949). Colonel Blotto: A Problem of Military Strategy. Fortune, June.

259. McFall, T., Knoeber, C. \& Thurman, W. (2009). Contests, grand prizes, and the hot hand. Journal of Sports Economics, 10, 236-255.

260. McKelvey, R. \& Palfrey, T. (1995). Quantal Response Equilibria for Normal Form Games. Games and Economic Behavior, 10, 6-38.

261. Michelitch, K. (2009). Do Quotas Make Gender and Ethnic Groups Expend Less Effort in Competition? Working Paper.

262. Millner, E.L. \& Pratt, M.D. (1989). An Experimental Investigation of Efficient RentSeeking. Public Choice, 62, 139-151.

263. Millner, E.L. \& Pratt, M.D. (1991). Risk Aversion and Rent-Seeking: An Extension and Some Experimental Evidence. Public Choice, 69, 81-92.

264. Minor, D. (2012). Coarse Thinking and Competition. Working Paper.

265. Mohamudally-Boolaky, A. (2011). A Laboratory Analysis of the Impact of Supply Uncertainty in All Pay Actions. Working Paper.

266. Moldovanu, B. \& Sela, A. (2001). The Optimal Allocation of Prizes in Contests. American Economic Review, 91, 542-558.

267. Moldovanu, B., Sela, A. \& Shi, X. (2007). Contest for Status. Journal of Political Economy, 115, 338-363.

268. Montero, M., Possajennikov, A., Sefton, M. \& Turocy, T.L. (2012). The Value of Votes in Weighted Voting Games: An Experiment. University of Nottingham, Working Paper.

269. Morgan, J. (2000). Financing public goods by means of lotteries. Review of Economic Studies, 67, 761-784.

270. Morgan, J. \& Sefton, M. (2000). Funding Public Goods with Lotteries: Experimental Evidence. Review of Economic Studies, 67, 785-810.

271. Morgan, J., Orzen, H. \& Sefton, M. (2012a). Endogenous Entry in Contests. Economic Theory, 51, 435-463.

272. Morgan, J., Orzen, H., Sefton, M. \& Sisak, D. (2012b). Strategic and Natural Risk in Entrepreneurship: An Experimental Study. Working Paper.

273. Morton, R.B. \& Williams, K.C. (2010). Experimental Political Science and the Study of Causality: From Nature to the Lab. New York, NY: Cambridge University Press.

274. Mosteller, F. (1952). The world series competition. Journal of the American Statistical Association, 47, 355-380.

275. Müller, W. \& Schotter, A. (2010). Workaholics and Dropouts in Organizations. Journal of the European Economic Association, 8, 717-743.

276. Nagel, R. (1995). Unraveling in Guessing Games: An Experimental Study. American Economic Review, 85, 1313-1326.

277. Nalbantian, H.R. \& Schotter, A. (1997). Productivity under Group Incentives: An Experimental Study. American Economic Review, 87, 314-341.

278. Nalebuff, B.J. \& Stiglitz, J.E. (1982). Prizes and Incentives: Towards a General Theory of Compensation and Competition. Bell Journal of Economics, 13, 21-43.

279. Niederle, M. \& Vesterlund, L. (2007). Do Women Shy Away from Competition? Do Men Compete Too Much? Quarterly Journal of Economics, 122, 1067-1101.

280. Niederle, M. \& Vesterlund, L. (2011). Gender and Competition. Annual Review of Economics, 3, 601-630. 
281. Niederle, M., Segal, C. \& Vesterlund, L. (2010). How Costly is Diversity? Affirmative Action In Light of Gender Differences in Competitiveness. NBER Working Paper.

282. Nieken, P. (2010). On the Choice of Risk and Effort in Tournaments-Experimental Evidence. Journal of Economics and Management Strategy, 19, 3, 811-840.

283. Nieken, P. \& Sliwka, D. (2010). Risk-taking tournaments - Theory and experimental evidence. Journal of Economic Psychology, 31, 254-268.

284. Noussair, C. \& Silver, J. (2006). Behavior in All Pay Auctions with Incomplete Information. Games and Economic Behavior, 55, 189-206.

285. O'Reilly, C., Main, B. \& Crystal, G. (1988). CEO Compensation as Tournament and Social Comparison: A Tale of Two Theories. Administrative Science Quarterly, 33, 257-274.

286. Öncüler, A. \& Croson, R. (2005). Rent-Seeking for a Risky Rent - A Model and Experimental Investigation. Journal of Theoretical Politics, 17, 403-429.

287. Onderstal, S., Schram, A.J.H.C. \& Soetevent, A.R. (2011). Bidding to Give in the Field: Door-to-Door Fundraisers Had it Right from the Start. Working Paper.

288. Ong, D. \& Chen, Z. (2012). Tiger Women: An All-Pay Auction Experiment on Gender Signaling of Desire to Win. Working Paper.

289. Oprea, R., Wilson, B.J. \& Zillante, A. (2012). War of Attrition: Evidence from a Laboratory Experiment on Market Exit. Economic Inquiry, forthcoming.

290. Orrison, A., Schotter, A. \& Weigelt, K. (2004). Multiperson Tournaments: An Experimental Examination. Management Science, 50, 268-79.

291. Orzen, H. (2008). Fundraising through competition: Evidence from the lab. CeDEx Working paper.

292. Otsubo, H. (2012). Contests with Incumbency Advantages: An Experiment Investigation of the Effect of Limits on Spending Behavior and Outcome. Working Paper.

293. Otsubo, H. \& Rapoport, A. (2008). Dynamic volunteer's dilemma in finite and discrete time: Theory and Experimental evidence. Journal of Conflict Resolution, 52, 961-984.

294. Parco J., Rapoport A. \& Amaldoss W. (2005). Two-Stage Contests with Budget Constraints: An Experimental Study. Journal of Mathematical Psychology, 49, 320-338.

295. Parker, G.A. \& Thompson, E.A. (1980). Dung Fly Struggles: A Test of the War of Attrition. Behavioral Ecology and Sociobiology, 7, 37-44.

296. Phillips, O. \& Mason, C. (1997). Wars of Attrition in Experimental Duopoly Markets. Southern Economic Journal, 63, 726 - 742.

297. Potters, J.C., De Vries, C.G. \& Van Winden, F. (1998). An Experimental Examination of Rational Rent Seeking. European Journal of Political Economy, 14, 783-800.

298. Prendergast, C. (1999). The Provision of Incentives in Firms. Journal of Economic Literature, 37, 7-63.

299. Price, C. (2010). Do Women Shy Away from Competition? Do Men Compete too much? A (Failed) Replication. University of Southern Indiana, mimeo.

300. Price, C. (2012). Gender, Competition and Managerial Decision. Management Science, 58, $114-122$

301. Price, C.R. \& Sheremeta, R.M. (2011). Endowment Effects in Contests. Economics Letters, 111, 217-219.

302. Price, C.R. \& Sheremeta, R.M. (2012). Endowment Origin, Demographic Effects and Individual Preferences in Contests. ESI Working Paper. 
303. Rapoport, A. \& Amaldoss, W. (2000). Mixed Strategies and Iterative Elimination of Strongly Dominated Strategies: an Experimental Investigation of States of Knowledge. Journal of Economic Behavior and Organization, 42, 483-521.

304. Rapoport, A. \& Amaldoss, W. (2004). Mixed-Strategy Play in Single-Stage First-Price AllPay Auctions with Symmetric Players. Journal of Economic Behavior and Organization, 54, 585-607.

305. Rapoport, A. \& Amaldoss, W. (2008). In Search of Experimental Support for an Alternating Equilibria Solution in Symmetric Investment Games. Journal of Economic Behavior and Organization, 67, 200-203.

306. Rapoport, A. \& Bornstein, G. (1987). Intergroup Competition for the Provision of Binary Public Goods. Psychological Review, 94, 291-299.

307. Roberson, B. (2006). The Colonel Blotto game. Economic Theory, 29(1), 1-24.

308. Roberson, B. \& Kvasov, D. (2012). The Non-Constant Sum Colonel Blotto Game. Economic Theory, 51, 397-433.

309. Rosen, S. (1986). Prizes and incentives in elimination tournaments. American Economic Review, 76, 701-715.

310. Ryvkin, D. (2010). Contests with private costs: beyond two players. European Journal of Political Economy, 26, 558-567.

311. Ryvkin, D. (2011). Fatigue in Dynamic Tournaments. Journal of Economics and Management Strategy, 20, 1011-1041.

312. Sacco, D. \& Schmutzler, A. (2008). All-Pay Auctions with Negative Prize Externalities: Theory and Experimental Evidence. Working Paper.

313. Savikhin, A.C. \& Sheremeta, R.M. (2012). Simultaneous Decision-Making in Competitive and Cooperative Games. Economic Inquiry, forthcoming.

314. Sbriglia, P. \& Hey, J.D. (1994). Experiments in Multi-Stage R\&D Competition. Empirical Economics, 19, 291-316.

315. Schelling, T. (1960). The Strategy of Conflict. Cambridge, MA: Harvard University Press.

316. Schmidt, D., Sheremeta, R.M., Shupp, R. \& Walker, J. (2011). Resource Allocation Contests: Experimental Evidence. Indiana University, Working Paper.

317. Schmitt, P., Shupp, R., Swope, K. \& Cadigan, J. (2004). Multi-Period Rent-Seeking Contests with Carryover: Theory and Experimental Evidence. Economics of Governance, $5,187-211$.

318. Schotter, A. \& Weigelt, K. (1992). Asymmetric Tournaments, Equal Opportunity Laws, and Affirmative Action: Some Experimental Results. Quarterly Journal of Economics, 107, 511-539.

319. Schram, A. \& Onderstal, A.M. (2009). Bidding to Give: An Experimental Comparison of Auctions for Charity. International Economic Review, 50, 431-457.

320. Sheremeta, R.M. (2010a). Expenditures and Information Disclosure in Two-Stage Political Contests. Journal of Conflict Resolution, 54, 771-798.

321. Sheremeta, R.M. (2010b). Experimental Comparison of Multi-Stage and One-Stage Contests. Games and Economic Behavior, 68, 731-747.

322. Sheremeta, R.M. (2011a). Contest Design: An Experimental Investigation. Economic Inquiry, 49, 573-590.

323. Sheremeta, R.M. (2011b). Perfect-Substitutes, Best-Shot, and Weakest-Link Contests between Groups. Korean Economic Review, 27, 5-32. 
324. Sheremeta, R.M. \& Wu, S.Y. (2011). Optimal Tournament Design and Incentive Response: An Experimental Investigation of Canonical Tournament Theory. Working Paper.

325. Sheremeta, R.M. \& Zhang, J. (2010). Can Groups Solve the Problem of Over-Bidding in Contests? Social Choice and Welfare, 35, 175-197.

326. Sheremeta, R.M., Masters, W.A. \& Cason, T.N. (2012). Winner-Take-All and Proportional-Prize Contests: Theory and Experimental Results. ESI Working Paper.

327. Shogren, J. \& Hurley, T. (1997). Tournament Incentives in Environmental Policy Economics. In Dragun and Jakobsson, (Eds.), Sustainability and Global Environmental Policy: New Perspectives. Edward Elgar Publishing, pp. 215-234.

328. Shogren, J.F. (1997). Self-interest and equity in a bargaining tournament with non-linear payoffs. Journal of Economic Behavior and Organization, 32, 383-394.

329. Shogren, J.F. \& Baik, K.H. (1991). Reexamining Efficient Rent-Seeking in Laboratory Markets. Public Choice, 69, 69-79.

330. Shogren, J.F. \& Baik, K.H. (1992). Favorites and Underdogs: Strategic Behavior in an Experimental Contest. Public Choice, 74, 191-205.

331. Silipo, D.B. (2005). The Evolution of Cooperation in Patent Races: Theory and Experimental Evidence. Journal of Economics, 85, 1-38.

332. Sisak, D. (2009). Multiple-Prize Contests - The Optimal Allocation Of Prizes. Journal of Economic Surveys, 23, 82-114.

333. Smith, A.C., Houser, D., Leeson, P.T. \& Ostadhossein, R. (2011). The Costs of Conflict. George Mason University, Working Paper.

334. Stahl, D. \& Wilson, P. (1994). Experimental Evidence on Players' Models of Other Players. Journal of Economic Behavior and Organization, 25, 309-327.

335. Stahl, D. \& Wilson, P. (1995). On Players' Models of Other Players: Theory and Experimental Evidence. Games and Economic Behavior, 10, 218-254.

336. Stein, W. (2002). Asymmetric Rent-Seeking with More Than Two Contestants. Public Choice, 113, 325-336.

337. Stracke, R., Höchtl, W., Kerschbamer, R. \& Sunde, U. (2012). Optimal Prizes in Dynamic Elimination Contests: An Experimental Analysis. Working Paper.

338. Sunde, U. (2009). Heterogeneity and performance in tournaments: A test for incentive effects using professional tennis data. Applied Economics, 41, 3199-3208.

339. Sutter, M. (2006). Endogenous versus Exogenous Allocation of Prizes in Teams - Theory and experimental evidence. Labour Economics, 13, 519-549.

340. Sutter, M. \& Strassmair, C. (2009). Communication, Cooperation and Collusion in Team Tournaments - An Experimental Study. Games and Economic Behavior, 66, 506-525.

341. Szentes, B. \& Rosenthal, R.W. (2003). Three-object two-bidder simultaneous auctions: chopsticks and tetrahedra. Games and Economic Behavior, 44, 114-133.

342. Szymanski, S. (2003). The economic design of sporting contests. Journal of Economic Literature, 41, 1137-1187.

343. Szymanski, S. \& Valletti, T.M. (2005). Incentive Effects of Second Prizes. European Journal of Political Economy, 21, 467-481.

344. Taylor, C.R. (1995). Digging for Golden Carrots: An Analysis of Research Tournaments. American Economic Review, 85, 872-90.

345. Tingley, D. (2011). The Dark Side of the Future: An Experimental Test of Commitment Problems in Bargaining. International Studies Quarterly, 55, 521-544. 
346. Tong, K. \& Leung, K. (2002). Tournament as a Motivational Strategy: Extension to Dynamic Situations with Uncertain Duration. Journal of Economic Psychology, 23, 399420.

347. Tullock, G. (1967). The Welfare Costs of Tariffs, Monopolies, and Theft. Western Economic Journal, 5, 224-232.

348. Tullock, G. (1980). Efficient Rent Seeking. In James M. Buchanan, Robert D. Tollison, Gordon Tullock, (Eds.), Toward a theory of the rent-seeking society. College Station, TX: Texas A\&M University Press, pp. 97-112.

349. Uske, T. (2008). Tournament Fever and the Perception of Strategic Uncertainty in Performance Contests. Working Paper.

350. Van Dijk, F., Sonnemans, J. \& van Winden, F. (2001). Incentives Systems in a Real Effort Experiment. European Economic Review, 45, 187-214.

351. Vandegrift, D. \& Yavas, A. (2010). An Experimental Test of Sabotage in Tournaments. Journal of Institutional and Theoretical Economics, 166, 259-285.

352. Vandegrift, D., Yavas, A. \& Brown, P. (2007). Incentive Effects and Overcrowding in Tournaments: An Experimental Analysis. Experimental Economics, 10, 345-368.

353. Vasilaky, K. (2011). Incentives for Information Exchange: Getting Women to Share in Rural Uganda. Working Paper.

354. Vogt, C., Weimann, J. \& Yang, C.L. (2002). Efficient Rent-Seeking in Experiment. Public Choice, 110, 67-78.

355. Wärneryd, K. (2003). Information in Conflicts. Journal of Economic Theory, 110, 121-136.

356. Wasser, C. (2012). Incomplete information in rent-seeking contests. Economic Theory, forthcoming.

357. Weigelt, K., Dukerich, J. \& Schotter, A. (1989). Reactions to Discrimination in an Incentive Pay Compensation Scheme: a Game-Theoretic Approach. Organizational Behavior and Human Decision Processes, 44, 26-44.

358. Weimann, J., Yang, C.L. \& Vogt, C. (2000). An Experiment on Sequential Rent Seeking. Journal of Economic Behavior and Organization, 41, 405-426.

359. Wu, S.Y. \& Roe, B. (2005). Behavioral and Welfare Effects of Tournaments and Fixed Performance Contracts: Some Experimental Evidence. American Journal of Agricultural Economics, 87, 130-146.

360. Wu, S.Y. \& Roe, B. (2006). Tournaments, Fairness, and Risk. American Journal of Agricultural Economics, 88, 561-573.

361. Wu, S.Y., Roe, B. \& Sporleder, T. (2006). Mixed Tournaments, Common Shocks, and Disincentives: An Experimental Study. Working Paper.

362. Young, H.P. (1978). A Tactical Lobbying Game, in Ordeshook, P.C. (ed) Game Theory and Political Science, New York University Press, New York.

363. Zhong, Z. \& Tang, F. (2010). Myopia in Contest: Accumulating Valuation All-Pay Auction Model and Experiment. Working Paper.

364. Zizzo, D.J. (2002). Racing with Uncertainty: A Patent Race Experiment. International Journal of Industrial Organization, 20, 877-902. 


\section{2}

\section{Economic Science Institute Working Papers}

12-20 Gómez-Miñambres, J. and Schniter, E. Menu-Dependent Emotions and Self-Control.

12-19 Schniter, E., Sheremeta, R., and Sznycer, D. Building and Rebuilding Trust with Promises and Apologies.

12-18 Shields, T. and Xin, B. Higher-order Beliefs in Simple Trading Models.

12-17 Pfeiffer, G. and Shields, T. Performance-Based Compensation and Firm Value: Experimental evidence.

12-16 Kimbrough, E. and Sheremeta, R. Why Can't We Be Friends? Entitlements, bargaining, and conflict.

12-15 Mago, S., Savikhin, A., and Sheremeta, R. Facing Your Opponents: Social identification and information feedback in contests.

12-14 McCarter, M., Kopelman, S., Turk, T. and Ybarra, C. Too Many Cooks Spoil the Broth: How the tragedy of the anticommons emerges in organizations.

12-13 Chowdhury, S., Sheremeta, R. and Turocy, T. Overdissipation and Convergence in Rent-seeking Experiments: Cost structure and prize allocation rules.

12-12 Bodsky, R., Donato, D., James, K. and Porter, D. Experimental Evidence on the Properties of the California's Cap and Trade Price Containment Reserve.

12-11 Branas-Garza, P., Espin, A. and Exadaktylos, F. Students, Volunteers and Subjects: Experiments on social preferences.

12-10 Klose, B. and Kovenock, D. Extremism Drives Out Moderation.

12-09 Buchanan, J. and Wilson, B. An Experiment on Protecting Intellectual Property.

12-08 Buchanan, J., Gjerstad, S. and Porter, D. Information Effects in Multi-Unit Dutch Auctions.

12-07 Price, C. and Sheremeta, R. Endowment Origin, Demographic Effects and Individual Preferences in Contests.

12-06 Magoa, S. and Sheremeta, R. Multi-Battle Contests: An experimental study.

12-05 Sheremeta, R. and Shields, T. Do Liars Believe? Beliefs and Other-Regarding Preferences in Sender-Receiver Games.

12-04 Sheremeta, R., Masters, W. and Cason. T. Winner-Take-All and Proportional-Prize Contests: Theory and experimental results. 
12-03 Buchanan, J., Gjerstad, S. and Smith, V. There's No Place Like Home.

12-02 Corgnet, B. and Rodriguez-Lara, I. Are you a Good Employee or Simply a Good Guy? Influence Costs and Contract Design.

12-01 Kimbrough, E. and Sheremeta, R. Side-Payments and the Costs of Conflict.

2011

11-20 Cason, T., Savikhin, A. and Sheremeta, R. Behavioral Spillovers in Coordination Games.

11-19 Munro, D. and Rassenti, S. Combinatorial Clock Auctions: Price direction and performance.

11-18 Schniter, E., Sheremeta, R., and Sznycer, D. Restoring Damaged Trust with Promises, Atonement and Apology.

11-17 Brañas-Garza, P., and Proestakis, A. Self-discrimination: A field experiment on obesity.

11-16 Brañas-Garza, P., Bucheli, M., Paz Espinosa, M., and García-Muñoz, T. Moral Cleansing and Moral Licenses: Experimental evidence.

11-15 Caginalp, G., Porter, D., and Hao, L. Asset Market Reactions to News: An experimental study.

11-14 Benito, J., Branas-Garz, P., Penelope Hernandez, P., and Sanchis Llopis, J. Strategic Behavior in Schelling Dynamics: A new result and experimental evidence.

11-13 Chui, M., Porter, D., Rassenti, S. and Smith, V. The Effect of Bidding Information in Ascending Auctions.

11-12 Schniter, E., Sheremeta, R. and Shields, T. Conflicted Minds: Recalibrational emotions following trust-based interaction.

11-11 Pedro Rey-Biel, P., Sheremeta, R. and Uler, N. (Bad) Luck or (Lack of) Effort?: Comparing social sharing norms between US and Europe.

11-10 Deck, C., Porter, D., and Smith, V. Double Bubbles in Assets Markets with Multiple Generations.

11-09 Kimbrough, E., Sheremeta, R., and Shields, T. Resolving Conflicts by a Random Device.

11-08 Brañas-Garza, P., García-Muñoz, T., and Hernan, R. Cognitive effort in the Beauty Contest Game.

11-07 Grether, D., Porter, D., and Shum, M. Intimidation or Impatience? Jump Bidding in On-line Ascending Automobile Auctions.

11-06 Rietz, T., Schniter, E., Sheremeta, R., and Shields, T. Trust, Reciprocity and Rules.

11-05 Corgnet, B., Hernan-Gonzalez, R., and Rassenti, S. Real Effort, Real Leisure and Real-time Supervision: Incentives and peer pressure in virtual organizations. 
11-04 Corgnet, B. and Hernán-González R. Don’t Ask Me If You Will Not Listen: The dilemma of participative decision making.

11-03 Rietz, T., Sheremeta, R., Shields, T., and Smith, V. Transparency, Efficiency and the Distribution of Economic Welfare in Pass-Through Investment Trust Games.

11-02 Corgnet, B., Kujal, P. and Porter, D. The Effect of Reliability, Content and Timing of Public Announcements on Asset Trading Behavior.

11-01 Corgnet, B., Kujal, P. and Porter, D. Reaction to Public Information in Markets: How much does ambiguity matter?

\section{0}

10-23 Sheremeta, R. Perfect-Substitutes, Best-Shot, and Weakest-Link Contests between Groups.

10-22 Mago, S., Sheremeta, R., and Yates, A. Best-of-Three Contests: Experimental evidence.

10-21 Kimbrough, E. and Sheremeta, R. Make Him an Offer He Can't Refuse: Avoiding conflicts through side payments.

10-20 Savikhim, A. and Sheremeta, R. Visibility of Contributions and Cost of Inflation: An experiment on public goods.

10-19 Sheremeta, R. and Shields, T. Do Investors Trust or Simply Gamble?

10-18 Deck, C. and Sheremeta, R. Fight or Flight? Defending Against Sequential Attacks in the Game of Siege.

10-17 Deck, C., Lin, S. and Porter, D. Affecting Policy by Manipulating Prediction Markets: Experimental evidence.

10-16 Deck, C. and Kimbrough, E. Can Markets Save Lives? An Experimental Investigation of a Market for Organ Donations.

10-15 Deck, C., Lee, J. and Reyes, J. Personality and the Consistency of Risk Taking Behavior: Experimental evidence.

10-14 Deck, C. and Nikiforakis, N. Perfect and Imperfect Real-Time Monitoring in a Minimum-Effort Game.

10-13 Deck, C. and Gu, J. Price Increasing Competition? Experimental Evidence.

10-12 Kovenock, D., Roberson, B., and Sheremeta, R. The Attack and Defense of Weakest-Link Networks.

10-11 Wilson, B., Jaworski, T., Schurter, K. and Smyth, A. An Experimental Economic History of Whalers' Rules of Capture. 
10-10 DeScioli, P. and Wilson, B. Mine and Thine: The territorial foundations of human property.

10-09 Cason, T., Masters, W. and Sheremeta, R. Entry into Winner-Take-All and Proportional-Prize Contests: An experimental study.

10-08 Savikhin, A. and Sheremeta, R. Simultaneous Decision-Making in Competitive and Cooperative Environments.

10-07 Chowdhury, S. and Sheremeta, R. A generalized Tullock contest.

10-06 Chowdhury, S. and Sheremeta, R. The Equivalence of Contests.

10-05 Shields, T. Do Analysts Tell the Truth? Do Shareholders Listen? An Experimental Study of Analysts' Forecasts and Shareholder Reaction.

10-04 Lin, S. and Rassenti, S. Are Under- and Over-reaction the Same Matter? A Price Inertia based Account.

10-03 Lin, S. Gradual Information Diffusion and Asset Price Momentum.

10-02 Gjerstad, S. and Smith, V. Household Expenditure Cycles and Economic Cycles, 1920-2010.

10-01 Dickhaut, J., Lin, S., Porter, D. and Smith, V. Durability, Re-trading and Market Performance.

\section{9}

09-11 Hazlett, T., Porter, D., and Smith, V. Radio Spectrum and the Disruptive Clarity OF Ronald Coase.

09-10 Sheremeta, R. Expenditures and Information Disclosure in Two-Stage Political Contests.

09-09 Sheremeta, R. and Zhang, J. Can Groups Solve the Problem of Over-Bidding in Contests?

09-08 Sheremeta, R. and Zhang, J. Multi-Level Trust Game with "Insider" Communication.

09-07 Price, C. and Sheremeta, R. Endowment Effects in Contests.

09-06 Cason, T., Savikhin, A. and Sheremeta, R. Cooperation Spillovers in Coordination Games.

09-05 Sheremeta, R. Contest Design: An experimental investigation.

09-04 Sheremeta, R. Experimental Comparison of Multi-Stage and One-Stage Contests.

09-03 Smith, A., Skarbek, D., and Wilson, B. Anarchy, Groups, and Conflict: An experiment on the emergence of protective associations.

09-02 Jaworski, T. and Wilson, B. Go West Young Man: Self-selection and endogenous property rights.

09-01 Gjerstad, S. Housing Market Price Tier Movements in an Expansion and Collapse. 


\section{8}

08-09 Dickhaut, J., Houser, D., Aimone, J., Tila, D. and Johnson, C. High Stakes Behavior with Low Payoffs: Inducing preferences with Holt-Laury gambles.

08-08 Stecher, J., Shields, T. and Dickhaut, J. Generating Ambiguity in the Laboratory.

08-07 Stecher, J., Lunawat, R., Pronin, K. and Dickhaut, J. Decision Making and Trade without Probabilities.

08-06 Dickhaut, J., Lungu, O., Smith, V., Xin, B. and Rustichini, A. A Neuronal Mechanism of Choice.

08-05 Anctil, R., Dickhaut, J., Johnson, K., and Kanodia, C. Does Information Transparency Decrease Coordination Failure?

08-04 Tila, D. and Porter, D. Group Prediction in Information Markets With and Without Trading Information and Price Manipulation Incentives.

08-03 Thomas, C. and Wilson, B. Horizontal Product Differentiation in Auctions and Multilateral Negotiations.

08-02 Oprea, R., Wilson, B. and Zillante, A. War of Attrition: Evidence from a laboratory experiment on market exit.

08-01 Oprea, R., Porter, D., Hibbert, C., Hanson, R. and Tila, D. Can Manipulators Mislead Prediction Market Observers? 